Georgia State University

ScholarWorks @ Georgia State University

Middle-Secondary Education and Instructional Department of Middle-Secondary Education and Technology Dissertations Instructional Technology (no new uploads as of Jan. 2015)

Spring 5-7-2011

\title{
Identifying Complex Cultural Interactions in the Instructional Design Process: A Case Study of a Cross-Border, Cross-Sector Training for Innovation Program
}

Lillian R. Russell Ph.D.

Georgia State University

Follow this and additional works at: https://scholarworks.gsu.edu/msit_diss

Part of the Education Commons

\section{Recommended Citation}

Russell, Lillian R. Ph.D., "Identifying Complex Cultural Interactions in the Instructional Design Process: A Case Study of a Cross-Border, Cross-Sector Training for Innovation Program." Dissertation, Georgia State University, 2011.

doi: https://doi.org/10.57709/1938423

This Dissertation is brought to you for free and open access by the Department of Middle-Secondary Education and Instructional Technology (no new uploads as of Jan. 2015) at ScholarWorks @ Georgia State University. It has been accepted for inclusion in Middle-Secondary Education and Instructional Technology Dissertations by an authorized administrator of ScholarWorks @ Georgia State University. For more information, please contact scholarworks@gsu.edu. 


\section{ACCEPTANCE}

This dissertation, IDENTIFYING COMPLEX CULTURAL INTERACTIONS IN THE INSTRUCTIONAL DESIGN PROCESS: A CASE STUDY OF A CROSS-BORDER, CROSS-SECTOR TRAINING FOR INNOVATION PROGRAM, by L. ROXANNE RUSSELL, was prepared under the direction of the candidate's Dissertation Advisory Committee. It is accepted by the committee members in the partial fulfillment of the requirements for the degree Doctor of Philosophy in the College of Education, Georgia State University.

The Dissertation Advisory Committee and the student's Department Chair, as representatives of the faculty, certify that this dissertation has met all standards of excellence and scholarship as determined by the faculty. The Dean of the College of Education concurs.

Wanjira Kinuthia, Ph.D. Committee Chair

Mary B. Shoffner, Ph.D.

Committee Member

Date
Laurie Brantley-Dias, Ph.D. Committee Member
Geeta Verma, Ph.D.

Committee Member

Dana L. Fox, Ph.D.

Chair, Middle, Secondary and Instructional Technology Department

R.W. Kamphaus, Ph.D.

Dean and Distinguished Research Professor

College of Education 


\begin{abstract}
AUTHOR'S STATEMENT
By presenting this dissertation as a partial fulfillment of the requirements for the advanced degree from Georgia State University, I agree that the library of Georgia State University shall make it available for inspection and circulation in accordance with its regulations governing materials of this type. I agree that permission to quote, to copy from, or to publish this dissertation may be granted by the professor under whose direction it was written, by the College of Education's director of graduate studies and research, or by me. Such quoting, copying, or publishing must be solely for scholarly purposes and will not involve potential financial gain. It is understood that any copying from or publication of this dissertation which involves potential financial gain will not be allowed without my written permission.
\end{abstract}

L. Roxanne Russell 


\title{
NOTICE TO BORROWERS
}

All dissertations deposited in the Georgia State University library must be used in accordance with the stipulations prescribed by the author in the preceding statement. The author of this dissertation is:

\author{
L. Roxanne Russell \\ 1217 Roman Point Drive \\ Norcross, GA 30093
}

The director of this dissertation is:

Wanjira Kinuthia, Ph.D.

Middle/Secondary Education \& Instructional Technology Department

Georgia State University

P.O. Box 3978

Atlanta, Georgia 30302-3978 
VITA

L. Roxanne Russell

ADDRESS: $\quad 1217$ Roman Point Drive

Norcross, GA 30093

EDUCATION: $\quad$ PH.D. $2011 \quad$ Georgia State University

Instructional Technology \& Design

M.A. $1997 \quad$ Auburn University

B.S. $\quad 1995 \quad$ Troy State University at Dothan

English and American History

PROFESSIONAL EXPERIENCE:

\begin{tabular}{|c|c|}
\hline 2002-present & $\begin{array}{l}\text { Online Faculty } \\
\text { University of Phoenix Online }\end{array}$ \\
\hline 2008-present & $\begin{array}{l}\text { Online Course Reviewer } \\
\text { Southern Polytechnic State University }\end{array}$ \\
\hline 2009-present & $\begin{array}{l}\text { Graduate Teaching Assistant } \\
\text { Georgia State University }\end{array}$ \\
\hline 2008-2009 & $\begin{array}{l}\text { Graduate Research Assistant } \\
\text { Georgia State University }\end{array}$ \\
\hline 2007-2009 & $\begin{array}{l}\text { Research Fellow } \\
\text { India, China \& America Institute }\end{array}$ \\
\hline 2005-2007 & $\begin{array}{l}\text { E-learning Designer \& Instructor } \\
\text { International Business English, Inc. }\end{array}$ \\
\hline 2003-2004 & $\begin{array}{l}\text { Instructor } \\
\text { North Carolina State University }\end{array}$ \\
\hline 2003 & $\begin{array}{l}\text { Instructor } \\
\text { Shaw University }\end{array}$ \\
\hline $001-2003$ & $\begin{array}{l}\text { Instructor } \\
\text { Michigan State University }\end{array}$ \\
\hline
\end{tabular}

\section{PUBLICATIONS}

Russell, L. R. \& Shoffner, M. B. (2010, April). Performance Analysis Case Study of United States to India Software Development Migration Process. Performance Improvement 49(4), pp. 35-40.

Russell, L. R. (2010). Case study on training collaboration between NASA and private Indian organization for immersive $3 \mathrm{D}$ visualization educational products. In $\mathrm{W}$. 
Kinuthia \& S. Marshall (Eds.) Cases'n'Places: Global Cases in Educational Technology.

Russell, L. R. (2008). Training for innovation in India: Cultural considerations and strategic implications. Performance Improvement Quarterly 21(2), pp. 37 - 48.

\section{PRESENTATIONS}

Russell, R. \& Cuevas, J. (2010). Animating the High School Student Reading Experience: A DIY Guide. In Proceedings of World Conference on Educational Multimedia, Hypermedia and Telecommunications 2010 (pp. 3070-3075). Chesapeake, VA: AACE.

Russell, R. L., Stone, D., Wang, Q. \& Wang, X. (2010). Exploring the Use of Social Networking Tools to Support a Community of Practice in China. In Z. Abas et al. (Eds.), Proceedings of Global Learn Asia Pacific 2010 (pp. 1372-1375). AACE.

Russell, L. R. \& Wang, C. X. (2009, October). Cross-sector, cross-border team navigating the instructional design process: A case study. Presented at the Association for Educational Communications and Technology (AECT) 2009 International Convention, Louisville, KY.

Russell, L. R. \& Cuevas, J. A. (2009). Design Decisions between Teacher and Technologist in Developing Classroom Reading Modules with Everyday Software. In I. Gibson et al. (Eds.), Proceedings of Society for Information Technology and Teacher Education (SITE) International Conference 2009 (pp. 2109-2114). Chesapeake, VA: AACE.

\section{HONORS}

Outstanding Doctor of Philosophy Student, Georgia State University, College of Education, Instructional Technology Program, 2008-2009

Royal Flame Award, Intercultural Program of the Year, Georgia State University, for Graduates in Instructional Technology Student collaboration with Zoo Atlanta's Academy for Conservation Training in China, 2009

Best Undergraduate English Student, Troy State University at Dothan, 1997 


\author{
ABSTRACT \\ IDENTIFYING COMPLEX CULTURAL INTERACTIONS IN THE \\ INSTRUCTIONAL DESIGN PROCESS: A CASE STUDY OF A \\ CROSS-BORDER, CROSS-SECTOR TRAINING \\ FOR INNOVATION PROGRAM \\ by \\ L. Roxanne Russell
}

The purpose of this research is to identify complex cultural dynamics in the instructional design process of a cross-sector, cross-border training environment by applying Young’s (2009) Culture-Based Model (CBM) as a theoretical framework and taxonomy for description of the instructional design process under the conditions of one case. The guiding question of this study is: How does culture, as defined by Young's (2009) CBM framework, interact with the instructional design process in this case of a cross-sector, cross-border training program?

This research uses the qualitative approach of case study and applies a cultural design framework to examine the process of instructional design by a team of designersby-assignment in a NASA/university consortium program to train applied research and development teams for an education software company headquartered in India. Fifteen representative participants were chosen to reflect each role involved in the training program and instructional design process, including management, instructors and students. In over two years of engagement with participants, data was gathered at a NASA space center and in Mumbai, India through interviews, observation and artifact analysis. Data was analyzed to identify where components of the design process, decisions of the design team, and perceptions of the stakeholders overlap with culture as defined by Young's CBM framework. 
The findings indicate that at least twenty-three distinguishable elements of culture interact with every component of the design process in the: 1) goals and funding decisions of the client; 2) goals and design decisions of the design team; 3) perceptions of the training program of all stakeholders; and 4) the observable outcomes of the training program. The findings also offer insight into what stakeholders do or do not consciously attribute to culture. By empirically illuminating the pervasive presence of cultural interactions across the instructional design process, this study advocates for culture to be recognized as a construct of importance in our field and demonstrates the powerful capabilities of using a comprehensive descriptive model as a lens for exploring cultural dynamics in the instructional design process. 


\title{
IDENTIFYING COMPLEX CULTURAL INTERACTIONS IN THE INSTRUCTIONAL DESIGN PROCESS: A CASE STUDY OF A CROSS-BORDER, CROSS-SECTOR TRAINING FOR INNOVATION PROGRAM \\ by \\ L. Roxanne Russell
}

\author{
A Dissertation \\ Presented in Partial Fulfillment of Requirements for the \\ Degree of Doctor of Philosophy \\ in \\ Instructional Technology \\ in
}

the Department of Middle-Secondary Education and Instructional Technology

in

the College of Education

Georgia State University

Atlanta, GA

2011 
Copyright by

L. Roxanne Russell

2011 


\section{ACKNOWLEDGEMENTS}

I would like to thank my committee chair, Dr. Wanjira Kinuthia, for inspiring me to take on the challenging topic of culture in this research project and for her insight and support throughout the process. I am very grateful to Dr. Laurie Brantley-Dias, Dr. Geeta Verma, Dr. Mary B. Shoffner, Dr. Jagdish Sheth and Dr. Charles Xiaoxue Wang for their thoughtful feedback and guidance throughout this research project and in my doctoral program. I would also like to thank Dr. Chris Oshima and Dr. Deron Boyles for being excellent teachers and prioritizing their interactions with students as part of their faculty responsibilities.

I am most grateful to the participants in this study, who were welcoming and generous with their time, knowledge and memories. I could not have completed all of the work of this project without those who helped with data analysis and presentation: Reeny Madathany, Dr. Winnie Tsang-Kosma, Daina Plitkins-Denning, and Dr. Anissa LokeyVega.

I would like to thank all of my classmates in the doctoral program for enjoyable learning experiences. In particular, I appreciate Dr. Joshua Cuevas for engaging with me in a productive and still generative research and design collaboration; and David Stone, for sharing his strength, craft and experience in this field to push me to the next level.

I am lucky to have too many wonderful and influential people in my life to list here, but I have leaned heavily on all of my friends and family and would like to express my deep gratitude and affection for their support. I am thankful for my father, Bill Russell, my sister, Candi Dickerson, and my best-friend, Trena Thierry for always being there. I am particularly grateful to my in-laws, Dr. Sudhanva Char and Padma Char, for 
welcoming me into their family and home and playing an active role in the daily support of my family to make this possible. I wish to honor the memory of my mother, Cookie Crews, and my grandfather, Williamson B. Simmons, for influencing me to greet each new day and person with practical enthusiasm. Their positive energy still keeps me going.

Finally, I thank my incredible husband, Adarsh Char, for encouraging me to take this path, clearing the way and picking me up and carrying me across certain parts. 


\section{TABLE OF CONTENTS}

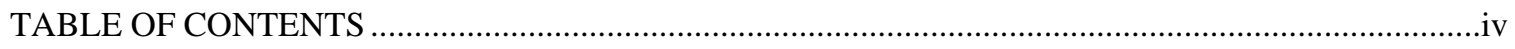

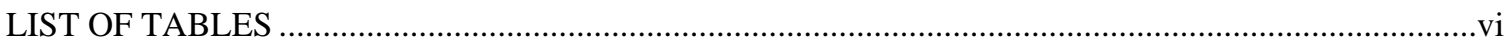

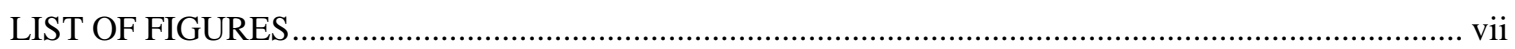

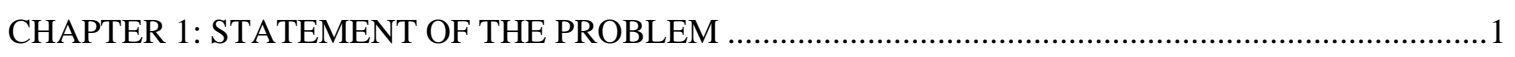

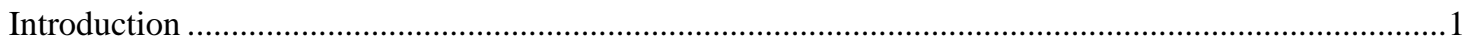

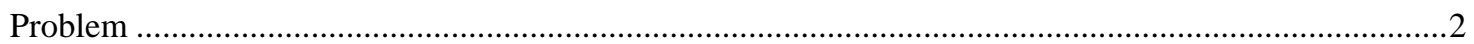

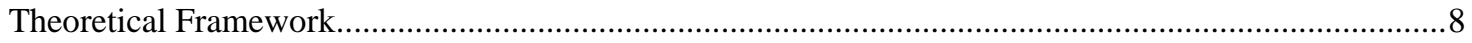

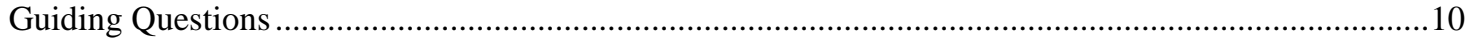

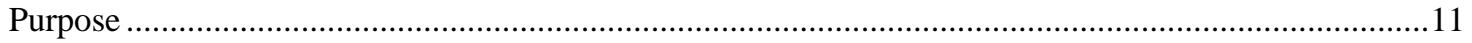

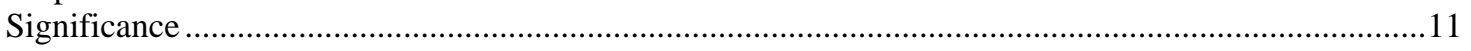

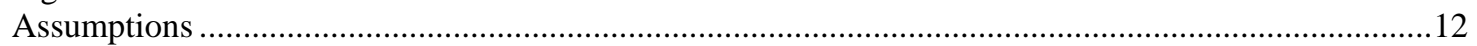

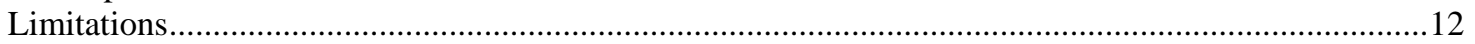

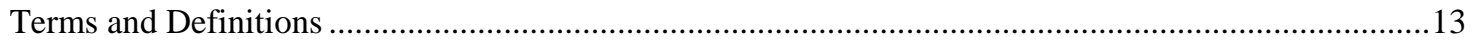

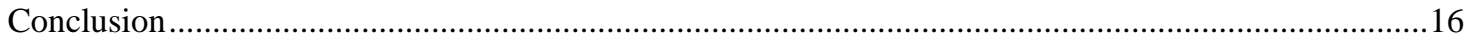

CHAPTER 2: REVIEW OF THE LITERATURE ……......................................................................17

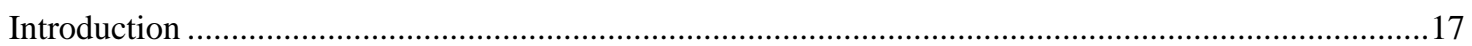

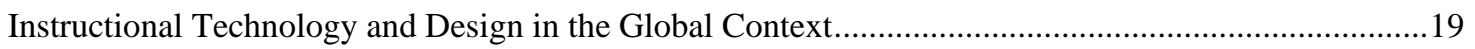

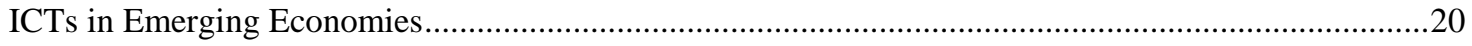

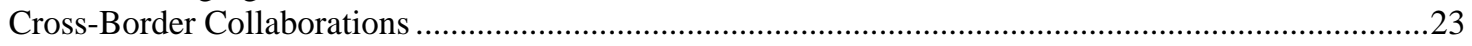

Attention to Culture in Instructional Design and Technology Literature ..................................................24

Culturally determined educational or pedagogical values .........................................................................24

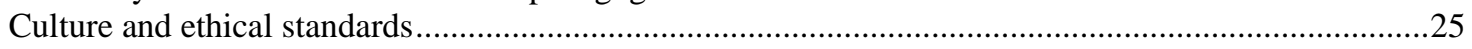

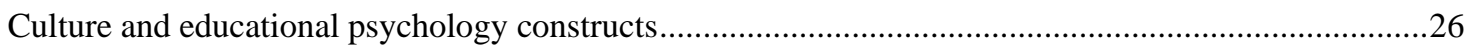

Cultural considerations in collaboration and communication.................................................................2.

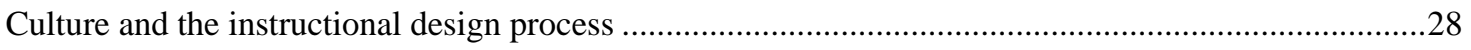

Review of ISD Models Acknowledging Culture ....................................................................................30

Limitations of Current Cultural Models for Research ...............................................................................33

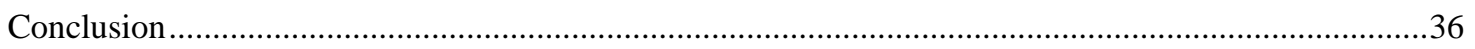

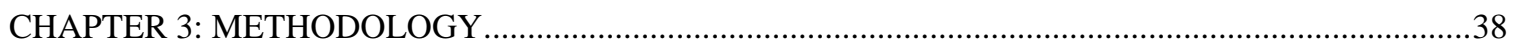

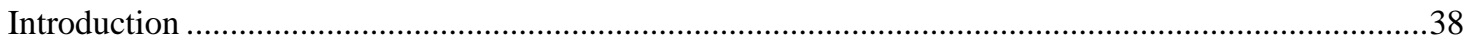

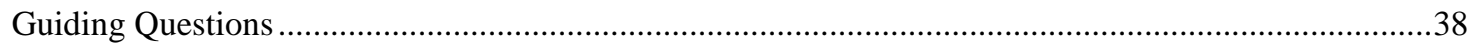

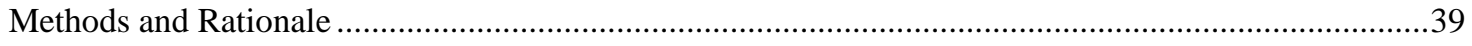

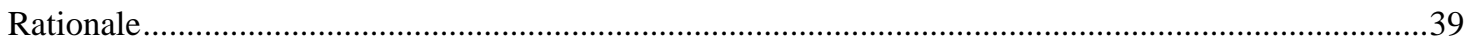

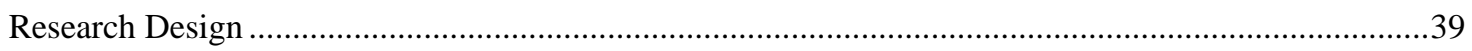

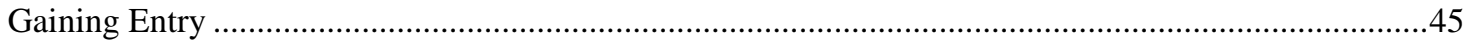

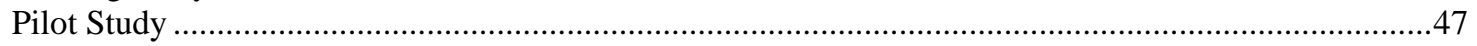

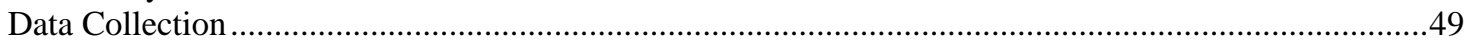

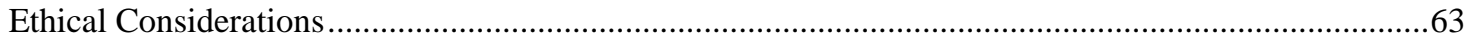

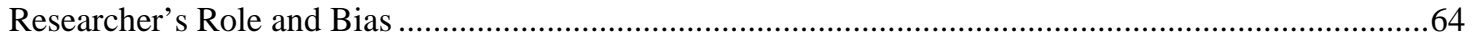

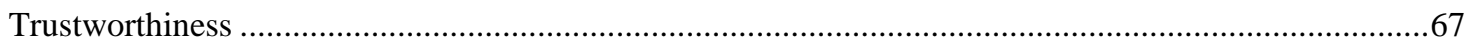

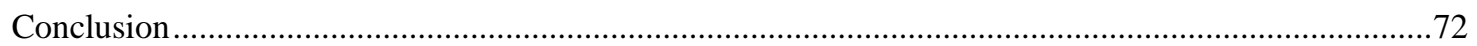

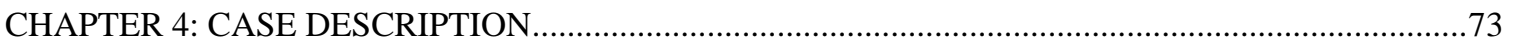

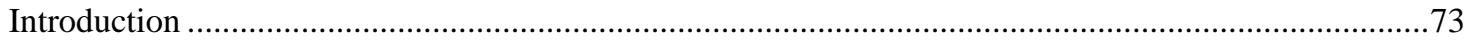

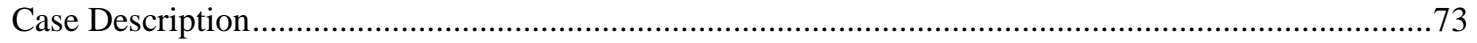

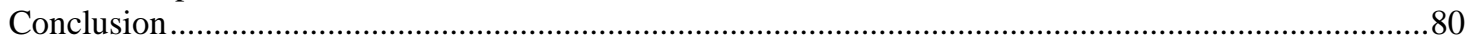

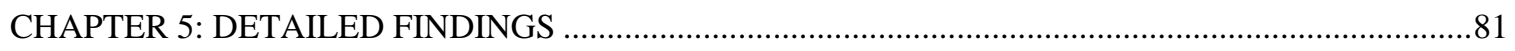




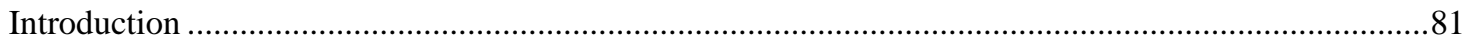

Cultural constructs of the CBM framework found to be evident in the data ............................................82

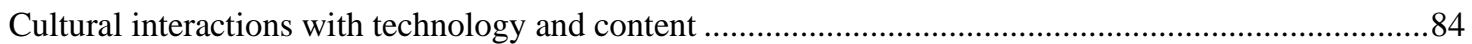

Cultural interaction with design specifications, technology format, audience assessment and quality ..117

Cultural interaction with the composition of the design team ................................................................135

Cultural interactions with assessing student learning ..........................................................................152

Cultural interaction with financial support and affordability, involvement of stakeholders, consideration

of cultural context and learning goals of the training program..............................................................159

Cultural interaction with designing learning environments and opportunities ......................................184

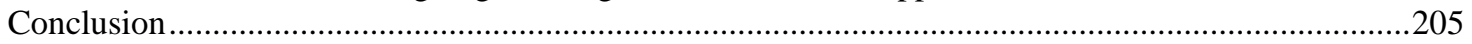

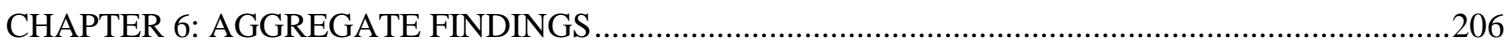

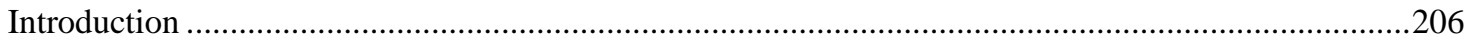

Limited participant acknowledgement of interaction between decisions, perceptions and outcomes with

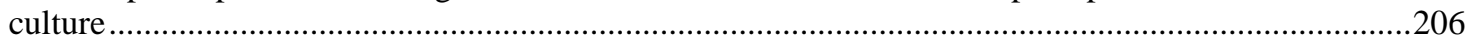

Systemic presence of cultural interactions in the instructional design process.......................................208

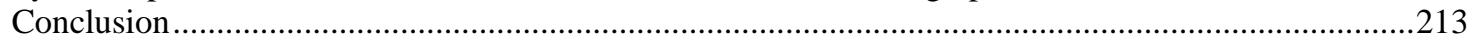

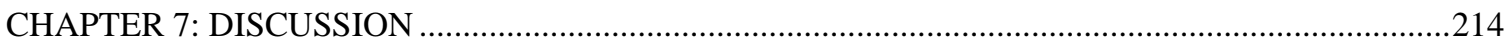

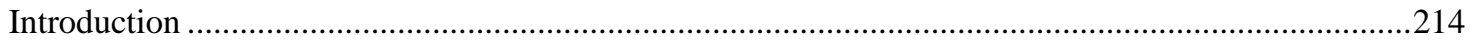

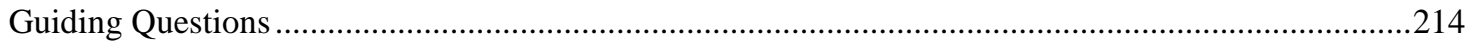

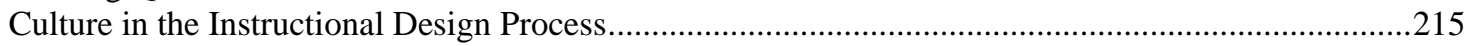

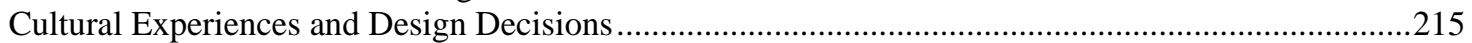

Cultural Interaction with Technology and Content Choices....................................................................216

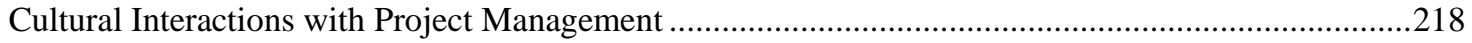

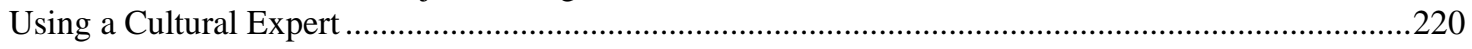

Cultural Interactions with Perspectives on the Role of Educators........................................................221

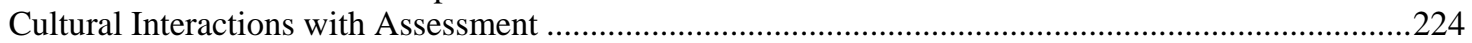

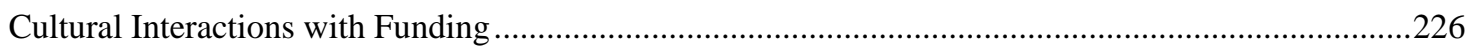

Cultural Interactions with Balancing the Needs of Stakeholders............................................................226

Cultural Interactions with the Design of Learning Environments \& Opportunities .................................227

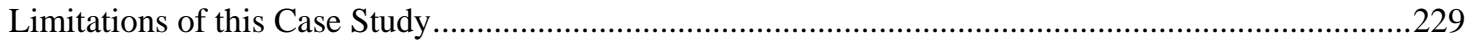

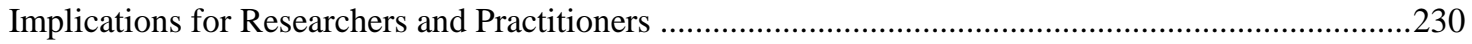

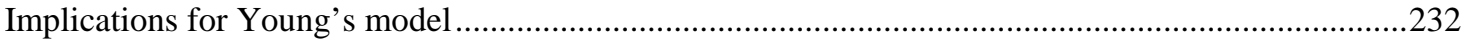

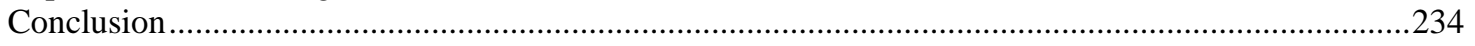

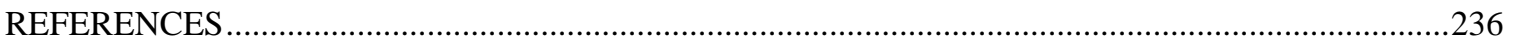

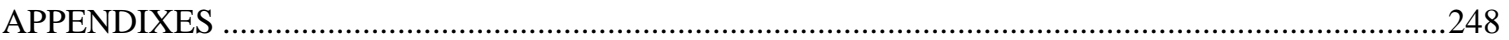




\section{LIST OF TABLES}

Table

Page

Table 1 Comparing Hofstede’s Cultural Dimensions and Young’s Cultural Elements ... 36

Table 2 Overview of Institute for Advanced Learning Training Curriculum................... 41

Table 3 Overview of NextGenEd's i3Dv First YearTraining Agreement with IAL ........ 41

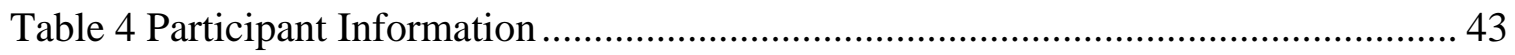

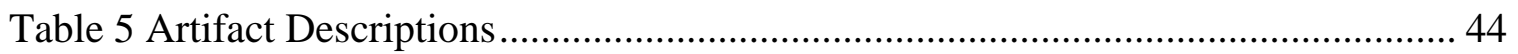

Table 6 ID-TABLET Components of Young's Culture Based Model (CBM) ................ 50

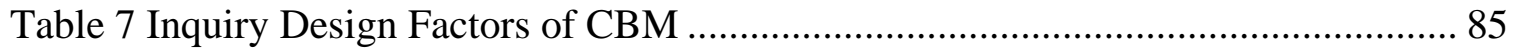

Table 8 Cultural Interaction Matrix: Inquiry ...................................................... 116

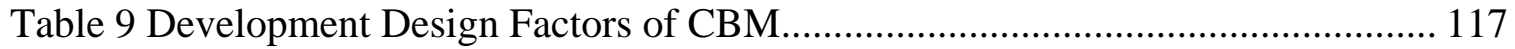

Table 10 Cultural Interaction Matrix: Development ................................................ 134

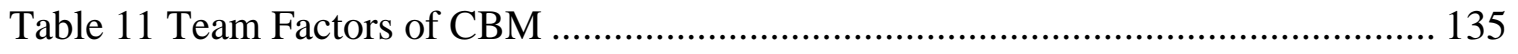

Table 12 Cultural Interaction Matrix: Team............................................................ 151

Table 13 Assessment Design Factors of CBM ......................................................... 152

Table 14 Cultural Interaction Matrix: Assessment .................................................... 159

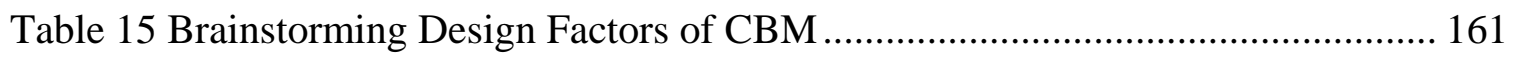

Table 16 Cultural Interaction Matrix: Brainstorming ................................................. 183

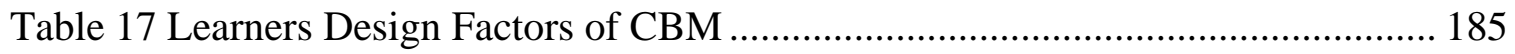

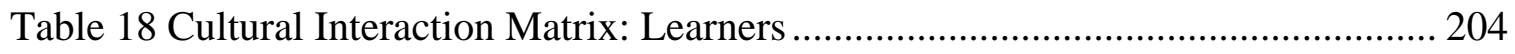

Table 19 ID-TABLET with Cultural Classification and Cultural Communications ...... 210 


\section{LIST OF FIGURES}

Figure $\quad$ Page

$1 \quad$ Young's 2009 Culture Based Model ............................ 9

2 Timeline of Case Events ..................................... 74 


\title{
CHAPTER 1: STATEMENT OF THE PROBLEM
}

\author{
$\underline{\text { Introduction }}$
}

Policy advisors have made a global call for nations to prioritize their knowledgeeconomy-building initiatives, and this call is being answered by a surge of non-profit and market-driven strategies to produce innovative educational technologies (Britz, Lorc, Coetzee \& Bestere, 2005; Dahlman \& Utz, 2005; Daniel, 1996; Morey, 2004; van der Wende, 2002). For organizations to innovate in the educational technology space, they have been forming partnerships across sectors and across borders in order to train personnel for high level innovation. Such cross-sector, cross-border training for innovation environments continue to increase in number and provide rich ground for examining dynamics of culture in the process of instructional design in a globalized knowledge economy. But culture is an abstract and slippery construct that poses a challenge for researchers and practitioners in the instructional design discipline.

Because instructional design and technology (IDT) research draws on the practices and beliefs of several research traditions from multiple disciplines, defining culture in the context of IDT requires pulling from interdisciplinary points of view. In his often cited and highly generative work on cultural dimensions, industrial anthropologist Hofstede (1984) defined culture as a "programming of the mind” (p.51). Young (2008) suggests that culture can be viewed from sociological, anthropological and psychological perspectives. From the sociological perspective, culture is a part of tradition and heritage; anthropologically, culture is a way of doing, thinking, acting, feeling and being; psychologically, culture involves the individual and mental activity. According to Collis 
(1999), culture functions on the following levels, societal, organizational, group, individual and domain/discipline. As an abstract concept, culture is often described in the ways that it functions or is manifested. For example, observable artifacts or behaviors may be characterized culturally, such as forms of communication.

Yet, characterizing an observed phenomenon culturally prompts questions about the confounding variables of individual influences or differences. This slipperiness of the concept of culture presents a problem for traditional methods of research in the instructional design discipline, but does not obviate the need for further study of it. Much of the current empirical research on culture in IDT relies on reductive characterizations of learners according to broad generalizations about national, regional or ethnic cultures (Gunawardena, Jayatilleke, \& Lekamge 1996; Ku \& Lohr, 2003; Paulus, Bichelmeyer, Malopinsky, Pereira \& Rastogi, 2005). What is needed is more acknowledgement of the slipperiness of the construct of culture while exploring ways to capture empirical glimpses of its complexity. Identifying complex cultural interactions in the instructional design process may allow us to better understand where the group-wide tendencies, frames of reference or characteristics of all stakeholders, not just learners, interact with the design process and learning experiences. This understanding is important to updating our concept of the IDT process to be more relevant and responsible in a globalized context.

\section{$\underline{\text { Problem }}$}

The roots of instructional design cling to the soil of the military-industrial complex and its call for more effective, efficient and productive processes for uniform training (Reiser \& Dempsey, 2007). Though still of legitimate concern in today’s learning 
environments that reflect the transitional growth from industrial to knowledge-based economies, calls for effectiveness, efficiency and productivity are accompanied by calls for equity, sustainability and innovation (Vrasidas, Zembylas \& Glass, 2009). For example, development was once seen from the Western point of view as a measure o2f economic growth through attention to gross domestic product indices; whereas, newer, more globally inclusive views show attention to development as a process of improving individual human rights and attention to environmental sustainability (Sen, 2006 qtd. in Vrasidas, Zembylas \& Glass, 2009). Petrina (2004) argues that the models proposed by instructional designers are lacking because "universal formulas” could only work in apolitical environments which arguably, do not exist. Visser and Suzuki (2007) observe that "the professional literature of the instructional design field draws heavily on the experience of its application and development in one country, the United States of America” (p.235). These critiques of applying Western-based models gain more significance as the practice of IDT continues to occur in increasingly global contexts.

Furthermore, the global proliferation of IDT projects has outpaced the availability of trained designers. Case studies of cross-border collaborations and reviews of emerging instructional technology trends in other nations repeatedly stress the need for local designers while acknowledging the lack of instructional design training available globally (Chitiyo \& Harmon, 2009; Kim \& Santiago, 2005; Perkins, Gwayi, Zozie \& Lockee, 2005; Soulier, 1999). Merrill (2007) refers to those who design without training as designers-by-assignment and claims that " $95 \%$ of all instructional design is done by designers-by-assignment” (p. 336). In describing factors impacting ID model validation, Richey (2005) cites evidence that “design models are typically interpreted differently by 
expert designers and novice designers” (p.177). These findings suggest that instructional design models in the global context must take novice practitioners into account.

Are current ISD models, based on the fundamental model of ADDIE, flexible, yet descriptive enough to provide cultural guidance for designers-by-assignment in environments of cross-sector, cross-border training for innovation?

Gustafson and Branch (1997) would answer yes. In a review of the history and emerging trends of instructional development models, these authors defend the fundamentals of ADDIE and its progeny of models as broadly applicable and accurate against claims that it is not well-suited to current pedagogies or conditions of dynamic, constructivist and cross-cultural environments. They acknowledge developments in instructional development models such as rapid prototyping and use of expert systems, but conclude that these models do not depart from earlier models if one views the process as iterative and recursive rather than linear and progressive: "While we have no quarrel with those who are exploring alternative ways of developing learning environments, we believe many claims for uniqueness are overstated” (p.86). They argue that the fundamental ADDIE model still accurately encapsulates the basic steps in the process of instructional design.

Yet, in a later collaboration, Gustafson with Visscher-Voerman (2004) found in gathering data from highly reputable designers that their activities "indeed, do deviate from the activities and order proposed by ADDIE models” (p. 70). Visscher-Voerman and Gustafson (2004) collect data through interviews and document analysis on twentyfour highly reputable designers in order to fill a gap in empirical research to support claims that activities in the instructional design process are more "heterogeneous and 
diverse” than those described in the ADDIE model (p. 70). This study shows some movement away from traditional views of ISD and welcoming of more complex characterizations of the process of instructional design.

However, Richey, Morrison and Foxon state that the "majority of ID practice is still dominated by instructional systems design models such as Dick \& Carey’s” (p.175, 2007). In “The Dick and Carey model: Will it survive the decade?,” Dick (1996) examines his popular and widely -used ISD model for future viability by reviewing its evolution and competitors. He pinpoints the first public introduction of the model to a presentation in 1968, "New Directions in Learning." He attributes changes in the most recent edition of the model (1996) to influences from: performance technology, context analysis, multi-level evaluation models, and total quality management. In a statement that may sum up the basis for much of the criticism of the lack of empirical basis for prescriptive models in instructional design, he admits: "There were almost no practitioners when the model was developed, therefore, it was never intended to be a reflection of what practitioners actually do" (p.58). Similarly, culture-focused research is emergent in the instructional design discipline (Richey, 2009) and proposed cultural models are often, like the Dick and Carey model, either untested or tested only by their creators and tend to prescribe rather than describe instructional design processes (Edmundson, 2007; Henderson, 1996; Young, 2009).

From a systemic view, every component of the instructional design process (from steps taken to products generated) engages culture. In a review of the history of instructional systems development models, Gustafson and Branch (1997) describe ISD as a systemic process; Branch and Deissler (2008) describe systemic processes as those 
where the whole system responds to individual stimuli because of non-linear relationships between components. Banathy (1987) describes the systems approach as addressing large-scale highly complex problems; the globalization of instructional technology and proliferation of cross-sector, cross-border training environments can be viewed as a large-scale, highly complex problem. The systems approach also uses strategies and tools that pay attention to interrelated concepts and principles for synthesisoriented and holistic analysis of problems. Including process in the discussion and research on culture in instructional design represents part of a systems approach to the challenges of instructional technology and design in a global context. Branch and Deissler (2008) also note that "useful processes must be capable of responding to emerging trends in instructional technology” (p.210).

There is a growing body of IDT literature acknowledging the need to better understand the function, impact and implications of culture and the globalization of IDT (Damarin, 1998; Heemskerk, Brink, Volman \& ten Dam, 2005; Powell, 1993; Seufert, 2001; Willis, 2005). Analytical perspectives call our attention to systemic considerations and examine the holistic influences of learners, teachers and environments (Henderson, 1996; Zhang, 2010). However, empirical research in this area has primarily focused on the culture of learners, whether it be to customize content, identify learning styles, explore communication challenges or understand attitudes towards technology (Gunawardena et al.,1996; Ku \& Lohr, 2003; Paulus, et al., 2005). Several studies about projects with multicultural stakeholders do acknowledge the complexity of cultural dynamics in their projects, but usually do so as afterthoughts or lessons-learned (Chitiyo \& Harmon, 2009; Eastmond, Gutierrez \& Shanley, 2010; Lim, 2007; Perkins, et al., 
2005). Few empirical studies focus on multiple stakeholders and seek to identify cultural interactions across the process of instructional design.

This research contributes to the IDT discipline by examining culture in the instructional design process in a way that goes beyond reductive cultural characterizations of learners and towards identifying the complex interaction of the cultures of all stakeholders with the design process.

\section{The Case}

In 2007, NextGenEd (pseudonym), a private education software company headquartered in India, contracted with the Institute for Advanced Learning (pseudonym) (IAL), a consortium of three US state universities, a community college and one of NASA's Space Centers, to train up to fifty employees to build applications that produce 3D graphical representations for fully immersive stereoscopic virtual environments. NextGenEd initiated this training program as a research and development project to potentially produce software and build immersive three-dimensional virtual (i3Dv) environments for thousands of higher education, primary and secondary institutions in India, the US and Europe. The IAL team, subject-matter experts in i3Dv programming with minimal experience as educators, prepared and offered an on-site training program at their location on the campus of a NASA space center. From January 2008 to December 2008, NextGenEd sent twenty-four employees to participate in this training program as students. This case study examines this training program from the initial planning stages beginning in late 2007 until post-training stages of research and development still in progress in late 2010. 


\section{Theoretical Framework}

So far, one of the most comprehensive design frameworks with attention to culture in the process of instructional design has been offered by Young in her body of work from 1999-2009. Young finds that methods of integrating culture in design are limited in scope: “design has not caught up with technology and that to create for diverse audiences the process must be deliberate... the integration of culture in the design of ICTs will require novel ways of engaging the design process” (2008, p.14). Young (2009) seeks to establish culture as a design construct. First, she establishes that design is a deliberate, creative, social action that generates meaning and that "design constructs function to explain, predict and interpret design related data” (p.26). Then, she proposes that "culture is a design" that is also a creative, social act that generates meaning and order (p.26). She sees this as a semiotic relationship that should be acknowledged in design frameworks.

Young offers the Culture-Based Model (CBM) with the acronym ID_TABLET: inquiry, development, team, assessments, brainstorming, learners, elements, and training with 70 design factors tied to these features (see Figure 1). As part of the ID-TABLET framework, she lists twenty-five elements that "can be used to understand, define or evaluate the target audience” in three categories: anthropology of culture, psychology of culture and science of culture (p.64). 


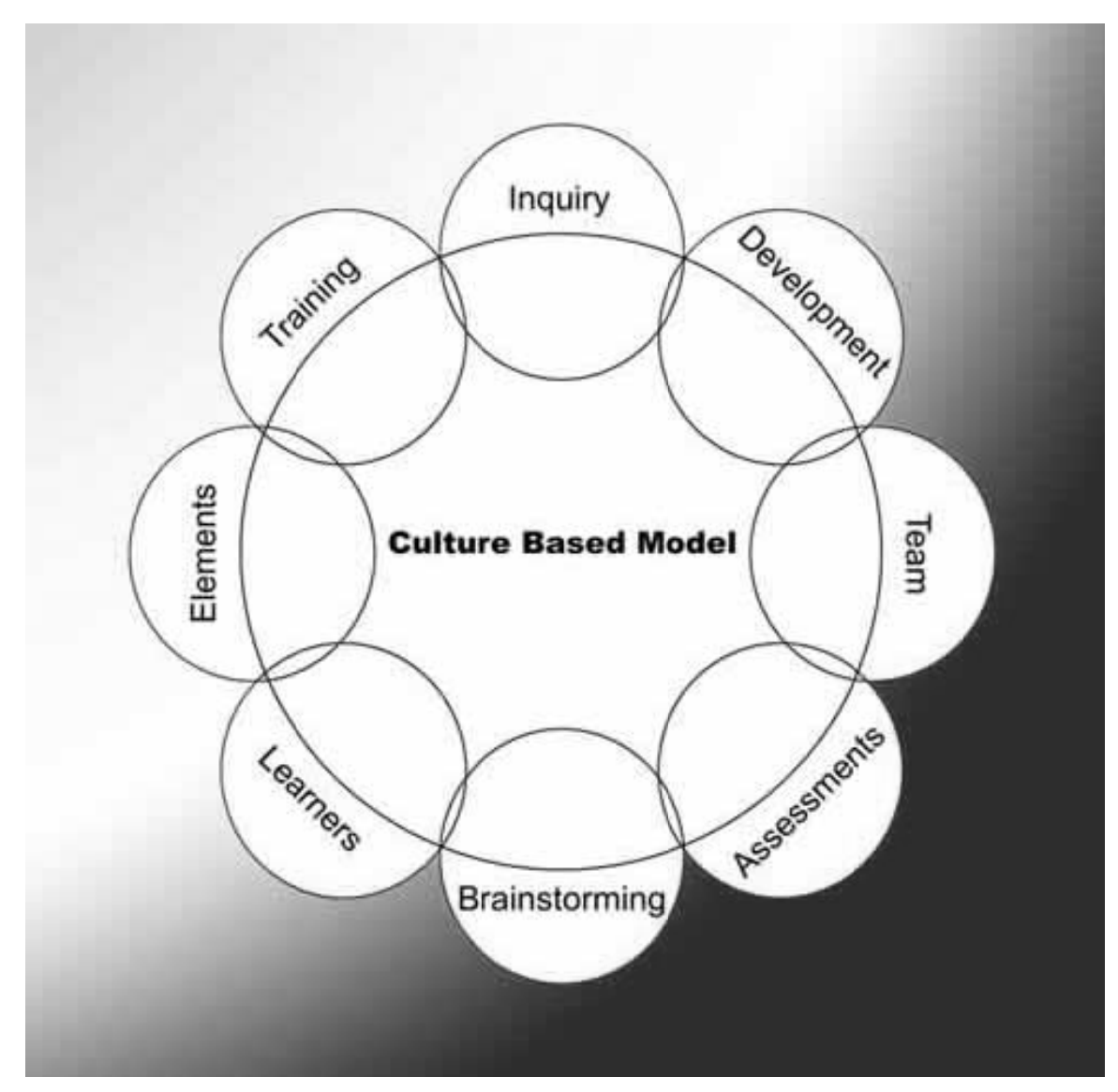

Figure 1 Young’s (2009) Culture Based Model

Young (2009) emphasizes that her work maintains the traditional definition of instructional design, citing Reigeluth’s (1983) emphasis on systematic processes and measurability and explaining that these processes are "grounded in the generic system" of the ADDIE model (p. xv). She proposes to fill the gap where a "comprehensive framework to align culture with the ADDIE model has not been available” (p. xv). In the Foreword to Young's book, Instructional Design Frameworks and Intercultural Models, Richey (2009) calls Young’s model an “over-lay model, one which adds the cultural component to a somewhat traditional ID model” (p. ix). However, she also says that Young’s model is "compatible with a systemic (rather than a systematic) view of the world” (p.xi). Young's work is new and cannot yet claim to have empirical support 
evaluating the effectiveness of what it prescribes to designers; however, Richey (2009) declares that Young's model is supported by rock-solid research. Young's method for developing the model is grounded in empirical observation and qualitative analysis of instructional design artifacts.

Therefore, applying the CBM taxonomy as a descriptive tool is consistent with its empirical basis and provides a research lens to investigate cultural dimensions of this case. However, no members of the IAL staff were aware of Young's Culture-Based Model framework nor set out to engage in activities in the manner prescribed by the CBM framework. The focus of this research will be to examine data about the design process and identify cultural elements, as identified in the CBM framework, to explore how they interact with the decisions and practices of a team of designers-by-assignment in a cross-sector, cross-border context. This focus also provides a chance to consider how descriptive some aspects of Young's prescriptive model are revealed to be in the circumstances of this case. Young's (2009) model offers: 1) a useful taxonomy for discussing the complexity and dynamism of culture as a construct in the instructional design process; 2) an existing instructional design paradigm in which to frame this approach; and 3) the opportunity to apply and explore the generative capabilities of a new model in the field that acknowledges culture as a complex construct.

\section{Guiding Questions}

How does culture interact with the instructional design process, as defined by Young's Culture-Based Model (CBM) framework, in this case of a cross-sector, cross-border training program? 
a) What design team decisions, stakeholder perceptions, and program outcomes relate to ID-TABLET components of the CBM framework?

b) With which CBM Elements of culture do design team decisions, stakeholder perceptions and program outcomes interact?

\section{$\underline{\text { Purpose }}$}

In this study, I seek to problematize traditionally reductionist approaches of IDT, in particular because of the cross-cultural implications of imposing only one world view as the truth. The purpose of this case study is to identify complex cultural dynamics in the instructional design process of a cross-sector, cross-border training environment by applying Young's (2009) Culture-Based Model as a theoretical framework and taxonomy for description of the instructional design process under the conditions of this case.

\section{Significance}

Trends of globalization in the practice of instructional design necessitate attention to culture in the instructional design process because of the systemic, cross-cultural and global development implications of assuming a universal perspective when approaching the design of learning opportunities. Using Young's (2009) CBM model to examine culture in the process of instructional design by a team of designers-by-assignment in a cross-sector, cross-border training project can provide referential guidance for practitioners and researchers working within similar contexts to inform the: 1) 
applicability or modification of Young's (2009) CBM model or other ISD models; 2) practice of IDT; and/or 3) development of tools for IDT in similar contexts.

\section{$\underline{\text { Assumptions }}$}

1. I take a pragmatic view with this case study approach in assuming knowledge about the IDT process is context-dependent and potentially useful for crossreferencing with other cases.

2. Culture is an abstract concept that may be viewed operationally for the purposes of empirical study (Kroeber \& Kluckhohn, 1952).

3. Young's (2009) CBM model may be applied as a theoretical framework and taxonomy for examination of attention to cultural factors in the instructional design process in a context where the model was not used to guide the process.

\section{$\underline{\text { Limitations }}$}

1. This case study is limited in generalizability by the special circumstances of this training program.

2. The anonymity of this case limits the amount of information available for cross-referencing this case and providing an audit trail (Yin, 2003).

3. Results of this case study will be "limited to describing phenomenon rather than predicting future behavior" (Merriam, 1998, p.41).

4. Participant sampling in this case represents only one client perspective of the NextGenEd i3Dv management team. 
5. Observation data in this case is limited to demonstrations and tours and does not include observation of training activities.

6. Document analysis is limited by the extent of "authenticity and accuracy” of the documents (Merriam, 1998).

7. Using Young's (2009) CBM as an a priori theoretical framework and taxonomy may limit the discovery of emergent themes by providing convenient categories for “data selection” instead of “generation” (Glass \& Strauss, qtd. in Merriam, 1998).

Attempts to mediate these limitations are described in Chapter 3 on Methodology.

\section{$\underline{\text { Terms and Definitions }}$}

Cross-sector: This study uses the term cross-sector to describe the partnership of academic, government and private, for-profit organizations. In this study, that partnership is between a US Government agency/public university consortium in the Southeastern US and a private education software company with headquarters in India and subsidiaries in the US.

Cross-border: This study uses the term cross-border to describe both the partnership of organizations across national borders and the placement of students in a foreign country. In this study, that partnership is between organizations in the US and India, and the students have been brought to the Southeastern US from several regions in India. 
Culture: Culture in this study is defined by using Young’s (2009) CBM Elements as taxonomy. The Elements component of ID-TABLET in the CBM framework provides a potentially comprehensive picture of what makes up all culture: both tangible and intangible (Young, 2009). Young (2009) pulls from cultural anthropology, cultural psychology and science to propose this compilation of elements which might be shared by a group. The purpose of Elements in the CBM framework for instructional design is to guide designers in exploring cultural factors when investigating their target audience. In this research, the Elements are used as taxonomy to classify aspects of cultural interactions in the design process. The CBM Elements of culture are applied to multiple cultures in this case study rather than only the target audience to explore cultural dynamics in the decisions and perceptions of all stakeholders.

The cultures distinguished in this study are categorized at two levels: national and organizational. The national cultures of the participants were determined by nation of origin and nation of current residence at the time of data gathering; some participants represent multiple cultures. National cultures represented by participants in this study include: India, US and a country in Southeast Asia. Only one participant in the study was originally from a country in Southeast Asia and now resides in the US. The nations where training program activities took place and observations were conducted include India and the US only. The organizational culture represents where training activities and observations occurred and where participants were employed at the time of the training program: IAL and NextGenEd. 
Designers-by-assignment: Subject-matter-experts without formal instructional design training who have been assigned to provide instruction (Merrill, 2007, p.336).

Innovation: This study uses the term innovation as an economic term evolved from Schumpeter's (1936) characterization of innovation as a new production function. In this study, that new production function is the entrepreneurial effort by the Indian company to use applied research and development in order to be the first to bring a new product, $\mathrm{i} 3 \mathrm{Dv}$ environments, to the Indian market on a large scale.

Instructional systems design (ISD) models: Instructional systems design models are distinguished from "generic lesson planning in their technological character" and involve "scientific thinking" such as the use of "empirical data gathering" throughout the process (Branch \& Deissler, 2008, p. 207).

Process: Process theories posit that "events result from particular input states that produce particular output states" and can be either descriptive or prescriptive: 1) “descriptive theories are passive, explain phenomena, illustrate relationships, and describe conditional (if-then) statements;” 2) “prescriptive theories are active, goaloriented, rule-based, normative guidelines and strategies, used to construct models, methods and procedures for practice” (Branch \& Deissler, 2008, p.199). Branch and Deissler (2008) define systematic processes as those that follow rules and procedures that apply to all steps in the process and predictably generate consistent results. Branch \& Deissler (2008) describe systemic processes as those where the whole system responds to 
individual stimuli because of non-linear relationships between components. In this case, the instructional design process is defined and categorized through Young's ID-TABLET framework.

\section{$\underline{\text { Conclusion }}$}

A review of institutionalized and emerging views of ISD models reveals different, sometimes conflicting, perspectives on whether fundamental models like ADDIE are flexible, yet descriptive enough to provide cultural guidance for designers-by-assignment in cross-sector, cross-border environments. Though there is much enthusiasm and optimism for the potential role of instructional design and technology globally for purposes of development, often these views of development are based on the championing of modernization prevalent in Western cultures; it is important to maintain a holistic view of emerging globalization in IDT trends in order to avoid the accompanying negative impact on cultural traditions and the environment. This chapter has introduced this problem and posited a theoretical framework and guiding questions for a study to contribute to the body of research informing the use or expansion of ISD models in the global context by examining the process of IDT under cross-sector and cross-border conditions with the lens of a culturally informed instructional design framework. In Chapter 2, literature on 1) IDT in the global context, 2) attention to culture in instructional technology and design literature, and 3) culturally informed ISD models will be examined to establish the gap in research this study seeks to fill and support the rationale and design of this study. 


\section{CHAPTER 2: REVIEW OF THE LITERATURE}

\section{$\underline{\text { Introduction }}$}

The amount of interest and research on culture in instructional design and technology (IDT) might be characterized by a quick internet search, which reveals a vast and growing number of journals, conference presentations, professional associations, divisions within existing professional associations, online discussion forums, blogs and social networks dedicated to this topic (See International Journal of Education and Development using Information and Communication Technology (IJEDICT); NAFSA: Association of International Educators; International Division of the Association for Educational Communications and Technology; UNESCO Education for All World Education Forum; International Higher Education Consulting Blog; The Global Education Collaborative Ning). In this vast body of research, there is attention to a wide array of topics such as the digital divide, multicultural education, cultural relevance, internationalization and localization of educational content and cross-cultural awareness (Aydin \& McIsaac, 2004; Barta, Jette \& Wiseman, 2003; Bentley, Tinney \& Chia, 2004; Debry, 2002; Powell, 1997). In addition to empirical studies in those areas, critiques, analysis, definitions and theories of culture abound as trends of globalization grow (Gunawardena \& LaPointe, 2008; Perkins, 2008; Subramony, 2004; Thomas, Mitchell \& Joseph, 2002).

Clearly, a great amount of attention has been paid to culture in the research and design projects of the instructional design discipline in recent years, yet there is still a noticeable absence of attention to culture in some of the major publications of the field (Subramony, 2004), including the Handbook of Research on Educational 
Communications and Technology, 3rd edition just published in 2007. When culture is attended to in the institutionalized texts of the field, it is often approached as a manageable factor of targeting the needs of an audience. For example, in the widely-used textbook, Trends and Issues in Instructional Design and Technology, in a chapter on Instructional Design in Business and Industry, Richey, Morrison and Foxon (2007) address globalization of training by acknowledging the trends of internationalization and localization, claiming that "internationalization produces a culturally free product" (p.181). This type of claim relies on the assumption that instructional designers and products can somehow achieve cultural neutrality and that the culture of the audience being targeted is the only factor influencing the design of a product.

Other views seek to avoid the messy entanglement of sorting out culture. In reviewing competencies for instructional designers in the same textbook, DavidsonShivers and Rasmussen (2007) list attention to characteristics of the target population, environment and situation as necessary for instructional designers; however, they do not mention culture. Perkins (2008) considers whether the challenges concerning culturallysensitive design may not deal with "the nebulous concept of culture, but instead context" (p. 19). Yet, context may be distinguished from culture in that culture, as defined across disciplines, describes influences on an individual or group derived from what humans share or have shared at a social level over at least an incubating period of time (Kroeber \& Kluckhohn, 1952). Context, on the other hand, may operate on for an individual without being shared and may exist only in a fleeting capacity. Context, though it may overlap in some places with culture, may not sufficiently address the complex, established and shared frames of reference individuals bring to learning experiences. 
Distinguishing culture from context squares with Tessmer and Richey’s (1997) approach to contextual analysis, where they identify culture as one of several contextual considerations.

This introduction highlights a lag in attention to culture in the institutionalized literature and divergent views on whether it should be recognized as a distinct construct of significance in the discipline. This current state of discourse on culture is similar to that of emergent fields of research in any discipline. Because attention to culture is emergent in the IDT literature, this review must weave together analytical and empirical studies on systemic considerations of IDT in the global context as well studies that show attention culture in a wide variety of ways in the IDT literature. Finally, culturally informed ISD models will be examined to establish the gap in research this study seeks to fill and to support the rationale and design of this research study.

\section{$\underline{\text { Instructional Technology and Design in the Global Context }}$}

To place this research within a systemic view of IDT and information and communication technologies (ICTs), I begin with a review of literature with attention to trends and implications educational technology and ICTs in emerging economies and cross-border collaborations. Anecdotal, qualitative and analytical approaches in this body of research provide multiple perspectives and particularistic findings on cultural factors in the instructional process and integration of technology across borders. 


\section{ICTs in Emerging Economies}

In reflecting on a previously conducted survey, Zhang and Shin (2002) compare the open and distance education models of China, India and Hong Kong. This study considers types of courses, delivery methods, student demographics, including gender and access, funding and staffing. They also show that India's flagship open learning institution (IGNOU) is primarily staffed by part-time adjunct faculty and that ICT initiatives lag behind the other two countries. These researchers conclude that the China's program is indigenous and Hong Kong and India’s are imported. Zhang and Shin’s findings are relevant to the case study for this research, design team members and students work with IGNOU to potentially introduce i3Dv technology into their open learning system.

In “Taking Ownership: Strengthening Indigenous Cultures and Languages Through the Use of ICTs” Lieberman (2003) considers the dynamics of using ICTs for the benefit of indigenous cultural causes. He develops this overview by starting from the broad perspective of the impact of globalization on indigenous cultures then narrowing his focus to the impact of ICTs. Though Lieberman acknowledges both actual and potentially negative consequences of ICTs on indigenous cultures, his aim in this article is to identify examples of positive initiatives and explore the potential for further use and benefits. He highlights indigenous culture ICT initiatives for community building, language revitalization, education, commerce and environmental protection and considers these initiatives with attention to policy, capacity building, usage and implementation. Throughout the article, Lieberman emphasizes the imperative of indigenous 
empowerment, self-determination and ideological sustainability in order to reach positive ends through ICTs.

Lieberman does not only focus on the use of ICTs in education, yet his examples of political and economic uses still lie in a form of education- the dissemination of information. By grounding his examples in the broader discussion of the impact of globalization and ICTs on indigenous cultures, Lieberman (2003) highlights some of the central questions about the socio-cultural implications of educational technology. Does widespread use of ICTs: Encourage homogenization of cultures? Replace indigenous forms of learning or the wisdom of tradition and elders? Reinforce detrimental economic hegemonies? His answer to these questions seems to be, "Possibly"; however, he states, “it is preferable to take a pro-active and culturally sensitive approach to technology introduction.” The argument he makes in this article is that 1) the use of ICTs is already widespread and inevitable, and 2) policies towards productive and positive uses of ICTs may mediate the potential for negative consequences. Lieberman’s analysis is relevant to this case study which offers an opportunity to examine cultural interactions with the decisions and perceptions of stakeholders in a project to introduce an educational technology innovation in a country where indigenous cultural causes are still prevalent.

In the context of higher-education, Ezer (2006) interviews faculty and students in India to get an impression of the attitudes towards ICTs and ICTs in education in India. Ezer explores what Indian faculty and students believe to be the purpose of ICT. In particular, he poses the question of whether ICT and ICT education should work towards the benefit of individuals or society. He lays the groundwork for his findings about attitudes towards ICT and ICT education by discussing the authority dependent roots of 
the educational system in India. He concludes that students and faculty show optimism about ICT and seem to have whole heartedly adopted the Western model of individualistic, rational and imperialistic success. He uses his conclusion to claim that this model does not follow Ghandian philosophy. Ezer's research is particularly relevant to the case in this research because attitudes towards ICTs by faculty and students in India interact significantly with the purpose of the training program, the students’ experience in the training program and the potential market for the i3Dv product.

In a chapter on African Education Perspectives on Culture and E-learning Convergence, Kinuthia (2007) highlights the complexities of encountering culture in elearning environments while stressing its importance as a factor in design decisions. Resistant to prescriptive models, she proposes acknowledgement of the multiple perspectives involved for “jointly-negotiated advances” in e-learning. This study is designed to gather and present multiple perspectives of complex cultural interactions in order to work towards more dialogic views of the instructional design process.

As the above review reveals, analysis and findings in the literature point to a need for more flexibility and attention to culture in the process of instructional design and integration of instructional technology in emerging economies. Research on distance education in the global context also provides insight from nations with developed economies, revealing the same need for attention to culture (Marchessou, 1999). For example, in a chapter for the Handbook of Distance Education reviewing literature on “Learning in a Global Society,” Visser (2007) characterizes cognition as a complex “ecological phenomenon” (p.641). He explores implications of global diversity on learning networks and discusses implications for interinstitutional collaboration. 
Albrechtsen, Mariger and Parker (2001) review the history and current trends of distance education in Europe and Japan and emphasize the challenges of language and cultural differences in Europe, calling it a "Babel effect” (p.109).

\section{Cross-Border Collaborations}

Studies on open learning and distance education in nations with emerging economies show a trend of collaborations with universities and expert instructional designers from nations with developed economies (Merrill, 2001; Perkins, et al., 2005; Visser \& Berg, 1999). This same trend of cross-border collaboration is evident in the literature on the impact and integration of ICTs in nations with emerging economies. In a case study describing a World Bank Institute sponsored project encompassing East and West Africa, Burniske (2003) found that participants faced cultural challenges in “fundamental activities in the telecollaborative process” (p. 108). Luschei, Padmo and Spector (2009) report on a partnership between the Open University of Indonesia and Florida State University and emphasize the importance of building friendships beyond professional relationships across borders to increase the "potential for real collaboration" (p. 22).

From a cross-border consultant's point of view, Marchessou (2001) argues that “The ethical dilemmas we are confronted with today as educational consultants overseas... could be roughly summarized in three pairs of alternatives: (a) connectivity vs. exclusion, (b) access vs. excess, and (c) transience vs. permanence” (p. 111). Reflecting on ten years of cross-border ICT consulting in West Africa, Hergert (2003) proposes handling such ethical dilemmas with careful attention to "cultural contexts" of 
the situation and an "empathetic” posture (p. 33). The above findings related to project management, such as ethics, roles, relationships, communication and barriers to implementation in cross-border collaborations highlight the need for attention to culture not only in the design of learning opportunities, environments and products, but also in the process of instructional design.

\section{$\underline{\text { Attention to Culture in Instructional Design and Technology Literature }}$}

This section will review the literature exploring cultural dynamics specifically in the IDT context and draw preliminary connections between findings in the literature and Young's (2009) CBM to help illuminate later discussion of data. The following topics related to culture will be covered: educational or pedagogical values, ethical standards, educational psychology constructs, collaboration, communication, and the instructional design process.

\section{Culturally determined educational or pedagogical values}

Several researchers have provided critical analysis of educational or pedagogical values across cultures (Bentley, Tinney \& Chia, 2004; Ku, Pan, Tsai, Tao \& Cornell, 2004; Loewer, 2003; Zhang, 2010). These analytical approaches often rely on literature review and reports of historical and current trends to frame characterizations of learning cultures defined by national, regional or tribal boundaries. Zhang (2010) defines learning culture as "historically-rooted attributes related to learning and education carried by an identifiable community. These cultural attributes are demonstrated as collective, intuitive understanding of what learning is about and how it should be practiced” (p. 232). In this body of literature, these learning culture characterizations are often offered to describe 
behaviors of learners and inform educational initiatives in these contexts or to advocate for resistance to the imposition of outside learning culture influences. In Young's (2009) CBM model cultural beliefs and values are included as an element of the psychology of culture and defined as "the ideals, principles, or standards" that "evolved historically from the various social and economic contexts in a society” (p.235).

\section{Culture and ethical standards}

Along with attention to culture in educational or pedagogical values, there is also a discussion in the IDT literature about the challenges of establishing ethical standards across cultures. There is consensus in this discussion that uniform rules for any online community should reflect a compromise and negotiated set of standards for that community (Bradshaw, Keller, \& Chen, 2003; Dodig-Crnkovic \& Horniak, 2006; Hergert, 2003; Marchessou, 2001). However, often this is not the case; rather rules are often established through power and to benefit those who are in power. Bradshaw, Keller and Chen (2003) suggest that "the cultural and social-power position of the ethics code creators, within both local and global contexts, and the cultural distribution and representation of individuals charged with making decisions regarding ethical standards, are important factors in considering the applicability of a code of ethics to an international community” (p. 18). Bradshaw et al. frame their discussion of power relations with the term "cultural capital” which they define as "symbolic power based on a variety of factors related to social status and cultural ascendancy” (p. 15). Young's (2009) CBM model includes attention to cultural capital as an element of the anthropology of culture but takes a more narrow view of this construct as part of the 
economics of a society or culture with a focus on production, distribution and consumption characteristics of a culture or target learner.

\section{Culture and educational psychology constructs}

Educational psychology constructs have also been examined in the IDT literature with attention to cross-border or cross-cultural dynamics. For example, in looking at components of motivation in a group of international distance education students, Visser, Plomp, Amirault and Kuiper (2002) use the ARCS model (attention, relevance, confidence and satisfaction) to find that attempts to personally customize motivational messages for students was time-consuming and no more effective than collective messages. Gunawardena et al. (1996) used Kolb’s Learning Style Inventory to characterize the learning styles of adult learners in Open University students in Sri Lanka. Kolb’s Learning Style Inventory identifies learning styles as accommodator, diverger, converger or assimilator on a Cartesian coordinate polarizing concrete experience and abstract conceptualization and active experimentation and reflective observation. Gunawardena et al. (1996) found the dominant learning style to be Assimilators and posit that "the dominant Assimilator style to a certain degree reflects the traditional ways in which students are taught in Sri Lanka, in a face-to-face lecture-style classroom where the acquisition of theory, facts, and abstract knowledge is of primary concern” (p.117). However, they do acknowledge that "one of the questions that remains to be answered in order to better understand learning styles is related to the appropriateness of the LSI for this cultural context” (p. 116). As Tirri and Campbell (2010) point out in a discussion of the current state of cross-cultural research in education, "the flow of ideas on the 
psychological measurements is a one-way flood of American constructs” (p.20). Young's (2009) CBM approach to psychology of culture allows for inductive analysis of learners in a particular situation through qualitative inquiry and avoids the problematic implications of applying psychological constructs across cultures.

\section{Cultural considerations in collaboration and communication}

Cultural dynamics related to collaboration and communication in learning teams and online settings has received a great deal of attention in the IDT literature (Burniske, 2003; Ku \& Lohr, 2003; Paulus, Bichelmeyer, Malopinsky, Pereira \& Rastogi, 2005; Shih \& Cifuentes, 2003). For example, Paulus et al. (2005) address the challenges of teams of international students working on project-based learning activities in a study exploring "whether or how one component of culture, power distance, could provide insight into group dynamics” (p.43). Paulus et al. (2005) take a case study approach and collect data through observation, interview and questionnaire data, and analyzed using an affinity diagram technique to organize. The participants are members of an elective course in graduate design at a large Midwestern university in the US, including both US and international students. Paulus et al. (2005) discuss the results in relation to Hofstede's two levels of power distance: low and high. They described the activities of the groups and cross-referenced with low or high power distance indicators to show where groups fell in different group dynamic topics, e.g. roles, decision-making, etc. They found that low power distance was revealed within group interactions of international students and high power distance was revealed in inter-group conflict between international students and US students. Ku and Lohr (2003) also rely on Hofstede’s dimensions to examine 
cultural influences in the online learning environment. Problems associated with the use of Hofstede’s dimensions will be discussed later in this literature review. Young's (2009) CBM model addresses group dynamics with attention to cultural relations, providing questions for guided inquiry of how learners relate to each other.

Burniske (2003) takes a case study approach to examine an online community of educators in Ghana and Uganda, finding that communication issues related to culture were a challenge: "Participants confronted myriad challenges, including a cultural bias with respect to questions and criticism (two fundamental activities in the telecollaborative process), which predisposed them to consider such gestures 'impolite' among strangers” (p. 107). In a case study of intercultural online communications between US and Taiwanese college students, Shih \& Cifeuntes (2003) found "six intercultural issues and phenomena during [e-mail] exchanges: a) the need for visual images, b) bewilderment of Taiwanese students, c) excessive expressions of gratitude of Taiwanese students, (d) disparate expectations, (e) direct versus indirect writings, and (f) misinterpretation” (p. 86). Young’s (2009) model provides extensive attention to cultural communications, defined as the exchange or transmission of information, and provides levels of inquiry on this topic that include: language, nonverbal and verbal; writing; temporal communications; visual communications; and semiotics, signs and symbols.

\section{Culture and the instructional design process}

In a review of literature on the impact of culture in online education, Wang and Reeves (2007) assume most designers recognize the importance of cultural factors but emphasize the relatively small body of research in this area. They trace interdisciplinary 
definitions of culture back to the original provided by British anthropologist Sir Edward Tylor in 1871. They also provide a review of Hofstede's oft-cited cultural dimensions, including criticism of his choice of nations as units for studying culture. They identify four threads of research on culture in online education: “(1) the interactions in an online course which involved culturally-diverse adult learners; (2) the access to the Internet among different groups; (3) the assessment criteria applied in online education; and (4) the design of virtual learning environments to accommodate the needs of culturally diverse learners” (pp. 9-10). Notably missing from Wang and Reeves' (2007) list is a thread of research on the impact of the process of developing online education.

A line of research on the cultural dynamics of engaging the process of instructional design has been emerging over the last decade or so. Two collections of studies, Armstrong (2004) and Kinuthia and Marshall (2010) illustrate the sensitivity of the process of IDT to environments and systems by presenting case studies of a variety of situations and discussing implications for instructional designers. In these collections, scholars and practitioners reflect on the use of instructional design practices across sectors and across borders and provide insight on lessons learned and challenges faced. Rogers, Graham and Mayes (2007) interviewed 12 instructional designers about their experiences creating online instruction for people of other cultures. In response to their question about importance placed on cultural differences, these barriers emerged: “a) an over-emphasis on content development as the center of practice and under emphasis on context and learner experience, b) a relative lack of evaluation in real-world practice, and c) the creation of less than ideal roles that instructional designers assume in the larger organizational structures involved” (p. 207). They also explore the impact of 
cultural awareness on instructional design and use a metaphor of "building bridges” to “[stimulate] a) separating deeper principles from particular application, b) identifying gaps where bridges are needed, c) allowing for more flexibility in the design process, and d) educating other stakeholders so they are invested in bridge building too” (p. 210). Debry (2002) explores the process of globalizing instructional materials at seven global companies, finding that all companies involved participants from target cultures in the design process.

Several case studies in the literature provide general descriptions of international projects and conclude with a list of challenges or lessons learned about the process of design in the cross-cultural, cross-border or cross-sector context. Common themes that emerge include: 1) culture as an important factor during stages of the instructional design process (Chitiyo \& Harmon, 2009; Eastmond, Gutierrez \& Shanley, 2010; Lim, 2007; Perkins, et al., 2005); and 2) calls for design models or modifications to models that better fit such situations by taking culture into account (Arya, Margaryan \& Collis, 2003; Soulier, 1999; Visser \& Berg, 1999; Zagoumennov, 2010). Young’s (2009) CBM is an attempt to answer these calls for attention to culture in the design process and as a design construct. This study seeks to fill a gap observed in the literature with attention to culture in the IDT context: an empirical case study applying Young's (2009) CBM to examine and describe cultural dynamics in the process of IDT.

\section{$\underline{\text { Review of ISD Models Acknowledging Culture }}$}

The following section reviews models and theories that have been offered to supplement or modify traditional ISD models in order to account for culture. 
Henderson (1996) "theoriz[es] cultural contextuality as a variable of consequence in IMM [interactive multimedia] instructional design” (p.85). First, she develops her argument that instructional design paradigms are influenced by “a) world view; b) values, ideologies, culture, class, and gender; and c) commitment to a particular design paradigm" (p. 86). Then she reviews paradigms found to inform instructional design: objectivism, constructivism, and eclectic; she follows this with an exploration of deracialization in instructional design before introducing and showing gaps in instructional design paradigms that approach issues of culture: inclusive or perspectives paradigm and the inverted curriculum approach. Finally, she proposes her own "multiple cultural model” to address the gaps and weaknesses in the examined paradigms. Modifying Reeves (1992) pedagogic dimensions of interactive learning, she lays multiple cultural contextuality across all dimensions of the continuum to emphasize its pervasive presence. Henderson's work has been generative.

Wild and Henderson (1997) propose a model for "investigating and developing culturally appropriate instructional materials” (p.181) and consider it a framework for conducting research in this area. Pulling from Henderson's (1996) work, they argue that culture is significant in instructional design because "distinctive and significant symbolic meanings and values develop around information, its use and structuring in any cultural group... when the act of instructional design translates this information into products or artifacts of learning that artifact embodies cultural influences, such as the instructional designer's world view, the designer's values, ideologies, culture, class and gender, and, the designer's commitment to a particular design paradigm” (p.184). McLoughlin (1999) uses Henderson’s (1996) multiple cultural model to “design instruction that conceived of 
multiple zones of development for Indigenous learners in terms of content, perspectives and pedagogies” (p. 236).

Edmundson (2007) offers a case study to test her proposed cultural adaptation process (CAP) model to evaluate e-learning courses and to include cultural profiles in learner analysis. She relies on an eclectic theoretical framework, pulling from instructional design and industrial anthropology. The "foundational framework" of course evaluation in Edmundson’s (2007) CAP model is based on Marinetti and Dunn’s (2002) guidelines for adapting courses for different cultures. Edmundson also modifies Henderson’s (1996) multiple cultural model for instructional design from fourteen dimensions represented in a continuum to nine and calls her modification the simplified multiple cultural model (SMCM): pedagagogical paradigm (instructivist/objectivistconstructivist/cognitive); experiential value (abstract—concrete); teacher role (didactic_facilitative); value of errors (errorless learning-learning from experience); motivation (extrinsic_-intrinsic); accommodation of individual differences (non-existentmultifaceted); learner control (non-existent-unrestricted); user activity (mathemagenic — generative) and cooperative learning (unsupported_integral). To include learner analysis based on cultural characteristics in the CAP model framework, she pulls from three industrial anthropology models of oppositional cultural dimensions: Hofstede’s (1984) five cultural dimensions (power distance, individualism, masculinity, uncertainty avoidance and long-term orientation); Trompenaars and Hampden-Turner’s (1998) seven cultural dimensions (universalism v particularism, individualism v communitarianism, specific v diffuse cultures, affective v neutral cultures, achievement v ascription, sequential v synchronic cultures and internal v external control); and Hall’s (1981) 
concept of monochronic v polychronic cultures. She then applies this model in a crossborder context between the US and India and uses case study research design to evaluate a course developed by a US corporate training company for Indian learners. Edmundson's data analysis is limited to description and evaluation of the process for course development and learner analysis, revealing that the current CAP model may not provide optimal guidance for the order of analyzing activities.

A challenge reflected in Henderson's and Edmundson's studies is that culture focused research is still emergent in instructional design (Richey, 2009), so proposed models are often either untested or tested only by their creators and tend to be prescriptive rather than descriptive. Henderson's and Edmundson's studies also reflect another challenge in conducting research with a cultural focus in instructional design: finding a theoretical framework for analysis of results that does not rely on structured, oppositional continuums. The neatness of these continuums makes them highly attractive and easy to apply. For example, Hofstede’s cultural dimensions have been applied ad nauseam and rarely reveal more in the findings than the presence of these differences in a learning environment or the predictable implications of how they function (Dunn \& Marinetti, 2007; Ku \& Lohr, 2003; Paulus et al., 2005;).

\section{Limitations of Current Cultural Models for Research}

This section considers the limitations of the above models relying on Hofstede's or other similarly structured oppositional constructs in exploring the complexity of culture in the instructional design process. 
In their review of literature on the impact of culture in online education, Wang and Reeves (2007) note that Hofstede’s (1984) model of cultural dimensions has been cited more than 2,000 times across several disciplines. Hofstede’s (1984) work was highly generative and has been supported by hundreds of studies; it has also been the subject of debate. Wang and Reeves (2007) rely on Sondergaard's (2002) review of Hofstede’s cultural dimensions to summarize criticisms of his work into five points: “1) inappropriate instruments to measure culture; 2) nations not the best unit for studying culture; 3) participants from one company represent entire national cultures; 4) data is old and obsolete; and 5) four or five dimensions cannot tell the whole story.” In an earlier cultural and political analysis of data from the study presented above, Nicholson and Sahay (2004), Nicholson and Sahay (2001) acknowledge that "to grasp a concept as vastly complex as national culture without succumbing to reductionist, instrumental treatment is potentially overwhelming” (p. 31). They sought to avoid the "cultural determinism in models such as Hofstede (1984)” by focusing rather on social structures and external influences on participants in the study (p. 31).

A poststructuralist critique of such oppositionally defined constructs of culture, applying Derrida’s (1974) technique of deconstruction of language, would emphasize their reliance on binary oppositions for labeling cultural characteristics and question the false hierarchy which it sets up between the opposing labels. Under this critique, any identification of cultural dimensions and binary labeling of such would be an attempt to construct meaning about culture through patterns and structure where poststructuralists would argue meaning is absent. However, one need not completely accept a relativistic epistemology as reflected in poststructuralism to question the hierarchical implications of 
using oppositionally defined approaches to describe culture in the instructional design process.

Postcolonialism offers another lens through which to question such approaches. Research on instructional design is particularly vulnerable to a postcolonial critique as Visser and Suzuki (2007) observe that "the professional literature of the instructional design field draws heavily on the experience of its application and development in one country, the United States of America” (p.235). Applying deconstructive analysis for postcolonial purposes, Bhabha (1994) in the Location of Culture argues that traditional binary approaches do not accurately reflect the complexity of cultural interaction. In the educational context, Carter (2004) argues that "a postcolonial interpretation would reveal Western and non-Western borders to be profoundly ambivalent constructs” and that “culturally diverse students' homogenized identities” should be “recast into multiple, mobile and provisional constructions” (p.833).

The model to be applied in this study, Young's (2009) CBM model, places structure on examining cultural dimensions; however, it does not rely on polar oppositions. Young states that "applying the polaric dimension to design should be done carefully and sparingly” (p.33). Furthermore, Young expresses a view of culture as "dynamic, malleable, fluid and always in motion" and claims that "to think about culture in design, the mind must be free of preexisting notions of what culture means” (p.27). Young's qualitative method of examining instructional design artifacts to derive the CBM framework bolsters her model against criticisms such as those made against Hofstede’s method for determining his cultural dimensions (See Table 1). 
Table 1

Comparing Hofstede's Cultural Dimensions and Young's Cultural Elements

Criticisms of Hofstede's Cultural Dimensions

\section{Differences in Young's Cultural Elements}

\begin{tabular}{|c|c|}
\hline $\begin{array}{l}\text { Used inappropriate instruments to measure } \\
\text { culture }\end{array}$ & $\begin{array}{l}\text { Derived from description and exploration } \\
\text { of culture rather than measurement }\end{array}$ \\
\hline $\begin{array}{l}\text { Chose nations as the unit for studying } \\
\text { culture }\end{array}$ & $\begin{array}{l}\text { Chose a minority group within a nation as } \\
\text { the unit for studying culture }\end{array}$ \\
\hline $\begin{array}{l}\text { Represented entire national cultures with } \\
\text { participants from one company }\end{array}$ & $\begin{array}{l}\text { Represented minority group culture with } \\
\text { multiple artifacts from diverse settings }\end{array}$ \\
\hline Derived from data that is old and obsolete & $\begin{array}{l}\text { Derived from multi-disciplinary literature } \\
\text { review and continuous qualitative data } \\
\text { gathering }\end{array}$ \\
\hline $\begin{array}{l}\text { Presents our or five polaric dimensions of } \\
\text { culture }\end{array}$ & $\begin{array}{l}\text { Offers twenty-five descriptive elements of } \\
\text { culture }\end{array}$ \\
\hline
\end{tabular}

Using Young's CBM Elements as a taxonomy in this study provided a framework for 1) description and exploration of culture rather than measurement; 2) application to multiple cultures and sub-culture units of study; 3) presentation of participant perspectives individually and contextually rather than as representations of entire groups of people; 4) collection and description of rich, contextualized data; and 5) offered twenty-five elements of culture for a more comprehensive description and analysis.

\section{Conclusion}

This review of the relevant literature on culture in training and development and IDT offers guidance on the challenges of researching this complex construct. This review also highlights the need for empirical studies on cultural dynamics in the process of instructional design by novice practitioners. Finally, analysis of new models seeking to 
acknowledge the importance of culture in this process shows reliance on potentially reductive characterizations of culture as well as prescriptive approaches that lack empirical support. This study seeks to fill this empirical gap in the literature by using an emergent, culturally-informed ISD model as a research lens to identify cultural interactions with the decisions of practitioners and the perceptions of stakeholders in a cross-sector, cross-border training for innovation environment. 


\section{CHAPTER 3: METHODOLOGY}

\section{$\underline{\text { Introduction }}$}

This research uses the qualitative approach of case study and applies a cultural design framework to examine the process of instructional design by a team of designersby-assignment in a US government agency/public university consortium program to train applied research and development teams brought to the United States by an education software company headquartered in India. This study seeks to consider decisions and perceptions of multiple stakeholders in order to identify complex cultural interactions in the instructional design process. Inquiry through case study allows an "analytic focus” on this “specific phenomenon” (Schram, 2006). I take a pragmatic view with this case study approach in assuming knowledge about the IDT process is context-dependent and potentially useful for cross-referencing with other cases.

\section{Guiding Questions}

How does culture interact with the instructional design process, as defined by Young's Culture-Based Model (CBM) framework, in this case of a cross-sector, cross-border training program?

a) What design team decisions, stakeholder perceptions, and program outcomes relate to ID-TABLET components of the CBM framework?

b) With which CBM Elements of culture do design team decisions, stakeholder perceptions and program outcomes interact? 


\section{Methods and Rationale}

\section{Rationale}

Qualitative research methods are particularly well suited to this research as they value data that allows for rich descriptions and identifying emergent themes (Schram, 2006). Merriam (1998) suggests that case study is a "particularly appealing design for applied fields of study” because "processes... can be examined to bring about understanding that in turn can affect and perhaps even improve practice” (p. 41). The guiding questions for this study focus on the process of IDT, and Creswell (2003) identifies case studies as particularly useful in describing processes.

Yin (2003) states that “case studies are the preferred strategy when 'how' or 'why' questions are being posed, when the investigator has little control over events, and when the focus is on a contemporary phenomenon within some real-life context” (p. 1). The overarching guiding question for this study is a "how" question; I had no control over events in the chosen case; and the focus and circumstances of the case are real and contemporary. Also, culture focused research is still emergent in instructional design (Richey, 2009), and Stake (1995) suggests that case study is the appropriate method for studying new and emerging phenomenon.

\section{Research Design}

Case

This study relies on a purposeful sample because of the uniquely appropriate circumstances of this case in relation to the research questions. Merriam (1998) explains that "purposeful sampling is based on the assumption that the investigator wants to 
discover, understand and gain insight and therefore must select a sample from which the most can be learned” (p. 61). As the broad context for this research is the proliferation of global innovative educational technology collaborations, the case sampled needed to relate to educational technology innovation in a global setting. Because the purpose and guiding questions of this research seek to explore complex cultural dynamics in an instructional design process, the sampled case needed to represent a multicultural environment and include all stages of an instructional design process. Since this case also seeks to highlight culture as defined at both national and organizational levels, the instructional design process needed to be undertaken across borders and across sectors. In order to address the context, purpose and guiding questions of this research, the selection criteria ensured the case sampled had the following attributes: 1) training program being completed across national borders; 2) training program being completed for the purpose of developing an educational innovation; 3) training program being completed through collaboration between private and public sector organizations; and 4) instructional design process activities being carried out from initial stages to post-implementation.

The chosen case fills all requisite criteria by presenting the instructional design process for a cross-border, cross-sector training for innovation project. A private company based in India, NextGenEd, contracted with the Institute for Advanced Learning (IAL), a consortium of three US state universities, a community college and one of NASA’s Space Centers, to train up to fifty employees to build applications that produce 3D graphical representations for fully immersive virtual environments (see Table 2). The Indian Company plans to produce software and build immersive threedimensional virtual (i3dv) environments for thousands of higher education, primary and 
secondary institutions in India, the US and Europe (see Table 3). It is incidental to this case that the instructional design team are subject matter experts who could be defined as designers-by-assignment.

Table 2

Overview of Institute for Advanced Learning Training Curriculum

Topic Proposed Time Frame Student Learning Goals

Introduction 1 week

Open GL 16 weeks

Framework

CAVE Programming 4 weeks

General Techniques 14 weeks

Porting to Desktop 9 weeks

Real-time, Real- 8 weeks

world Projects
Adapt graphics to scientific data

Modify existing and produce new

visualization programs

Transport a visualization program

among commodity computers to

commercial grade large graphic

displays

Table 3

Overview of NextGenEd's i3Dv First YearTraining Agreement with IAL

Investment Training Product

$>\$ 600,000 \quad$ Fully train staff of $12 \mathrm{i} 3 \mathrm{Dv} \quad$ Produce a completed,

programmers; Start the training commercially viable product for

of additional $10+$ programmers the education market 


\section{Participants}

Purposeful sampling was used to select participants. Ideal participants were intended to represent a range of perspectives on the program and process through the following criteria: representative participants were chosen to reflect each role involved in the training program and instructional design process, including management, instructors and students.

The limits of the sample size available in this case are portrayed in Table 4. All members of the IAL team were sampled except the secondary instructor who could not be reached. The sample of IAL team members included: one participant for the director role and three participants in instructional design roles. One member of NextGenEd management in the US participated in the study; no members of NextGenEd management in India participated in this study. Twelve members of NextGenEd’s training program team participated in the study: one participant for the project manager role, one participant for the team lead role, and ten participants for student role. This sample provided "reasonable coverage of the phenomenon given the purpose of the study" (Patton, qtd. in Merriam, 1998) as it included perspectives from both members of IAL management and one of three members of NextGenEd's i3Dv project management, perspectives of all but one member of the IAL instructional team, and perspectives from students until a point of redundancy was reached. Among student participants, network sampling, a process of “asking each participant or group of participants to refer you to other participants” (Merriam, 1998, p. 63), was also used to select participants until a point of “redundancy” had been reached (Lincoln \& Guba, 1985). Students were sampled 
until "no new information [was] forthcoming from new sampled units" (Lincoln \& Guba, 1985).

Table 4

Participant Information

Participant

Country of Origin Organization Gender Age

\begin{tabular}{lllll}
\hline Director & United States & IAL & $\mathrm{M}$ & $>30$ \\
Program Manager & United States & IAL & $\mathrm{M}$ & $>30$ \\
Primary Instructor & Southeast Asia & IAL & $\mathrm{F}$ & $>30$ \\
Secondary Instructor & India & IAL & $\mathrm{M}$ & $>30$ \\
Supporting Instructor & United States & NextGenEd & $\mathrm{M}$ & $>30$ \\
Senior Project Manager & India & NextGenEd & $\mathrm{M}$ & $>30$ \\
Team Lead & India & NextGenEd & $\mathrm{M}$ & $<30$ \\
Student 1 & India & NextGenEd & $\mathrm{M}$ & $<30$ \\
Student 2 & India & NextGenEd & $\mathrm{M}$ & $<30$ \\
Student 3 & India & NextGenEd & $\mathrm{M}$ & $<30$ \\
Student 4 & India & NextGenEd & $\mathrm{F}$ & $<30$ \\
Student 5 & India & NextGenEd & $\mathrm{M}$ & $<30$ \\
Student 6 & India & NextGenEd & $\mathrm{M}$ & $<30$ \\
Student 7 & India & NextGenEd & $\mathrm{M}$ & $<30$ \\
Student 8 & India & NextGenEd & $\mathrm{M}$ & $<30$ \\
Student 9 & India & NextGenEd & $\mathrm{M}$ & $<30$ \\
Student 10 & NextGenEd & $\mathrm{M}$ & $<30$
\end{tabular}


Artifacts

Artifacts were chosen according to the following criteria: 1) prepared or used within the context of the instructional design process or training program; 2) prepared or used by participants in the training program; and/or 3) published in relation to the training program. The sample of artifacts includes documents, websites and 3D visualization applications. Table 5 presents a description of the artifacts.

Table 5

Artifact Descriptions

Artifact

\section{Description}

IAL Website

“About” page describing purpose, history, current projects, personnel and future plans of the i3Dv program

"Work" page offering data, project documentation and user manuals for visualization projects completed at the center

IAL i3Dv Training Eleven page document describing the experience of the

Curriculum

IAL team, requisite qualifications for students of the curriculum, resources, topics with objectives, number of programming assignments and intended time-frame for each topic

IAL Recommendations for List of desired qualifications for training program provided i3Dv Training Candidates to NextGenEd during the recruitment process

IAL Lecture Materials PowerPoint slides and supporting graphics and programs 
from twelve lectures

IAL Assignments

IAL Feedback Notes

IAL Press Release

NextGenEd i3Dv Business

Plan

\section{Gaining Entry}

At a NASA shuttle launch party in December 2007, I was introduced to the Director of IAL by a family member who was involved in NextGenEd's i3Dv project at the time. My family member and I had been invited to this event by the Director to celebrate the recent signing of the i3Dv training program agreement between IAL and NextGenEd. Because of my background as an ESL teacher and experience hosting 
groups of exchange students in a higher education setting, the Director and I connected over his upcoming similar circumstances. The IAL team was preparing for students from India to arrive at the NASA space center to begin training in January 2008. I told him that as a graduate student in instructional design and technology and Research Fellow at the India, China and America Institute I was focusing on educational collaborations between the US and India and that I would be very interested in his training program as a focus for research. The Director welcomed the idea.

In February 2008, the Director invited me to join him, the Program Manager, the Primary Instructor and the Supporting Instructor in a conference call about the program and my research interests. On this phone call, these members of the IAL team expressed openness to participating in the research. Over the next year, I stayed in contact with the IAL team through phone calls and e-mails while I completed the research concept paper and gained IRB approval for the pilot study research. In order to gain IRB approval, I sought a letter of consent from NextGenEd's President of US Operations through e-mail. He sent a signed letter of consent to me through e-mail stipulating the condition that NextGenEd remain anonymous.

In September 2010, I recruited the NextGenEd participants through Linked-In. This professional networking site allowed me to send the students an invitation through their connections to other research participants. I made arrangements for face-to-face interviews with five participants using the Linked-In messaging service. NextGenEd’s President of US Operations put me in touch with the Vice President of Human Resources in India who granted consent for me to conduct interviews and observations on-site at NextGenEd. After arriving in India and conducting these interviews, the first five 
participants suggested additional participants and passed my contact information on to the remaining five participants who also consented to participate in interviews.

\section{Pilot Study}

After gaining IRB approval in March 2009, I conducted a pilot study for this research informed by a broad theoretical framework of IDT and ISD process modeling in a global context (Branch \& Deissler, 2008; Damarin, 1998; Gustafson \& Branch, 1997; Heemskerk, Brink, Volman \& ten Dam, 2005; Henderson, 1996; Seufert, 2001;VisscherVoerman \& Gustafson, 2004; Willis, 2005). The purpose of the research at the time of the pilot study was to describe the process and highlight the distinct features and challenges of instructional design in a US government agency/public university program to train applied research and development teams brought to the United States by an Indian company. The guiding questions were:

1. How does a cross-sector team navigate the process of instructional design?

- How do organizational differences shape decision making in the process of instructional design?

- How does the market-driven goal of creating innovation shape decision making in the process of instructional design?

2. How does a cross-border navigate the process of instructional design?

- How do cross-cultural dimensions shape decision making in the process of instructional design?

- How does the expansive proximity of the stakeholders shape decision making in the process of instructional design?

As part of this pilot study, I conducted and audio recorded two remote interviews in June 2009 using Skype: 1) a 62 minute interview with the IAL Director and 2) a 53 
minute interview with the IAL Primary Instructor of the US Consortium training program. These interviews were transcribed by a professional transcription agency within one week. I altered the data for anonymity and added observer's comments, noting emergent themes and prompts for further inquiry. Artifacts including the IAL Website, IAL Training Curriculum and NextGenEd Business Plan were also collected. The interview transcripts and observer's comments were peer-reviewed by graduate students in a graduate level class on qualitative case study methods for education and an Associate Professor of Research, Measurement \& Statistics. These reviewers offered additional insight and constructive feedback to the observer's comments.

I coded the pilot data for emergent themes and identified the following preliminary issues of how a cross-sector, cross-border team navigates and makes decisions in the instructional design process: 1) Policies: the impact of national policies for educational technology initiatives and the impact of cross-border relations on global networks for knowledge creation and dissemination; 2) Ethics: company agreements with employees for training; instructor evaluations in high stakes situations; and student obligations to maintain organizational commitment after training; 3) Roles: limitations of subject matter experts in the role of instructional designers; students as employees, employees as students; and non-profit instructors being involved in for-profit product development; 4) Communication: corporate organizational structure impact on lines of communication; and cultural impact on lines of communication; 5) Training components: influence of organizational goals on design and delivery; influence of training on organizational commitment; presence and/ or absence of formative and summative assessments; and addressing cultural differences in learning environments. These 
preliminary findings were presented at the 2009 International Conference of the Association for Educational Communications Technology (Russell \& Wang, 2009). Conducting this pilot study and engaging with conference participants prompted me to narrow the research focus to the variable of culture and pointed to the need for a comprehensive theoretical framework to examine cultural interactions with all stakeholders and all stages in the instructional design process.

\section{Data Collection}

This case study includes data gathering though the use of interviews, artifact analysis and observation. Yin (2003) recommends that a case study "rel[y] on multiple sources of evidence, with data needing to converge in a triangulating fashion” (p.14). Participant interviews and observation offered a variety of perspectives and exposure to learning environments and revealed dynamics of actual practice. Artifacts provided examples of assignments, feedback and student production and reflected ideal versions of plans and broad organizational policies. These different levels of vantage made it possible to pay attention to organizational and individual cultural dynamics in this crosssector, cross-border IDT setting.

Because of the comprehensive treatment of culture in the instructional design paradigm in Young's (2009) CBM, it was chosen to provide the theoretical framework for data collection and analysis. Since data analysis in this case relies on Young's (2009) CBM Elements component of the ID-TABLET framework as taxonomy to identify cultural dynamics, data collection activities relied on Young's ID-TABLET framework to categorize the instructional design process. This design was intended to bolster internal 
validity in the application of the model's cultural constructs in analysis. The components of ID-TABLET (Inquiry, Development, Team, Assessments, Brainstorming, Learners, Elements and Training) with 70 design factors depicted in Table 6 provided a comprehensive guide to shape and inform the interview, observation and document analysis protocols as well as coding schema and data analysis.

Table 6

ID-TABLET Components of Young's Culture Based Model (CBM)

\section{Component Description}

Inquiry Genre

What ICTs are being used and why?

Which ICTs are more effective given the content?

Is the project affordable to the target audience, given the ICTs used?

How have ICTs influenced the design of the product?

\section{Framing}

Who is the target audience?

How is the content presented to the target audience?

What is the content presented?

Is the content appropriate for the target audience and why?

Where, within the products design, is the content most appropriate?

Why is this content appropriate?

Omission

What has been intentionally omitted and why? 
What has been unintentionally omitted and why?

What has not been considered?

Will these omissions be detrimental to the project and why?

\section{Backgrounding}

What has been backgrounded?

Is the backgrounding intentional or unintentional and why?

Will this backgrounding be detrimental to the project?

\section{Foregrounding}

What is emphasized and why?

Is this what should be emphasized?

How does this emphasis influence the overall design?

\section{Visual Representations}

How do the visual representations frame the product?

How do visual representations assist in the instructional process?

Who is portrayed in these visual representations?

What is portrayed in these visual representations?

What purpose do the visual representations serve?

Are inappropriate visual representations in the design?

Where are these visual representations placed in the product?

Why were these visual representations selected?

Development Consider technical, aesthetic, content, culture-based, and target audience design specifications. 
Mass distribution formats.

Effective technology.

Diversify ICT format.

Understand target audience.

Explore environmental and individual/group cultures.

Quality design.

Authenticate product.

Control for interference.

Model the product or process.

Team

Cultural expert.

Enlist educators.

Culturally informed team.

Assessments Multiple evaluation options.

Assess the assessment.

External review.

Culture-specific assessments.

Brainstorming Financial support.

Pilot studies/field tests of product.

Assess community’s response.

Community representative on team.

Investigate target audience to authenticate product.

Reflect and assess learning goals.

Affordable design. 
Meet needs of target audience.

Discuss and consider cultural context.

Present and consider outcomes.

Learners Extend learning.

Differentiate opportunities to learn.

Empower and engage learners.

Teach proactive learning.

Identify educational objectives.

Culture-specific instructional strategies.

Enrich instructional content.

Adapt instruction to learner.

Plan for instruction.

Enculturate the learner.

Elements Anthropology of culture

Cultural aesthetics: that which is considered beautiful.

Cultural artifacts: products that exist or remain.

Cultural capital: economics and material wealth.

Cultural classification: divisions in a culture or society.

Cultural communications: the exchange or transmission of information.

Cultural demographics: characteristics of a population.

Cultural environment: physical or social conditions in which a human being, other species or entity lives and develops. 
Cultural history: narrative representation of historical events.

Cultural knowledge: what is known and what one comes to know.

Cultural language: language form, content, use and meaning.

Cultural physiology: physiological characteristics of a human being, other species or entity.

Cultural relations: the relationship of one being to another being.

Cultural resources: use and cultivation of resources.

Psychology of culture

Cultural beliefs and values: shared truths and shared ideas.

Cultural experiences: interpretation of the world from inside and out.

Cultural ideas: the use and meaning of ideas and perceptions.

Cultural identity: distinguishing qualities of a human being, other species or entity.

Cultural interests: deeply personal desires, wants, wishes.

Cultural misconceptions: untruths, myths, stereotypes.

Cultural ways: behaviors, norms, feelings.

Science of culture

Cultural anomalies: happenings that promote, initiate, or force cultural change.

Cultural cultures: the scientific identification of cultures, worlds, ecosystems.

Cultural futures: that which is to come.

Cultural infinities: those things without limits: time, space, distance. 
Cultural nature: intrinsic characteristics of a human being, other species or entity.

Training Product training.

Culture-based training.

Note. Taken from Young (2009) pages 41-45.

Interviews

Interviews were conducted over an eighteen-month period while the training program was still being conducted and after it had concluded. As noted above, two interviews were conducted in the pilot study. These same participants and the remaining members of the IAL team were interviewed in the US at the training site over two days in July 2010: a 103 minute interview on the second day with the Director; a 60 minute interview on the first day and an 80 minute interview on the second day with the Program Manager; a 91 minute interview on the first day and a 34 minute interview on the second day with the Primary Instructor; and a 38 minute interview on the first day with the Supporting Instructor. Interviews with the students were conducted in India at the Indian company on two days, one week apart, in September 2010: ten students were interviewed for between 25-35 minutes each, six students were interviewed on the first day and four students on the second day one week later.

Two participants were interviewed through written questionnaires: 1) a student, who was also the team lead; and 2) the NextGenEd US Project Manager [Appendix A \& B]. The team lead questionnaire was kept brief at the participant's request. The questions for both questionnaires were chosen after all other data had been collected, transcribed 
and coding had begun; therefore, they were informed by attention to initial discoveries in the data.

Interviews were conducted according to separate protocols for the design team [Appendix C \& D] and students [Appendix E]. Interviews were transcribed within one month of data collection. Transcripts of interviews were e-mailed to participants for their feedback. Participants acknowledged receipt of the transcripts, but no feedback was offered.

Each interview was audio recorded in digital format with a Livescribe Smartpen. The Smartpen synchronized the audio recordings with notes taken on dot paper and indexed this recorded audio with the handwritten text for easy retrieval. During the interviews, I used the bookmark feature in the notepad to highlight connections to previous data collection and emotional responses to the data. This allowed me to pinpoint places for data analysis triangulation and monitor potential bias in the interpretation of data. The synchronized recordings and PDF versions of the notes were added to a case study database on a secure content management website and shared with the dissertation committee chair and transcriptionists. The synchronized recordings and notes were referenced to check accuracy of transcriptions.

\section{Artifact Analysis}

Artifact analysis was conducted over a two-year period while the training program was still being conducted and after it had concluded. A list of artifacts appears above in Table 4. The following artifacts were referenced and discussed during the interview with the Primary Instructor: IAL i3Dv Training Curriculum, IAL Lecture 
Materials, and IAL Assignments. The following artifacts were referenced and discussed during the interview with the Program Manager: IAL Recommendations for i3Dv Training Candidates, IAL Assignments and IAL Feedback Notes. Each artifact was coded according to Young’s (2009) CBM ID-TABLET framework (Appendix G) and artifacts discussed in interviews were cross-coded with the interview. Artifact analysis served as a cross-referencing tool for triangulation of data found in observation and interviews and provided additional prompts for interview questions.

Observation

Observations were conducted on site at IAL and at the Indian headquarters of NextGenEd. Because training activities had concluded one year prior to the on-site visits for interviews, observations were limited to demonstrations and tours of facilities.

One observation at the US site was conducted in July 2010. The observation consisted of the primary instructor leading a demonstration of the CAVE technology and a tour of the IAL training facility. The CAVE technology demonstration included 1) CAVE applications originally presented to the NextGenEd President of US Operations, 2) CAVE applications used in the training program; and 3) CAVE applications produced by the students during the training program. The observation lasted approximately one hour and was audio recorded with the permission of the Primary Instructor. The observation recording was transcribed within one month of the observation.

One observation at the India site was conducted in September 2010. The observation consisted of four former students of the training program leading a demonstration of the CAVE technology and a tour of the facilities, including 1) CAVE 
applications produced by the students during the training program; 2) all of the CAVE applications produced by the students since returning to India; and 3) CAVE applications presented to potential investors in India since the conclusion of the training program. The observation lasted approximately one hour.

\section{Field Notes}

Within three hours of each observation, I made handwritten notes in a notepad of my overall impressions and noted specifics following the prompts from the Observation Protocol [Appendix F]. Within one week of the observation, I reviewed the handwritten observation protocol documents and typed the handwritten notes into the observation protocol document. At this time, I also expanded descriptions and noted interpretations and impressions as Observer Comments. Data collected in the field notes from observations were used to triangulate interview and artifact analysis data.

\section{Data Analysis}

Data analysis, coding practices and peer debriefing strategies of this case were designed to "increase confidence in the dependability of the judgments without the preoccupation with or the illusion of 'objective’ judgments” (Boyatzis, p. 150, 1998). The strategies are chosen to suit the purpose, theoretical framework and guiding questions of this research while bolstering trustworthiness through attention to bias, validity and reliability. 
Selection of the Code

The coding framework selected for data analysis was derived from the theoretical framework for the research, Young's (2009) CBM. As noted above, the pilot study revealed the need for a comprehensive approach to analyzing the divergent stakeholder perspectives, multiple components of the instructional design process and multidimensional nature of cultural interactions emerging in the preliminary findings. As described in Chapters 1 and 2, Young's CBM framework offers the most comprehensive characterization of culture available in the instructional design and technology literature. Richey (2009) declares that Young's model is supported by rock-solid research. Young’s method for developing the model is grounded in empirical observation and qualitative analysis of instructional design artifacts:

Traditionally, instructional design models have been based on learning theories. However, CBM evolved from an empirical study of instructional products designed by and for African Americans. A treasure of themes and concepts related to culture were found in these materials and were classified as cultural remnants. Cultural remnants are racial, ethnic, linguistic, political, social, historical, educational and economic artifacts embedded in discourses. The cultural remnants found in these instructional products were generalized to meet the design needs of cross-cultural audiences, and this translation resulted in CBM (Young, p.39, 2009).

The CBM framework developed by Young was deemed as an appropriate coding strategy for this research because the methodology is also qualitative and also includes artifacts of and interviews about products of instructional design. However, the use of this 
framework for coding of this research expands past its empirical basis in applying it to an instructional design process rather than a product and to a different cultural setting. It is Young's premise in providing this model, however, that the framework should be applicable in multiple instructional design settings.

Application of the code and Peer-Debriefing

Detailed attention to the data began with handwritten coding of the artifacts and field notes according to the a priori framework of Young's (2009) CBM model [Appendix G]. Artifacts and field notes were coded first because they represented smaller, more manageable amounts of data. This exercise allowed me to practice applying the codes according to the coding framework in a systematic manner and to examine where and how some codes overlapped with each other or did not translate appropriately to this case.

Next, I coded the primary instructor's interview because it contained the most information about the instructional design process from the perspective of the primary instructional designer. In the next two stages of coding, peer-debriefers were included to force articulation of qualifications and exclusions in applying the codes in order to promote consistency in judgment in code application across all of the data (Boyatzis, 1998). Two peer debriefers were chosen for the first exercise based on their advanced education in instructional design research, extensive instructional design experience and multi-cultural perspectives: both have over ten years of experience in instructional design; one earned her doctorate in instructional design and technology and completed a qualitative dissertation; one was in the advanced stages of doctoral work in an 
instructional technology and design program at the time of this research; both are originally from Asia, one from Taiwan and one from India.

For the peer-debriefing sessions, I prepared a codebook to promote "consistency of judgment” in applying the codes (Boyatzis, p. 146, 1998). See Codebook (Appendix H). For the first peer debriefing exercise, two peer debriefers were asked to study the codebook prior to arriving at a peer-debriefing session. At the session, I reviewed the codebook with the peer debriefers in detail and answered any questions. Next, the peer debriefers were asked to use the codebook to independently code a strategically selected portion of raw data. Using NVIVO 9, I had selected the most densely coded portion of the primary's instructor's interview that I had coded. This selection represented the application of the highest number of separate codes in the fewest number of pages. I presented this raw data to the peer-debriefers without the codes on it. When the peer debriefers completed the coding, we compared all of our results, and I made notes about convergence and divergence in our decisions. In this exercise, I was forced to articulate boundaries I had unconsciously placed around some of the codes during the coding process and check those boundaries against the peer-debriefer perspectives. This allowed me to more clearly define qualifications and exclusions in applying the codes (Boyatzis, 1998).

Next, I completed handwritten coding of all of the interview data. Then, I used another peer debriefing exercise to assist with consistency of judgment. As a code training exercise, I asked a third peer debriefer, an experienced instructional designer in the final stage of her Master's degree in instructional technology and design, to study the codebook and code the same portion of data as used in the prior session. She completed 
this exercise remotely and e-mailed me this coded portion with electronically inserted comments and questions about applying the code. I answered these comments and questions to clarify application of the code through e-mailed comments and a phone conversation. She then independently coded an additional portion of the primary instructor's interview that was three times larger than the original selection. I reviewed her coding with written comments in order to again be forced to articulate boundaries of the codes. This exercise prompted me to both further refine and be more aware of my coding parameters after one complete cycle of handwritten coding. Finally, I coded all of the interviews, artifacts and field notes again, but this time electronically using NVIVO 9.

Next, I used NVIVO 9 to sort all of the data according to the umbrella labels for the codes of ID-TABLET: Inquiry, Development, Team, Assessment, Brainstorming, Learners and Elements. During the coding process, it was determined that none of the codes for the umbrella label Training which were specific only to products were applicable to this case study. Under each umbrella label, data was sorted according to individual codes and coded references were organized under units of analysis. Units of analysis were identified as each of the interview participants, each of the individual artifacts and each of the observation sessions. These raw results files were added to a case study database on a secure content management website and shared with the dissertation committee chair and peer debriefers: “every case study project should strive to develop a formal, presentable database, so that in principle, other investigators can review the evidence directly and not be limited to written case study reports” (Yin, 2003, p. 102). The content management website informed me that the dissertation committee 
chair and peer debriefers all accessed the raw data directly during the data analysis process.

Next, I analyzed the results to organize the information in categories for presentation of the findings and examined where components of the design process, decisions of the design team, and perceptions of the stakeholders overlap with cultural Elements in Young's (2009) CBM model. Units of coding were cross-referenced between units of analysis for triangulation of data, and validated data was chosen to present in the findings. In order to visually present where cultural elements interacted with decision making and perceptions of components of the design process in this case, I then used NVIVO to build a matrix of overlapping coded references between 1) components of the design process: Inquiry, Development, Team, Assessment, Brainstorming, Learners; and 2) culture: Elements.

Finally, I developed a broad narrative of the case drawn from the data in order to offer a rich, thick description of the circumstances of the case. This case description offers holistic attention to the data by providing a clear context for presentation of the detailed findings (Yin, 2003).

\section{Ethical Considerations}

The rights of the participants in this study were considered at all times. Initial IRB approval for this research was granted in 2009, renewed in March 2010, and amended in August 2010 [Appendices I, J \& K]. The organizations involved in the training program provided letters of consent that are on file with the IRB protocol. All interviewed participants during the pilot study and data collection stages signed consent forms with 
the IRB's stamp of approval. The identity of IAL and NextGenEd and all participants has been kept confidential as promised in the consent forms.

My family member previously worked on the i3Dv project under study and is included as a participant. This potential conflict of interest was noted in the IRB application and did not interfere with approval for this research. My connection to the members of this study through my family member undoubtedly helped me gain entry and build rapport with the stakeholders in this study; however, at no time did my family member act as an intermediary for me in obtaining consent for this research or recruiting participants. At the time that data collection for this research began, my family member was no longer assigned to the i3Dv project.

\section{Researcher's Role and Bias}

My interest in the cultural aspects of cross-border collaborations started with my first job as an ESL instructor in 2001. In describing my experiences to friends or colleagues, I would talk about tendencies of students by national identity and use phrases like "they do...” or "they always ask...” As I continued to work with students from diverse backgrounds over the years, I realized the shortcomings of such blanket descriptions based on limited exposure. I also noted that I rarely reflected on the influence of my cultural background on my instructional tendencies. My experience reflects what I see as a central problem: how to acknowledge culture in learning environments as an important factor while avoiding reductive descriptions or characterizations of individuals and groups of people. I would characterize my personal 
interest in culture in the instructional design process as a desire to explore this central dilemma.

I also have a personal interest in exploring instructional technology solutions for US companies with personnel in India. I am from the Southeastern US and still live in this region with my family. My husband is a native of Bangalore, India and we have a second home there where we plan to spend half of our time in the years to come. We lived with my South Indian in-laws for four years in the US, and they keep a very traditional Hindu home (specifically Sri Vishnavism). My immersion in their culture domestically has offered me a unique opportunity to become part of the Indo-American scholarly exchange on instructional design and technology topics. However, this immersion may also have interfered with my objectivity in interpreting cross-cultural aspects of the data. For example, my familiarity with only one subculture of a diversely vast and multicultural country such as India may have introduced bias into my understanding of one of the national cultures identified in this study.

Also, I have worked in higher education institutions for fifteen years and in a nonprofit research institution setting for two years. I have only worked in a corporate environment for less than eight months. My imbalance of experience in the sectors under study may introduce bias into my interpretations of the organizational dynamics of this case. I may be more inclined to trust the intentions of those working in a non-profit organization such as the university consortium than the intentions of those working for profit.

However, in the last two years I have purposefully been challenging my own assumptions about those working from a profit-motive in my role as a research fellow at 
the India, China \& America Institute: “The purpose of the ICA Institute is to provide a sustainable, non-profit, non-governmental platform to identify and drive synergies among India, China and America in the areas of emerging markets, commercial growth and alignment of policies for the benefit of a vast number of people” (www.icainstitute.org). In this role, my job is to facilitate knowledge creation and dissemination about the type of endeavor that is the focus of this study- a market-driven collaboration between the US and India and public and private sectors to bring an educational product to the masses in India. Though not dogmatic about it, the pragmatic side of me is inclined to believe that this collaborative model is the type of middle ground needed for innovative approaches to social problems like education of the mass population in India. So, I may have a bias towards wanting the efforts of this project to be colored in a positive light.

Finally and significantly, since my family member previously worked on the project under study and is included as a participant, it is possible that I may not be objective and the participants being interviewed may not have been as candidly forthcoming when considering issues related to this family member's role in the project. In the early stages of this project, I was aware of my interest in researching it and instituted a "no talk zone” around this topic with my family member to help counter overexposure to the family member's perspectives on the program.

I negotiated my role as the researcher by maintaining awareness of the biases I bring to the research through the following methods: 1) noting emotional responses to data and 2) requesting special attention to potential bias from peer-debriefers. I also worked to both acknowledge and mediate those biases through participant and peer review of data analysis, triangulation of data sources and providing an explicit audit trail. 


\section{Trustworthiness}

In this study, I take the qualitative research perspective that it is possible for there to be different, equally valid accounts from different perspectives (Schram, 2006). By acknowledging my research position as a problematizer to reductionist views of IDT, I maintain trustworthiness and credibility by avoiding pat answers to problems of subjectivity and inconsistencies in data sources. Therefore, though this study includes measures intended to mediate potential threats to the validity and reliability of findings in this context, it does not claim that the findings lead to any universal truth about the process of IDT.

\section{Validity}

The criteria of validity comes out of the quantitative tradition in research and the view that knowledge gained in research should be valid- square with one, true reality. Since qualitative researchers seek instead to inform understanding, rather than claim truth, the criteria of validity is interpreted and addressed differently (Merriam, 1998). Such interpretations of validity and appropriate methods for addressing validity in qualitative educational research are still being debated in the field; however, certain norms have emerged and are addressed below for both internal validity, how accurately the findings reflect discoveries of the project, and external validity, possibilities for generalizing the findings to other situations. 
Internal Validity

Merriam (1998) suggests six techniques for improving internal validity in a qualitative study: 1) triangulation, 2) member checks, 3) long-term observation, 4) peer examination, 5) participatory or collaborative modes of research, and 6) clarification of researcher's biases. I will briefly describe each below and how each was addressed in the study.

1) Triangulation requires the use of multiple participants and multiple methods of data collection and sources of data (Merriam, 1998). This case study includes multiple participants with different roles in the training program and three methods of data collection: interviews, artifact analysis and observation. Units of coding were cross-referenced between units of analysis for triangulation of data, and only validated data was included in describing and presenting findings.

2) Member checking involves asking research participants to provide feedback on collected data. This process helps maintain transparency of process with participants and provides a check to the researcher's subjectivity. Each participant's transcript of his or her interview was e-mailed to him or her with a request for feedback including questions or concerns. Some, but not all, participants acknowledged receipt of the transcripts, but no feedback or objections were presented.

3) Long-term observation and/or gathering data over an extended period of time is seen to increase validity of findings because of prolonged exposure to data sources. I first became engaged with the research participants in late 2007, began 
preliminary data gathering through informal focus group discussions in 2008, obtained IRB approval and conducted pilot interviews in 2009 and continued data collection and analysis activities through late 2010.

4) Peer examination invites interdisciplinary peers of the researcher to examine collected data, analytical processes and analysis and provide feedback. Because this is a dissertation project, it is already set up to go through extensive analysis by interdisciplinary peers, the doctoral dissertation committee. In addition to this faculty examination, I included multiple peer debriefers in both the coding process and analysis of results. A detailed description of peer debriefers' involvement is provided in the Application of Coding section above. After completing the initial analysis of results, I created a detailed outline of the findings, including the cultural interaction matrices described above in the Data Analysis section. I presented this outline as well as access to all of the raw results in a case study database on a secure content management website and asked two peer debriefers to review these materials and provide feedback. The content management website informed me that both peer debriefers accessed the raw data directly during this review process. The peer debriefers offered suggestions for refining my analysis with additional insight from IDT disciplinary concepts and presenting findings according to qualitative standards.

5) Participatory or collaborative modes of research include participant input throughout the research process, not just as sources of data. The purposive and network sampling procedure described above, as well as member checking, involved participants throughout the process. 
6) Clarification of researcher's biases acknowledges the researcher's perspective as shaping the design, methods and analysis of the research. I negotiated my role as the researcher by describing relevant biases I brought to this research and maintained awareness of such by acknowledging and mediating those biases through member checking, peer examination, triangulation of data sources and participatory modes of research.

\section{External Validity}

Some qualitative research scholars dismiss the idea of making claims of external validity or generalizability in qualitative research, particularly in the case of a single case study (Merriam, 1998). However, comparable alternatives have been suggested, and my beliefs about knowledge gained in case study are compatible with the idea of user or reader generalizibility (Walker, 1984 cited in Merriam, 1998), also called case-to-case transfer (Firestone, 1993 cited in Merriam, 1998), where the researcher leaves it up to the readers of the study to decide what from the study provides useful guidance for their own needs. This places a burden on the researcher to offer rich, thick description and categorizations to aid in cross-referencing.

This study offers a full narrative description, direct excerpts from the data and clear explanations of the setting and how it might be categorized to address concerns of external validity. The findings in this study represent a broad range of design activities and stakeholder perceptions that overlap with findings from the literature in ways that suggest some may be generalizable. Decisions of the design team and perceptions of the 
stakeholders in this study are presented in context in the findings so readers can make independent judgments about the applicability of findings to their needs.

\section{Reliability}

Reliability is another research criteria born in the quantitative, experimental tradition and addresses whether or not the results of the study can be replicated exactly. In qualitative research, Lincoln and Guba (1985) suggest focusing on dependability or consistency of results rather than reliability, recommending methods similar to those used for enhancing internal validity: 1) explanation of the investigator's position (addressed above); 2) triangulation (addressed above); and 3) audit trail.

\section{Audit Trail}

Yin (2003) recommends maintaining a chain of evidence so that external observers can trace all steps, decisions and rationales for decision making in the research process. To ensure that peer reviewers in this research had access to all raw data, I maintained a web accessible case study database throughout the process which includes detailed explanations of procedures, protocols, methods for data analysis, rationales for decision making in this study, and anonymous versions of the raw results sorted according to codes. Yin (2003) suggests keeping such a case study database as part of the audit trail and claims that it "increases markedly the reliability of the entire case study" (p. 102). I ensured the safety of the data in this database by making transcribed notes and recordings anonymous and using a secure, password, protected content management website. 


\section{$\underline{\text { Conclusion }}$}

This research was designed to move beyond reductive cultural characterizations of learners and towards understanding cultural dynamics in the instructional design process by applying and exploring the generative capabilities of a new model in the field that acknowledges culture as a complex construct. By adhering to rigorous qualitative methods, this research design provided sufficient data and an appropriate analytical strategy to offer trustworthy answers to the guiding questions of the study. Findings gleaned from this research are presented in the next chapter. 


\title{
CHAPTER 4: CASE DESCRIPTION
}

\author{
$\underline{\text { Introduction }}$
}

This chapter presents a narrative description of the case gleaned from the data to provide a holistic picture in which to contextualize the detailed findings.

\section{Case Description}

In 2007, an executive of NextGenEd, an education software company based in Mumbai, India with United States of America (US) headquarters in Atlanta, Georgia visited the Institute for Advanced Learning (IAL). IAL is a consortium of two state universities, one community college and a NASA space center location in the US. At IAL, the NextGenEd executive attended a demonstration of stereoscopic, immersive 3D visualization (i3Dv) technology, a Cave Automatic Virtual Environment (CAVE). This technology allows users to become fully immersed in an interactive 3D virtual environment for the purposes of education, research, or entertainment. Enthusiastic about the possibilities for using this technology in education and aware that this technology was not available anywhere in India, the executive pursued collaboration with IAL's Director and team of i3Dv programmers to train up to fifty employees to produce educational applications for i3Dv environments. IAL did not have any major projects at the time and readily pursued the funding and opportunity for the training collaboration. The planning process moved rather quickly and within a couple of months, a memorandum of agreement had been drawn up between NextGenEd and IAL to offer a training program for NextGenEd employees to learn how to create i3Dv applications for CAVE environments. The Director of IAL traveled to India for a press event to sign an official two year training agreement between NextGenEd and IAL and to promote the concept to 
potential clients for NextGenEd. Tables 2 and 4 in Chapter 3 present details of the training program and i3Dv project. Figure 2 provides a timeline of major events during the research study.

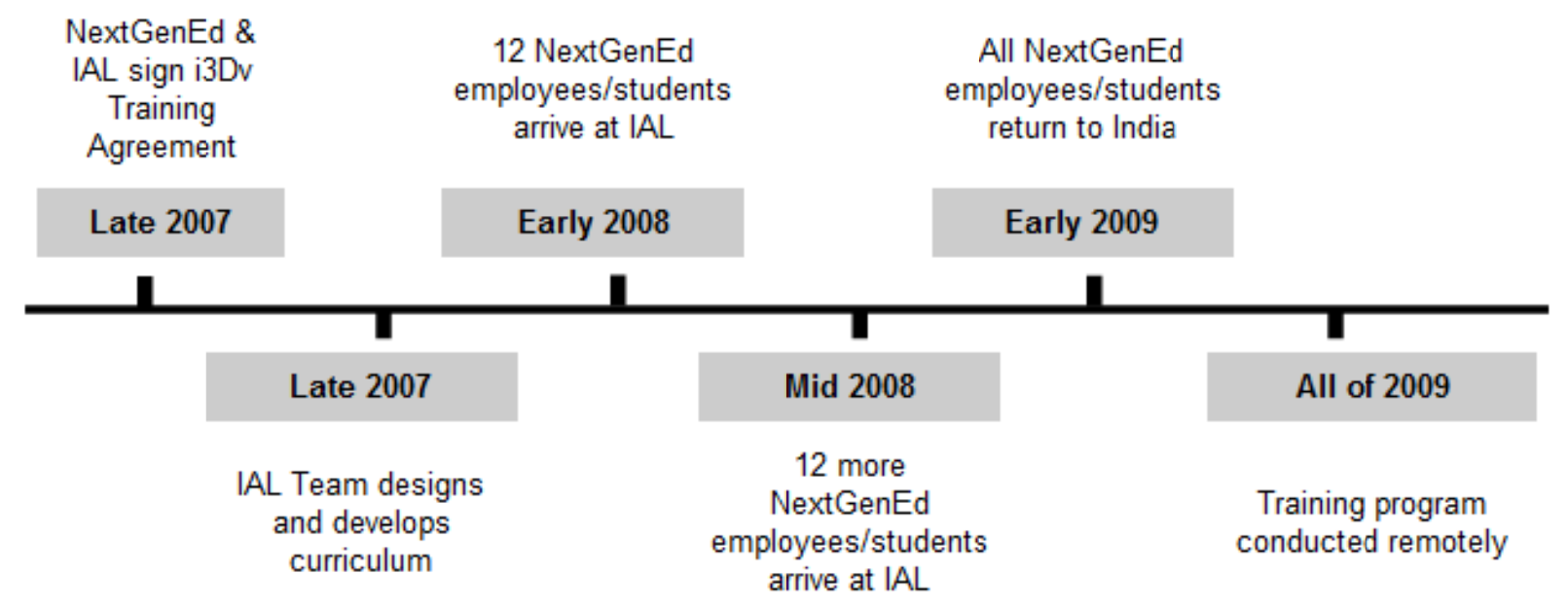

Figure 2 Timeline of Case Events

The Program Manager at IAL had formerly trained the staff of i3Dv programmers at IAL and recruited a prior graduate to come back and serve as the instructor of the program. The IAL team worked together to develop a curriculum for the training program, based on the IAL team's subject-matter-expertise and past experience and the goals of NextGenEd. The written curriculum developed by the IAL team and initially suggested to NextGenEd offered a twelve-month program beginning with nine months of training in OpenGL and CAVE programming and ending with three months of working on real-time, real world projects.

NextGenEd recruited 12 new hires to send to IAL in the United States for this training program. NextGenEd worked closely with the IAL staff to determine the 
appropriate qualifications for the new hires and included IAL staff on conference call interviews with many of the candidates. The majority of the recruits had undergraduate computer science backgrounds; however, there were some with graphics, engineering and biotechnology backgrounds. Most of the new hires were honor graduates from Indian universities. Some students graduated from the most prestigious universities in India, the India Institutes of Technology. These institutions have earned a global reputation for excellence and are known to accept applicants from only the top $1 \%$ of performers on a competitive national standardized exam. Several of the new hires were also recruited from jobs in top software companies in India.

In January of 2008, the first group of new hires from NextGenEd, to now be referred to as students, arrived in the US. They participated in a brief orientation on US customs at the Atlanta headquarters before being escorted by NextGenEd's Senior Project Manager to their residence in a city nearby IAL at a NASA space center location. The students were housed in shared apartments, given professional driving lessons and provided with two vans for transportation. Two members of the student group had been appointed by NextGenEd in India as team leads. These team leads represented the highest level of NextGenEd supervision on location at IAL for the duration of the training program. The NextGenEd US management, President of US Operations and Senior Project Manager, visited on at least three separate occasions to monitor progress, offer logistical support to students and remind students of their roles and responsibilities as NextGenEd employees.

After receiving the initial written curriculum from IAL, NextGenEd management had requested that the curriculum timeline be expedited. The Primary Instructor at IAL 
began the course schedule at an expedited pace and designed course materials accordingly. After approximately two weeks, the Primary Instructor received feedback from the students that they felt overwhelmed and would like for her to start from the beginning again and to slow down the pace. The IAL Director communicated with NextGenEd and it was agreed that the original curriculum plan of twelve months would be appropriate. The Primary Instructor revised the course materials, reviewed all of the beginning material with the class and slowed the pace of the instruction going forward.

Also during this early stage of the training program, the IAL Director hired a Secondary Instructor with NextGenEd funding. This Secondary Instructor, a computer science professor from a nearby university, was trained on OpenGL and CAVE technology along with the first group of students in order to prepare to be the instructor for a second group which was expected to arrive before the end of the training for the first group. This professor was from India and interested in i3Dv technology. He attended classes along with the first group of students and also offered office hours for students.

The Primary Instructor conducted lecture style classes using PowerPoint slides, a WACOM board for drawing, and a desktop computer to run application demonstrations. Students attended classes three days a week and worked on weekly assignments at the IAL location two days a week. Soon after arriving, students also requested and received from NextGenEd, high-end laptops that were capable of handling complex graphics programming, so they could work on assignments at home.

Each week, students presented their assignments in open feedback sessions in the classroom. The Primary Instructor, Program Manager and the Supporting Instructor, a i3Dv programmer on the IAL staff, visited each student at their workstation and provided 
feedback on the week’s assignment or individual project. Students were asked to prepare a written report for these feedback sessions and to stand and verbally present the report. The Program Manager and Primary Instructor kept a record of pass or fail for assignments and projects; the criteria to pass were a written report and an application that executed successfully. The written reports were also used as a jumping off point to discuss issues with the assignments and to provide back up for communication challenges. The Supporting Instructor offered specific programming language and troubleshooting advice during these sessions.

After these initial OpenGL training assignments, students began to work on realtime, real world projects in groups. These projects were chosen by the Primary Instructor, the Program Manager and the Supporting Instructor. These projects assigned teams of students to build: structural engineering applications; earthquake applications; a dental dataset model viewer; a 3D stereo movie; file loaders; a virtual racquetball physics engine; and a non-traditional tracker interface using a game controller. Two of these projects were with universities in India and targeted to be marketable products in collaboration with potential clients in India; the Primary Instructor traveled to India to meet with professors at these universities about their needs for i3Dv applications. These clients were then put in touch directly with the student groups assigned to those projects and IAL staff served as support for the student groups.

Within the first few months of training, one of the team leads decided to leave the program for personal reasons. The remaining team lead served as a liaison between the IAL staff and students and the students and management in India for the remainder of the training program. 
Approximately six months after the training program began, a second group of 12 students arrived. This group of students had also been recruited as new hires from NextGenEd but without any further input from the IAL staff about qualifications and without IAL staff participating in the interview process. Most of these students were honor graduates from Indian universities and had engineering backgrounds.

When the second group of students arrived, the Secondary Instructor acted as their primary lecturer for classroom activities. There was no team lead appointed from this second group as a representative for this group; after some time, it became clear to the second group that the team lead for the first group was also to serve as their team lead. Within the first several weeks of their training program, members of the second group communicated directly with the NextGenEd Chief Operations Officer (COO) in India about problems they were having with the program. Some complained that they were unsatisfied with the Secondary Instructor because he was perceived as inexperienced since he trained with the first group. Others complained that the training program overall was not living up to their expectations.

The IAL staff began having weekly conference calls with the COO to report on student progress and the program. NextGenEd began to urgently request that the program be expedited and the second group be accelerated into CAVE programming. IAL staff reported that some students were not attending classes, were making unauthorized trips to local tourist spots with the company's van and were turning in code taken from the internet for their assignments. The COO came to the US to visit the site along with the NextGenEd US Senior Project Manager soon after the second group arrived. The COO 
interviewed all of the students individually, asking for their feedback on the program as well as reminding them of their role and responsibilities as employees of NextGenEd.

Two months after this visit and ten months after the initial training program had begun, NextGenEd management held a conference call with all of the students and announced that they would all be brought back to India by the end of the year. The IAL staff was asked to prepare the students for their return by quickly finishing any necessary on-site training and modifying materials to finish the training program remotely. At this stage, the first group of students had completed all of the OpenGL and CAVE training and had begun to work on real-time, real world group projects. The second group of students training was cut short by six months. They were just completing OpenGL training and were rushed through some initial CAVE training before returning to India.

Before the students returned to India, NextGenEd purchased a CAVE unit from a US company and installed it at their headquarters in India. It was the first and still only CAVE unit in India, an updated model that significantly exceeded the resolution and display capabilities of the ten year old IAL model in the US.

After the students arrived back in India, the first group continued to work on group projects in collaboration with Indian universities and met with IAL staff through web meeting and videoconferencing tools. The second group of students completed their remaining assignments remotely and also presented their work to IAL staff through web meeting and videoconferencing tools. After both groups had completed the training, the IAL staff sent certificates of completion to the NextGenEd management to distribute to the students. Communications between IAL and NextGenEd slowed significantly and talks of continuing the program halted. 
Within six months after the training was completed, many of the students in the training program left NextGenEd. The remaining employees who participated in the training program have continued to work on CAVE projects and completed the following i3Dv simulations: driving a racecar; riding a rollercoaster, walking in a revolving corridor, interacting in a virtual biology lab, standing in a hallway during an earthquake and touring the Taj Mahal. They also regularly demonstrate the applications in the CAVE environment to potential clients. To date, no clients have entered into revenue generating agreements with NextGenEd to use these or produce new CAVE related applications or to purchase CAVE equipment. At the time of this writing, upper management of NextGenEd in the US has just requested that these employees be moved onto non-CAVE related projects.

\section{$\underline{\text { Conclusion }}$}

This chapter presented a narrative description of the case gleaned from the data to provide a holistic picture in which to contextualize the detailed and aggregate findings. In the next chapter, the findings are presented according to the applicable categories of the ID-TABLET framework, including direct excerpts from the data and a visual diagram of cultural interactions with each component. 


\section{CHAPTER 5: DETAILED FINDINGS}

\section{$\underline{\text { Introduction }}$}

In this chapter, the findings of this research are organized according to the IDTABLET components of Young's CBM framework. The organization of findings according to the ID-TABLET framework (Table 6) is consistent with the data collection and analysis strategies of this study and serves the purpose of illuminating cultural interactions in the process of instructional design to answer the guiding question and subquestions:

How does culture interact with the instructional design process, as defined by Young's Culture-Based Model (CBM) framework, in this case of a cross-sector, cross-border training program?

a) What design team decisions, stakeholder perceptions, and program outcomes relate to ID-TABLET components of the CBM framework? b) With which CBM Elements of culture do design team decisions, stakeholder perceptions and program outcomes interact?

Each section begins with a summary statement of results to indicate the thematic findings of the section. Then the ID-TABLET component related to each thematic finding is explained according to Young's CBM framework and contextualized to the findings of this case. Next, findings related to the component are presented with supporting excerpts from the data. In applying the CBM framework as a lens for research on this case, I present findings in the data that triangulate to reveal: 
1. where decisions were made and stakeholder perceptions were formed that relate to each ID-TABLET component;

2. where the connection between these decisions and program outcomes are related;

3. what stakeholder perceptions were expressed about these decisions and program outcomes; and

4. where these decisions, stakeholder perceptions and program outcomes interact with or are related to cultural Elements.

Because the findings of this research are multi-dimensional, visual diagrams are used to show overlapping coded references between: 1) each component of the design process: Inquiry, Development, Team, Assessment, Brainstorming, Learners; and 2) culture: Elements. Since the identification of CBM cultural Elements in this data is relevant to all of the findings, preliminary examples of data about each of the twenty-five cultural Elements is presented first, followed by the remainder of the ID-TABLET components found in the data.

\section{Cultural constructs of the CBM framework found to be evident in the data}

Although the ID-TABLET acronym places Elements close to the end, this acronym is not intended to reflect a preferred order of events in the design process. All components of the ID-TABLET are considered to "operate simultaneously; they maintain an interactive relation” (Young, p. 40, 2009). Therefore, it does interfere with the clarity of presentation to begin the presentation of results with Elements. Since the focus of this research is the function of culture in the instructional design process, all of the findings 
presented for the remainder of the ID-TABLET components will be related to Elements in order to reveal cultural interactions in the instructional design process.

The Elements component of ID-TABLET in the CBM framework provides a potentially comprehensive picture of what makes up all culture: both tangible and intangible (Young, 2009). Young (2009) pulls from cultural anthropology, cultural psychology and science to propose this compilation of elements which might be shared by a group. The purpose of Elements in the CBM framework for instructional design is to guide designers in exploring cultural factors when investigating their target audience. She provides a list of guiding questions that help define each element at a general level of culture and a list of related target audience questions to prompt consideration of the target audience's view when making design decisions.

In this research, the Elements are used as taxonomy to classify aspects of cultural interactions in the design process. Young's Elements of culture are applied to multiple stakeholders in this case study rather than only the target audience to reveal cultural dynamics in the decisions and perceptions of all stakeholders. The cultures distinguished in this study are categorized at two levels: national and organizational. The national cultures of the participants were determined by nation of origin and nation of current residence at the time of data gathering; some participants represent multiple cultures. National cultures represented by participants in this study include: India, US and a country in Southeast Asia. Only one participant in the study was originally from a country in Southeast Asia and now resides in the US. The nations where training program activities took place and observations were conducted include India and the US only. The organizational culture represents where training activities and observations occurred and 
where participants were employed at the time of the training program: IAL and NextGenEd.

To clarify how each Element of culture was coded in the findings, I define each Element of culture in the CBM framework, provide a description of how each Element was interpreted in the context of the case, and offer one example from the data in Appendix L.

\section{Cultural interactions with technology and content}

In the Culture-Based Model (CBM) framework, the Inquiry component provides detailed questions for examining technology and content decisions (Young, 2009). This component provides a list of questions for all stages of the design process to "monitor development, automate the internal flow of the process and function as an internal sensor” (Young, p. 41, 2009). Under the component of Inquiry, questions to guide the design are categorized in six design factors: genre, framing, omission, backgrounding, foregrounding and visual representations. Table 7 shows the purpose of each design factor. In this research, these design factors are explored as factors in a training program rather than a product, so some questions do not apply or are slightly modified for this context. The findings below reflect where decisions were made that address or fail to address the questions of the Inquiry component of CBM; where the connection between these decisions and program outcomes are related; what stakeholder perceptions were expressed about these decisions and program outcomes; and where these decisions, 
stakeholder perceptions and program outcomes interact with or are related to cultural Elements.

\section{Table 7}

Inquiry Design Factors of CBM

\section{Factor Description}

\begin{tabular}{ll}
\hline Genre & Aids in the selection of ICTs \\
Framing & Assists in maintaining the target audience's perspective \\
Omission & Helps in assessing a design \\
Backgrounding & Helps in providing a balanced design \\
Foregrounding & Helps in providing an objective design \\
Visual Representations & Assists in conveying meaning
\end{tabular}

Quoted from Young (2009) p. 56

Genre: Cultural interaction with technology choices

Summary Result: Of the twenty-five elements of culture in the CBM model, eleven elements of culture were found to interact with design decisions, stakeholder perceptions and project outcomes related to software, hardware, faceto-face, and distance technology choices: cultural capital, cultural classification, cultural communications, cultural relations, cultural resources, cultural beliefs and values, cultural experiences, cultural ideas, cultural ways, cultural futures, and cultural infinities. 
The design factor Genre in the CBM framework focuses on the information and communication technologies (ICTs) used in an instructional technology product. In this study, it refers to the ICTs used for all aspects of the training program. The following questions are the focus of the design factor: Genre.

- What ICTs are being used and why?

- Which ICTs are more effective given the content?

- Is the project affordable to the target audience, given the ICTs used?

- How have ICTs influenced the design of the product?

In this section, I describe the circumstances of the case as related to the above questions. In this training program, courses were conducted in a face-to-face environment and remotely.

Face-to-face

In the face-to-face environment, the ICTs used to conduct classes at IAL included: 1) visualization equipment: the CAVE; 2) hardware: a Wacom digital tablet, state-of-the-art desktops and laptops to run example applications; and 3) software: PowerPoint.

\section{CAVE}

The CAVE equipment was the primary purpose of the program and represents the centerpiece of the IAL facility. The CAVE technology is a cultural resource, available in the US and not available in India, which significantly influenced the design of the program. The CAVE technology was demonstrated to the students as soon as they arrived, but they did not directly work on CAVE applications until after a few months of training. During the observation at IAL, the Primary Instructor described the CAVE: 
Primary Instructor: We have four screens. Each screen is driven by a single computer... You have one very large, very powerful projector behind the screen. It shoots out about 90 images per second. Half of those images are for left eyes and the other half is for right eyes and the way the brain works is, you have two eyes. If you close one of your eyes and open the other real quickly, you can see slightly different...and in order to see 3D or stereo you need the shadow glasses... the shadow glasses will close the right eye and vice versa for the right images. It does it so quickly, 90 images per second, that your brain cannot really see that this is fake, this is not real world, this is a series of still images being displayed on the screen. It's so quick it just fools your brain.

The CAVE at IAL was about eight years old at the time of the training program and already beginning to be outdated in resolution and memory capabilities. In demonstrating a data visualization application of polygons, the Primary Instructor also described the limitations of the CAVE at IAL:

Primary Instructor: This is something that is kind of bumpy and it doesn't make much sense because of the resolution. So the resolution would determine the distance or how-good you can feel connected to the data. So, that all depends on the data and the resolution of the data. We can do it higher but the computer would take so many resources to crank this up and you would not have enough resources to have for your navigation so you can see pretty picture but you can't move around... Computers need to use memory. It can’t read directly from the hard drive and show the content on the screen. Computers need to use memory. It 
can't read directly from the hard drive and show the content on the screen. The memory is-well this CAVE technology is only $764 \mathrm{mb}$, it's not even a gig. In each interview students acknowledged that the CAVE technology was a cultural resource only available in the US at the start of the training program

Student 8: The first time I saw the technology in IAL I was blown away...During that time, the technology wasn't ready in India.

However, the students also came to be aware of the limitations of the CAVE technology at IAL:

Student 10: Facilities in terms of the CAVE there was very old.

Student 2: At first we were very awestruck and all that but after one month or two month we came to know that this is not the latest technology exactly.

This finding highlights the importance of the CAVE as a cultural resource in the students' perceptions on ICTs in the program.

Even though the IAL CAVE technology was older, some felt the CAVE was the only justification for traveling to the US for the training program and should have been the only focus of the program:

Student 2: The CAVE technology and the hardware part we couldn't have gotten in India. So the best solution was to have instead of a year-long training we could have gone there only for the CAVE training.

In the next excerpt, Student 3 highlights a belief emphasized by a few students: that training at the university with the prestige of discovering the CAVE technology would have provided more up-to-date technology and better training: 
Student 3: ...the place where CAVE was discovered. I think it's in Chicago. Yeah, Illinois. Yeah, for example if we are spending money we will go there and have better access to knowledge and technology.

Another of Student 3's comments on the technology of the program shows how the connection between cultural beliefs about prestige interacted with some students' expectations for the level of technology that would be available at IAL:

Student 3: In India, the NASA is a big thing for us. So we expected high level technology.

These findings reveal a connection between cultural resources, cultural beliefs, cultural ideas and cultural classification and the students' perception of the CAVE technology at IAL.

Hardware

The Primary Instructor combined the use of PowerPoint, example programs and a Wacom pad in each lecture. Here she describes the Wacom pad:

Primary Instructor: The Wacom Pad... is like a whiteboard you would use to write down material physically. The WACOM Board is electronic. Whatever I wrote on the board, it will be shown on the screen. Since explaining how the computer works, explaining the math, you just have to write down as you go.

She chose the Wacom pad in order to present the dynamic nature of the content:

Primary Instructor: It involves seeing a moving objects and in order to explain them how this work, everything has to be drawn slowly, frame by frame, with simple objects, and use this device...It is called Wacom, W-A-C-O-M. It's a high resolution mouse pad and it come with a mouse and a pen so anything I write on 
here, it will appear so fine like a writing on here, so this is what they see on the screen...I would draw it live, explaining to them...Power Point is static. You explain the concept statically. But the concept is dynamic.

A state-of-the-art desktop was available in the instructor's office, in the front of classroom to show examples when explaining the students' assignments and at each student's workstation in the classroom:

Primary Instructor: At the end of ... each session, I would have sample program, so they could see, oh, when the program runs, this is the result that they get.

All of the equipment was funded by NextGenEd and returned to NextGenEd at the end of the training program. Decisions about what PC equipment would be used were made by the Program Manager during the first stages of program planning. His decisions were primarily based on providing state-of-the-art equipment for the advanced graphics content; he expressed attention to affordability to the client, NextGenEd, only in acknowledging that the cost was expensive:

Program Manager: It's...what's the state of the art...computer cards that support the Open GL and we have 32 bit operating systems so you could have about 3.2 gigs of memory so what you needed, the maximum amount of memory. You need enough disk space, whatever was the best at the time...Because, um, when you buy a computer you should buy the best that you can because it's going to be outdated in two to three years... So we try to get them on the cutting edge... basically I went in and just here's... the computers you need to buy and this is the cost...so you provide them and you're going to spend thousands and thousands and thousands of dollars. 
In this case, the wealth of NextGenEd, cultural capital, made the best equipment available for the program. After the program began, students requested laptops to work at home. They expressed their need for the laptops to the IAL team. The Program Manager told them to ask NextGenEd directly:

Program Manager: We needed desktops here because you need to do the highend 3D graphics but they wanted to work when they were at home. So the students requested to NextGenEd to get the laptops. I was like you'll have to call NextGenEd, you're going to need to write it up professionally and send the request in. Tell them-and explain why you need this-and that's going to work. In this circumstance, the Program Manager suggests direct contact between the students and their employer, believing it is more suited for success for their organizational cultural communications and cultural ways. NextGenEd provided high-end laptops for the students to work on at home: one per apartment, but not for each student. ICT decisions also influenced the intensity of the program by offering high-end technology to both the instructor and the students and both in the classroom and at home:

Primary Instructor: They came in at 9:00, and they leave at 4:30, so they have time to write their program, do their assignment and study at IAL. Also, they had the laptops, which they can do some programming at work, so they have to be constantly learning basically both days and nights.

Software

The Primary Instructor chose PowerPoint because it was a norm, part of her past cultural experience as a student and teacher and conveniently available on her machine: 
Primary Instructor: It was something that everybody does and I taught classes before and I used Power Point... Microsoft program is something we have in our computer which is a convenient thing.

Her decision is influenced by her own cultural experience, and some students' perceptions of this

choice reveal a similar influence:

Student 8: The way of teaching we had [in India]... it was, like, kind of same... PowerPoint presentations, classroom lectures When Student 4 was asked his opinion of the use of PowerPoint slides for the lectures, he stated:

Student 4: Yes, that's the way we generally expect.

These findings show similar cultural experiences between the instructor and the students that created similar cultural ideas about what ITCs were appropriate for the training program.

The use of PowerPoint slides also made it possible for the students to access the materials easily after they returned to India. Several students acknowledged that they still referred to the slides in their development process while creating CAVE applications in India. Distance

When both groups of students returned to India, the IAL team adapted their program to offer it remotely. The IAL team continued the training for both groups through weekly meetings: 1) the first group continued to work on group projects and presented their products to IAL team through web meeting and videoconferencing tools; 2) the second 
group of students completed some assignments remotely and also presented their work to IAL team through web meeting and videoconferencing tools.

Director: They're [the students are] coming back and then so our next question was well, do you want us to finish the training? And the answer was well yes. How do we do it? ... So that's when we set out to find different ways to go with the training. And we came up you know with the virtual approach where through computers, computer cameras and the internet we are able to create a virtual classroom and now the only challenge we had was overcoming the time difference...So we met with the students on a weekly basis on Monday morning our time which translated to Monday evening in India and it worked fine. We were able to see every student - I mean literally, see every student and look at their work on their computer as we're sitting in NASA Space Center and they're sitting in Mumbai. So that the internet technology enabled us to complete this very hard part of the training, again, the applications part of the training but doing it $11 \frac{1 / 2}{2}$ time zones away.

This sudden change in the program was related to cultural capital, the client organization's ability to fund the training program, and cultural resources, NextGenEd had now purchased and installed a CAVE in India. The remote locations also introduce a need to accommodate the cultural infinities of time and space in the design process. The challenges identified by the IAL team, the students and the client once the training program became a distance learning program were related to technology, time differences, and communications: 
Senior Project Manager: Project management challenges related to the relocation of the students were experienced when the second batch was moved back to India prior to the completion of the program. The challenges were similar to those experienced when the students were at NASA Space Center location but were amplified due to the fact that communications between the IAL team and the students were significantly restricted due to technology constraints such as video conferencing and in particular, the time difference.

Technological problems required some work-arounds. They began the meetings using the web meeting tool, gotomeeting, to share screens, but soon found that it did not work well for viewing the high resolution work for 3D visualization applications. Then the students were asked to e-mail their assignments to the Primary Instructor so she could review them before the meeting and the IAL team could provide feedback during the meeting. They also switched to videoconferencing equipment to conduct the meetings. However, glitches with technology continued to make providing feedback more difficult than it was in the face-to-face environment.

I3Dv programmer: We had some issues with the computer being too slow and they would have to use just one computer over there and sort of switch off as each one showed their assignment and the computer was kind of clunky and it would take a while to load up. While here everybody had their own computer, they could have it preloaded, we could walk around, get moving, get going, sort of traverse the crowd, so it just took a lot longer to do it through the distance learning type mechanism. 
Primary Instructor: The problem with video conference is the resolution is so small, I can't really see the detail of the program. So, what I asked them was to finish the assignment ahead of time, send all the programs to me so that I can rerun on my machine and see the high-risk solution as we talk on the conference phone. The problem with that was when they're trying to demonstrate their work, since this is an interactive program, I can't duplicate what they do while try to listen to them and looking at that program on the screen; it was difficult.

These challenges and the decisions made to overcome the challenges are also related to cultural capital and cultural resources; the tools needed to overcome the problems were bought by NextGenEd and available in both countries.

The time difference, as described in the Elements section on cultural infinities, was a challenge in the distance learning that was noted by several participants, and this challenge was also associated with communication problems:

Student 8: Because of the time difference, there are communication differences. And the communication gap on the feedback, you preferred it when you were all together.

The difference in communication abilities between face-to-face and distance learning was mentioned by IAL team and students. The Program Manager felt it interfered with his ability to use his presence to motivate performance in students:

Program Manager: Because, well, if they're here and I tell you I need something on Friday, they can look in my eyes and they know, I'm going to see him again on Friday whereas here, if I say I need it on Friday and I don't get it, and, you know, well email's down, the Internet's not working. It became a way to get around you. 
In this excerpt, the Program Manager's attitude about the distance learning environment is related to his sense of what cultural relations should be between instructors and students that will also be noted in later sections. The students also expressed a preference for face-to-face presence in feedback situations:

Student 4: It's always better when you have a person who is inspecting right next to you. Far better experience like physically present and he's able to get immediately what's happening.

For the client, the affordability of the training program was much more manageable using technology for distance learning. Even the IAL Director acknowledged the distance learning option was more affordable.

Director: We can do it virtually and it's a heck of a lot cheaper.

For the findings under the Genre category of the Inquiry component, the following cultural elements are found to interact with the design process and the students' perceptions of the training program: cultural capital, cultural classification, cultural communications, cultural relations, cultural resources, cultural beliefs and values, cultural experiences, cultural ideas, cultural ways, cultural futures and cultural infinities.

\section{Framing: Cultural Interaction with content choices and presentation}

Summary Result: Of the twenty-five elements of culture in the CBM model, eighteen elements of culture were found to interact with content design decisions, stakeholder perceptions and project outcomes: cultural classification, cultural communications, cultural demographics, cultural environment, cultural history, cultural knowledge, cultural language, cultural relations, cultural resources, 
cultural beliefs and values, cultural experiences, cultural ideas, cultural identity, cultural interests, cultural misconceptions, cultural ways, cultural futures, and cultural infinities.

The design factor Framing in the CBM framework focuses on "how content is presented or the point of view" (Young, 2009). Young includes this category in the Inquiry component to help designers maintain awareness of bias in presenting information. In this study, aspects of framing refer to decisions of the design team and perceptions of the stakeholders related to content and how it is presented. With the additional focus on the interactions of cultural elements with framing, how biases function in content decisions may also be evident in these findings. The following questions are the focus of the design factor: Framing.

- Who is the target audience?

- How is the content presented to the target audience?

- What is the content presented?

- Is the content appropriate for the target audience and why?

- Where, within the products design, is the content most appropriate?

- Why is this content appropriate?

In this section, I describe the circumstances of the case as related to the above questions about Framing. The IAL team referred to their target audience in five consistent ways: programmers or engineers, recent college graduates, Indians, employees and students. In this section of findings about Framing decisions, these labels are used interchangeably, and represent who the IAL team understood their target audience to be. 
The primary decisions about how the content was presented can be categorized as: pace and sequence, materials and assignments. The question of pacing played an integral role in the design of the training program and the stakeholders' perceptions of the program. From the beginning of the training program discussions between IAL and NextGenEd, there was a difference in the two organizations' requests for how long the training program would last. IAL believed it would take a full year for each group of students; NextGenEd only wanted it to take six months per group of students.

Director: We were always being asked when's the training-how long is it going to take? We got to get this done fast, it can't take a year... We were like if you want a quality student, a quality graduate, it's going to take a year. So, that's it, that's what we're going to do and finally NextGenEd Atlanta and India relented.

The IAL team's belief that the training would take longer was based on the cultural history of the IAL organization's past training activities and cultural experience of the IAL team, expressed by all members of the IAL team.

Director: [The Program Manager] trained his team and we envisioned using the same process to train the folks from India that would be coming at some time in the future.

The team that was trained by the Program Manager in this excerpt included both the Primary Instructor and the i3Dv programmer. NextGenEd's desire to speed up the training was related to cultural capital of the organization and cultural futures. The timeline in the business plan shows an intention to launch educational i3Dv products into the Indian market within one year of the beginning of the training program. 
In considering the pacing needs of the client and the students, the Primary Instructor eventually decided to prioritize the needs of the students:

Primary Instructor: Even though I could do what NextGenEd originally asked, but if the students could not take it then we're not gonna be going anywhere, and everybody will be in trouble, so I just have to set the NextGenEd's goal at the beginning aside and then concentrate onto the student to bring them to the point where I can really speed up the teaching because when they came, they knew nothing about computer graphics, it was like teaching someone to talk... NextGenEd want us to teach them to do what we do, but it took years to do what we do... So, the only way to do it was to speed teaching them, and I did that for one week, and they were just falling apart. So, my focus was on the student ability to learn first before teaching them the ability to do the work... NextGenEd want us to teach them to do the work and that how I understood, but I could not teach them to do the work until they understand what the work was and then feed that back to NextGenEd, have them to understand that you can't speed them up in the learning when they don't know anything about it.

Computer is something that very difficult to digest, and you need time to digest. And we tried to tell NextGenEd that for them to allow the time to expand a little bit if they want a student to really do what we do over here at IAL. And they understood, so they were lenient with us, too. So, we have to talk to NextGen Ed weekly, feeding them input how the students were doing.

The Primary Instructor slowed the pace of the class by reducing class lectures from five days a week to three. The students worked at IAL on their weekly assignments and participated in feedback sessions on the other two days a week. Members of the IAL team 
felt that the proper sequencing of the material was essential and that pace was determined by the students' reaction to each step in the sequence:

Director: Now the important part of this and part of the reason why it took a year is these are building blocks, if you don't understand day one, you're not gonna be able to do day two. So she had to make sure everybody understood day 1 before she was able to go to day 2. And that was easy at the beginning but as you got toward the middle of the classroom presentation that really got to be an issue because some students really were still kind of confused about some things from day 1, but now we're on day you know 40 and man it starts to surface as... an issue. So she would have to go back and then you know revisit those earlier principles in order to get everybody back where - you know back up to speed where they needed to be you know halfway through the lecture.

Primary Instructor: Computer language is like building blocks, you just have to have a real good foundation on one step before you can take another step. Without that strong foundation, the building will collapse.

All of the interviewed students from the first group agreed that after the first few weeks of lectures on OpenGL, they made a collective decision to have the team lead ask the Primary Instructor to slow down the pace of the class. The Primary Instructor attributes their method of communicating to be a form of cultural communications specific to their cultural ways as a part of their Indian heritage:

Primary Instructor: Being Indian as they are, so they have a lot of consideration, they sometime feel like they don't wanna bother my time, so they would get 
together as a group first. So, what they did was the leader of the team will collect questions and then he will come and talk to me.

Student 7's perception of why they chose not to communicate directly with the Primary Instructor about problems they were having in class supports her interpretation:

Student 7: At IAL, we didn't say because we are a little bit humble. We did not say directly. We feel like teacher is like a god to us. First is mother, next to father, next to teacher. We won't directly blame, we won't directly point it out.

Student 7's response was presented as the example of cultural beliefs and values and also and reflects elements of cultural communications, cultural classification, and cultural ways because this student attributes the behavior of not communicating criticism to the teacher's status.

After requesting that the pace of the course be slowed down, however, in the end these same students complained that the pace was not rigorous enough and that the six months spent on OpenGL, twenty-six weeks, was too long.

Student 5: Now they were only teaching us OpenGL for five months which is just not required.

Student 7: They need to reduce their time... What they used to be giving us for one week we used to get [in India] in one day itself. Going that much slow is not required. Actually we got used to fast way of learning.

In Student 7's excerpt two elements are mentioned in forming his perception of the pace of the course: cultural experience, the pace of schooling as experienced in India, and cultural infinities, how time is paced in learning.

The client representative also expressed some frustration with the changes made in pace: 
Senior Project Manager: The distance between me and the personnel and the project I was managing meant that I did not find out about what was being covered and the purpose of that instruction until it was too late. For instance, despite there being a specific curriculum in place, there were often diversions from the curriculum due to students' reactions to the coursework and their understanding of the material.

In this excerpt, the client representative attributes project management and communication problems related to pace to distance, a cultural infinity.

Materials

The Primary Instructor presented all of the materials in class, starting with a PowerPoint lecture, followed by running an example program on the machine and ending with a template assignment for students to write programs themselves. All of the materials were made available in twenty-six weekly modules on the classroom computer.

As discussed above in the Genre section, PowerPoint was used in the lectures in the classroom. As part of Framing, findings about the PowerPoint slides themselves are considered as part of the presentation of content. The Primary Instructor describes her process in preparing the PowerPoint slides:

Primary Instructor: The development of the materials was simple and very informative, no style, no fancy font or anything like that. In order to teach someone, you see PowerPoint and explain them about computer was by itself difficult. Then sometime I had to put in some math and some physics, and all those math symbol and physics symbol, which is difficult to type. So, my PowerPoint was planned, and it was getting to the point. 
From artifact analysis, I noticed the slides used a basic black font on all white slides. When asked about the style of the PowerPoint materials, the Primary Instructor explained:

Primary Instructor: My theme is keep it simple stupid because the material itself is hard enough.

The students pointed to the slides as useful resources both while they were training in the US and after they returned to India.

Student 6: It had all the brief explanation of the content. Even now we always have a look at the slides when we have problems.

However, as part of a general dissatisfaction with the lack of advanced or original content of the course expressed by most the students, some students pointed to the content of the PowerPoint slides.

Student 7: What was in the book was transferred to slides. Nothing extra from the book. The examples are also from the book itself.

Student 8: The slides were made...mostly made out of the books we were reading. So it was, ok, like we could have same information from reading the book... Whatever was on the slides, there was like, very basic explanation.

This shared desire, or cultural interest, for more advanced levels of information was expressed by most of the students and attributed to their cultural identity as Indians by Student 7.

Student 7: So when dealing with the Indian students, especially, what we expect is more and more. We want to learn more and more.

Assignments 
The weekly assignments in the OpenGL part of the training program asked students to build basic structures as they became familiar with working with graphics. As they entered the CAVE applications portion of the training program, they were asked to complete data visualization projects moving through the concepts of space, time and data merging.

Program Manager: So there were six projects and these covered everything from planets to make your face 3D to population of the U.S. and use digital elevation models from three different places with three different formats.

Several students expressed a preference for the assignments over the lecture portion of the course. They also felt the assignments introduced them to new material.

Student 7: They gave us some assignments. Assignments are new, because their data is new... So when they gave us assignments, we learned a lot.

The type of data used for the assignments came from the IAL's organizational collection, a G Topo dataset publicly available and Internet sources.

Director: [The Program Manager] in training his team had over the years developed a number of different projects. He had some canned data which he would give to his students and tasked them to make certain things happen with the data.

Program Manager: So I gave them real word data sets I pulled off the Internet and that I pulled from other data sources I might have... I pulled the data sets out from projects I had done before... you don’t want to make an Internet search contest. 
The cultural resources and cultural experience of the IAL organization influenced the assignments and data made available to the students.

However, some students expressed a lack of challenge with these assignments.

Student 8: Assignments, they were not as challenging as I thought they would be. Student 9: They were simple...A few of them we had to struggle to get done, but most of them were pretty simple.

The students also expressed a shared desire for more diversity in the assignments and data.

Student 7: And one bad thing about assignments was assignments all similar type... Same kind of job.

Student 10: After a certain point, after two or three assignments from [Program Manager] I was, I mean everybody, has a feeling that more of the assignments are falling into the same category. They're not diverse enough...he give a lot of scientific visualization problems to us. And the problems were very similar in nature. So I wish he would have given... some diversity in the assignments. Different kinds of assignments. I was expecting that.

After the individual data visualization assignments, students were assigned to groups and worked on real-time, real-world projects. In the original plans with NextGenEd, IAL had intended to have all of the students working on projects for NextGenEd clients However, by the time the students reached this portion of the course, there were only a couple of potential client projects. These two projects were included in a group of seven projects designed for the students. One of the artifacts from IAL Assignments showed that these projects included: structural engineering applications; earthquake applications; a dental 
dataset model viewer; a 3D stereo movie; file loaders; a virtual racquetball physics engine; and a non-traditional tracker interface using a game controller. Two of these projects were with universities in India and targeted to be marketable products in collaboration with potential clients in India.

\section{Content}

The content areas stated in the curriculum are OpenGL and CAVE programming. From the IAL perspective, most of the students had no background in graphics, so they needed to be taught a basic programming language for graphics to build towards creating i3Dv products.

Director: If they all had done a year of training in this OpenGL programming language we could have curtailed the training significantly and had them just work on you know real applications. But they all came in basically with no understanding of this programming language at all.

The Program Manager had originally chosen OpenGL when first training his team because it was open source, and he thought it was a good fit for the NextGenEd students because it would not cause any licensing problems for the future business plan. In the business plan, NextGenEd lays out a vision of producing thousands of applications to distribute across India.

Program Manager: That's why we went Open GL...That's why I decided that ten years ago, I came here, I said let's not to buy packages because it is open source... and especially when this India project came along, I was just like-it’s open...So if they want to print out 10,000 copies, there’s no licensing issues. 
The Program Manager's primary content decision, then, relates to his cultural experience at IAL, a shared cultural resource between India and the US in open source and cultural futures, the company's vision for the Indian market.

The client representative and several students were particularly disappointed in this content decision: the singular focus on OpenGL.

Senior Project Manager: One of the failings of the program, was that despite the company’s frequent and clear communications with [IAL Team] about what we were hoping to achieve, the training team focused more on the theoretical aspects of OpenGL development, IAL’s core competency, rather than training the student team on some of the more popular tools that are more frequently used to develop the kind of content that we were interested in developing... the difference in creating a 3D application using OpenGL versus some of the tools available is akin to the difference between baking a cake from scratch with individual ingredients versus using a storebought cake mix.

The client representative attributes IAL's decision to their cultural experience and cultural knowledge.

The students also expressed disappointment about this content decision because they felt they could have learned OpenGL in India.

Student 1: We could have gotten better training over here in India [on OpenGL]. The CAVE technology and the hardware part we couldn't have gotten in India. So the best solution was to have instead of a year-long training we could have gone there only for the CAVE training. 
Student 8: What we learned there, we could have learned, the open GL part at least, we could have learned on by our own.

The students, like the Program Manager, view OpenGL as a shared cultural resource and shared cultural knowledge, and they believe this makes OpenGL a less desirable choice of content. As discussed in the Genre section, the CAVE technology was the centerpiece of the training and considered an appropriate part of the content by all parties.

Omission: Cultural interaction with what content was not included

Summary Result: Of the twenty-five elements of culture in the CBM model, nine elements of culture were found to interact with design decisions, stakeholder perceptions and project outcomes related to what content was not included: cultural capital, cultural classification, cultural communications, cultural knowledge, cultural resources, cultural beliefs and values, cultural misconceptions, cultural ways, and cultural futures.

The design factor Omission in the CBM framework focuses on "what has been intentionally or unintentionally omitted" (Young, p.59, 2009). Young includes this category in the Inquiry component to help designers consider multiple points of view on the positive and negative effects of omissions and what may not have been considered. In this study, aspects of omissions refer to decisions of the design team and perceptions of the stakeholders related to what was left out of training program content. The following questions are the focus of the design factor: Omission.

- What has been intentionally omitted and why?

- What has been unintentionally omitted and why? 
- What has not been considered?

- Will these omissions be detrimental to the project and why?

In this section, I describe the circumstances of the case as related to the above questions about Omissions. As discussed above in the Framing section on OpenGL, the IAL team intentionally omitted 3D development authoring tools other than OpenGL to avoid expense and potential licensing issues. They did not consider other 3D development tools to be important to the cultural knowledge base that NextGenEd was building through this training program. This decision negatively influenced student and client perceptions of the quality of the program.

Student 3: We were expecting more on other topics. The course is 3D graphics. The syllabus... everything was not covered there I think. One of the topics that is called, spelled VERS is one of the challenging topics of 3D. It's the latest thing, you can say. That was not taught there. So we learned that by ourselves after coming here.

Senior Project Manager: I believe that it was critically important for the students to learn how to manipulate 3D content using OpenGL, but I believe a great disservice was done in not exposing the students to available development environments.

Because the decisions and perceptions about OpenGL as the content choice excluded the use of other tools, the same Elements of culture highlighted in the Framing can also be seen at work here as well: cultural resources and cultural futures. 
Backgrounding: Cultural interactions with what content was not emphasized

Summary Result: Of the twenty-five elements of culture in the CBM model, five elements of culture were found to interact with design decisions, stakeholder perceptions and project outcomes related to what content was not emphasized: cultural capital, cultural communications, cultural knowledge, cultural experiences, and cultural interests.

The design factor Backgrounding in the CBM framework focuses on "what... is deemphasized” (Young, p.61, 2009). Young includes this category in the Inquiry component to help designers consider multiple points of view on the positive and negative effects of content that is not emphasized, intentionally or unintentionally. In this study, aspects of backgrounding refer to decisions of the design team and perceptions of the stakeholders related to what was included but not emphasized in the training program content. The following questions are the focus of the design factor: Backgrounding.

- What has been backgrounded?

- Is the backgrounding intentional or unintentional and why?

- Will this backgrounding be detrimental to the project?

In this section, I describe the circumstances of the case as related to the above questions about Backgrounding. The content of the training program focused on programming languages and not hardware. The students were taught basics of running the CAVE components, but the focus of the training program was building applications for the hardware, not the hardware itself. In this training program, therefore, the topic of hardware was backgrounded or de-emphasized. The IAL Director ties this decision to meeting the needs of the client: 
Director: We wanted to be sure that we were training to the expectations of NextGenEd. That was - we were very concerned about meeting their expectations. You know if they wanted people to be hardware experts we could have trained them as hardware experts. But we felt based on our interactions with NextGenEd, what they really needed was people that were strong in programming and that's what we focused on... they did get some you know familiarity with the hardware, the firmware, what have you...But we knew that NextGenEd wanted programmers and if they needed an expert on the installation of a visualization suite of hardware, they could hire a contractor to do that which is how they did install their system in Mumbai.

However, even though the CAVE technology was the purpose of the training program, one student was also disappointed that they were not exposed to other hardware available for 3D environments.

Student 9: They only taught us the software part of technology. Not much about the hardware part, what would be the various options. We only had one type of system to experience... There are 3D display technologies that were there at that time, but we were not exposed to that.

The decision to background hardware topics was related to what IAL believed NextGenEd's needs to be in forming cultural knowledge in the organization and what cultural resources IAL believed NextGenEd would have available in India. There were no observable outcomes to this decision that were detrimental to the project. 
Foregrounding: Cultural interactions with what content was emphasized

Summary Result: Of the twenty-five elements of culture in the CBM model, seven elements of culture were found to interact with design decisions, stakeholder perceptions and project outcomes related to what content was emphasized: cultural capital, cultural communications, cultural knowledge, cultural resources, cultural beliefs and values, cultural misconceptions, and cultural futures.

The design factor Foregrounding in the CBM framework focuses on what in the content is “emphasized" (Young, p.62, 2009). Young includes this category in the Inquiry component to help designers consider whether there is too much emphasis on any particular content to the detriment of the design. In this study, aspects of foregrounding refer to decisions of the design team and perceptions of the stakeholders related to what was emphasized in the training program content. The following questions are the focus of the design factor: Foregrounding.

- What is emphasized and why?

- Is this what should be emphasized?

- How does this emphasis influence the overall design?

In this section, I describe the circumstances of the case as related to the above questions about Foregrounding. As discussed above in the Framing section on content, OpenGL received the most attention in the curriculum for this training program. This foregrounding was considered appropriate because of past experience at IAL, the building block nature of the content and the goals of NextGenEd to mass produce applications. 
Director: We felt based on our interactions with NextGenEd, what they really needed was people that were strong in programming and that's what we focused on. And once we ascertained that then [Program Manager] basically really formalized what he had been doing with his own team and his own students in the past. And [the Primary Instructor] and he collaborated in developing this syllabus and it was very up to date. It included all the latest in the programming language... it is called OpenGL because it is an open language.

This decision also influenced the pace and materials as part of the overall design. As found in excerpts above in the Framing and Omissions sections, the students and client felt that OpenGL was overly emphasized. Also as described above, this decision and resulting perceptions are related to Elements of cultural capital, cultural resources, cultural knowledge and cultural futures.

\section{Visual Representation: Cultural interactions with image choices}

Summary Result: Of the twenty-five elements of culture in the CBM model, eight elements of culture were found to interact with design decisions, stakeholder perceptions and project outcomes related to image choices: cultural classification, cultural communications, cultural environment, cultural history, cultural resources, cultural experiences, cultural anomalies, and cultural futures.

The design factor Visual Representations in the CBM framework focuses on visual aspects of the design because of their semiotic relationship with the content (Young, p.63, 2009). Young includes this category in the Inquiry component to help designers consider who and what is being portrayed by visuals, as well as whether or not they are purposeful 
and appropriate. In this study, findings about decisions of the design team and perceptions of the stakeholders related to the visual content of course materials are presented. The following questions are the focus of the design factor: Visual Representations.

- How do the visual representations frame the product?

- How do visual representations assist in the instructional process?

- Who is portrayed in these visual representations?

- What is portrayed in these visual representations?

- What purpose do the visual representations serve?

- Are inappropriate visual representations in the design?

- Why were these visual representations selected?

In this section, I describe the circumstances of the case as related to the above questions about Visual Representations. Visual representations are inherent to the content of this graphics and visualization based training program. In this training program, visual representations: 1) present the dynamic nature of visualization science; 2) demonstrate functions of visualization applications; and 3) reveal problems with assignments. The Primary Instructor used static, dynamic and interactive visual elements in all course materials.

As described above in the Framing section on data and assignments, students were often asked to work with geographical data because it offered the opportunity to work with space, time and merging data and because these were the data sets available at IAL. Even though IAL provided a variety of exposure to topographical data sets for visualization, including planets for universal perspective, GTopo for global perspective 
and even the students' own faces, a few students expressed some dissatisfaction with working mostly with terrain mapping instead of being exposed to other visual domains. Student 7: I wanted it from different domains. For example some medical, some scientific, some proteins, GSA, different domains. Every time we got [geospatial] data - the data we got we literally did almost 5 to 6 assignments. It's boring. Much like other aspects of Inquiry in this section, Elements of cultural resources, cultural experiences and cultural futures interact with decisions about visual representations. Cultural history, cultural nature and a cultural anomaly also interact here since one of the reasons IAL came to have a collection of geographical datasets was a natural catastrophe.

\section{Cultural Interactions with Inquiry component of ID-TABLET}

The above findings highlight through excerpts where multiple cultural elements interact with decision-making, perceptions and outcomes of Inquiry components in the instructional design process. Table 8 provides a visual display of where Elements of culture were coded along with components of Inquiry to reveal frequency and breadth of cultural interactions with these design factors. 
Table 8

Cultural Interaction Matrix: Inquiry

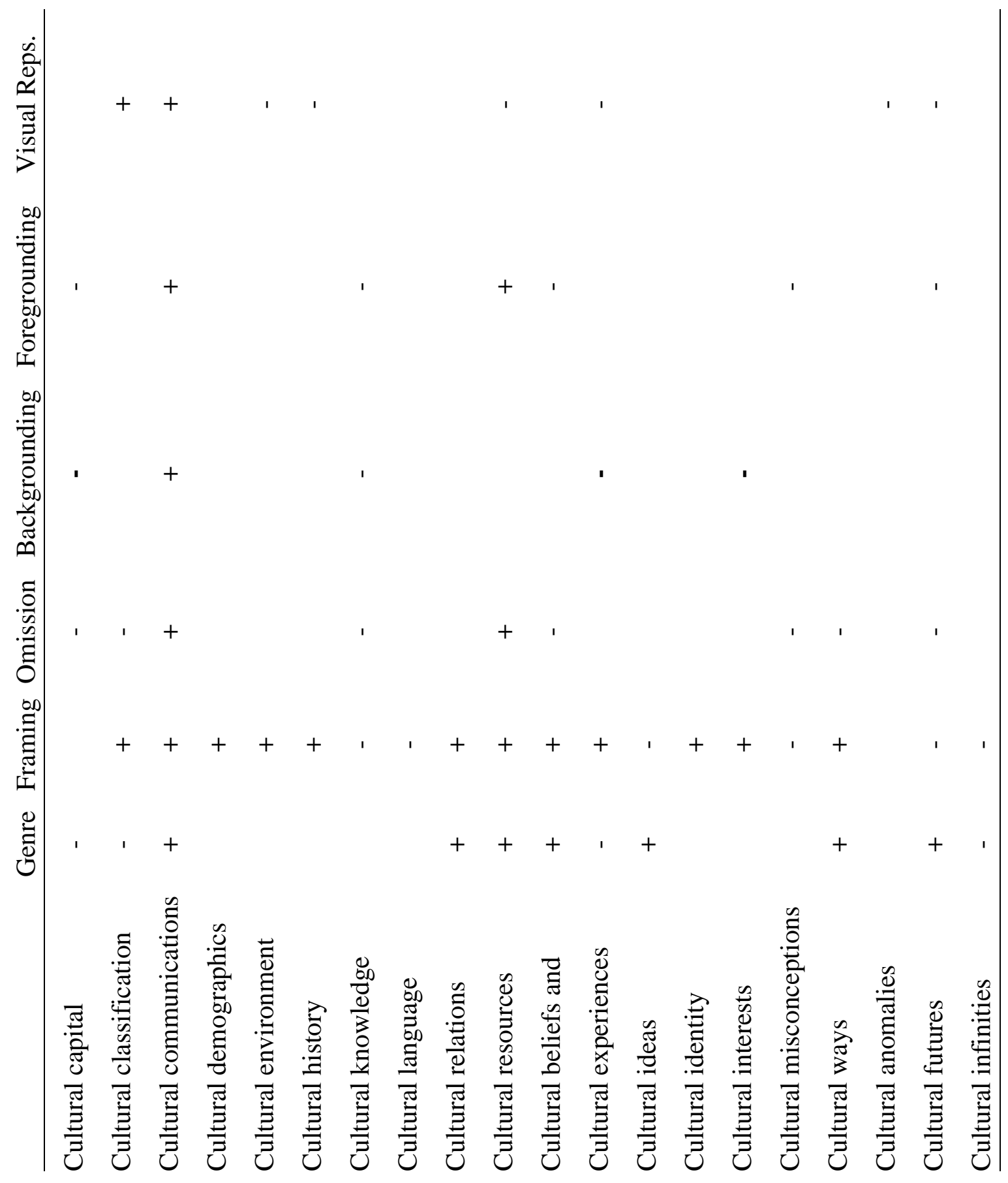

- One overlapping coded reference

+ More than one overlapping coded reference 


\section{Cultural interaction with design specifications, technology format, audience} assessment and quality

In the Culture-Based Model (CBM) framework, the Development component is categorized as an area of project management. This component provides "the management structure for problem solving” (Young, p. 65, 2009). Under the component of Development, guidelines are offered as ten features for overall development: Table 9 describes these features. In this research, these features are explored as factors in a training program rather than a product, so some features do not apply or are slightly modified for this context. The findings below reflect where decisions were made that address or fail to address the features of the Development component of CBM; where the connection between these decisions and program outcomes are related; what stakeholder perceptions were expressed about these decisions and program outcomes; and where these decisions, stakeholder perceptions and program outcomes interact with or are related to cultural Elements.

Table 9

Development Design Factors of CBM

Factor Description

Design Specifications

Consider technical, aesthetic, content, culture-based and target audience design specifications

Mass Distributions Formats $\quad$ Produce in formats for mass distribution that allow access and equity

Effective Technology

Use the most efficient and effective technology available to produce the product

Diversify ICT Format

Provide multiple forms of information and communication technologies or manipulatives to meet the needs of the target audience 
Understand Target Audience

Explore environmental and individual/group cultures

Quality Design

Authenticate Product

Control for Interference

Model the Product or Process
Know and focus on your audience throughout the design

Environmental cultures explore societies and cultures' ways of life. Individual/group cultures explore people.

Create a good product for other people who desire to create similar products

Authentic representations of target audiences are needed to validate the product

Provide products that limit bias, attitudes and prejudices; Try to control for human, machine and environmental interference

Create prototypes, sketches, storyboards or visual languages

Adapted from Young (2009) p. 66

Design Specifications: Cultural interaction with technical, aesthetic, content, culturebased, and target audience design specifications.

Summary Result: Of the twenty-five elements of culture in the CBM model, eleven elements of culture were found to interact with design decisions, stakeholder perceptions and project outcomes related to design specifications: cultural capital, cultural classification, cultural communications, cultural history, cultural language, cultural relations, cultural resources, cultural experiences, cultural identity, cultural interests, and cultural futures.

This feature of the Development component provides guidance to identify and categorize design specifications based on technical, aesthetic, content, culture-based and target audience (TACCT) parameters. In this study, the design specifications of the training program are considered in the context of the TACCT parameters of this case. 
A somewhat informal approach was taken in preparing the design specifications for this training program. The documentation that set up the client's goals and expectations included a memorandum of understanding between IAL and NextGenEd that was followed by a contract for services. Documentation for content, location and equipment was drawn up ad hoc and communicated through e-mail:

Program Manager: So we just laid out, here’s the kind of stuff we want to do... who do we need and how much space do we need and what kind of computers do you need? All that grew from that. So you know you're going to need to come over here, they need places to live and they need computers to use and on and on and on. So as those things came up, we just sat down and design at the computer. Documentation that described the content of the training program was an outline of the curriculum.

Program Manager: An email attachment, off hand...It was the curriculum....It was basic-I don’t know if it was-it wasn’t down to the detailed level but it was, you know, here's all the subject matter we're going to teach with all the headings... it wasn't the full book of stuff...Created for NextGenEd...before that, like I said, it was more free form as I gained or lost people.

NextGenEd considered this project part of Research and Development and did not provide any formal project management requirements internally or to NextGenEd. Senior Project Manager: There were no specific requirements drawn up. This initiative was a very quickly initiated project and as such was treated as more of an $R \& D$ project than a traditional project.

Technical Specifications 
As noted above and in the Genre section of Inquiry, the technical specifications for this project included state-of-the-art computer equipment funded through cultural capital of NextGenEd and the CAVE at IAL, a cultural resource. Student perceptions of technical design specifications, as shared in above findings in the Genre section of Inquiry, included: 1) satisfaction with high end computer equipment and 2) initial excitement and eventual disappointment in IAL's model of the CAVE.

\section{Aesthetic Specifications}

Aesthetic or visual aspects of the project, visualization data sets, were influenced by past cultural experience of the IAL team as found in the Visual Representations section of Inquiry. Student perceptions of aesthetic design specifications, as shared in above findings in the Visual Representations section of Inquiry, included: 1) satisfaction with new visualization data sets; and 2) dissatisfaction with lack of diversity in visualization data sets.

\section{Content and Culture-based Specifications}

Content decisions interacted with multiple Elements of culture as discussed in the Framing section of Inquiry, and overlap here with culture-based specifications. Culturebased specifications included: 1) the CAVE technology was chosen as content for the training program because it was not a cultural resource available in India as described in the Framing section; and 2) OpenGL was chosen as content to avoid licensing issues for mass production in India as described in the Framing section. Student perceptions of culture-based specifications of content, described above in the Framing section of inquiry, include: 1) satisfaction with CAVE technology as content; and 2) dissatisfaction with the overemphasis on OpenGL as content. 


\section{Target Audience Specifications}

Target audience specifications were based on the students' qualifications as computer scientists and programmers, status as employees of NextGenEd, and nationality as Indians. As discussed in above findings in the Framing section of Inquiry, pace and material specifications were changed as part of constant negotiation between the students' abilities to keep up and NextGenEd's request that the training be sped up. Elements of cultural capital, cultural classifications, cultural knowledge, cultural demographics, cultural interests and cultural futures interact with these decisions. In addition, no-excuses deadlines were imposed on all assignments because of the Program Manager’s past experience with Indian students.

Program Manager: [Prior Experience] They seemed to come in groups, the Indian students, with excuses... I had more of that...issues with the Indian students. [NextGenEd training program] The only thing I did was no excuses, you're going to be coming and nipping it in the bud. And it happened just like I thought, and we shut it down at the very beginning and it's over.

The Program Manager's decision about deadline specifications is attributed to his cultural experience at IAL that prompted him to form a cultural misconception, a hasty generalization, about Indian students. As noted earlier in the Framing section on inquiry, the pace of the course, including assignment deadlines, was a challenge for the students.

Student 5: I don't know there was something the environment something was there that we were not able to, maybe the pressure. Yeah, one important thing: the deadlines that were there. They were set like, you had to submit it within a week. I don't know, maybe some people could do it. They wanted quality results as well 
along with just the timely completion of the application. They were looking for two things. So whatever assignments we used to do I used to focus on the quality part rather than submitting it on time...They were focused on pressure and deadlines...Yeah, mostly it was pressure and deadlines. That used to take away from the quality part... This amount of time you have to do it. Because this is research. This is not something that is established you have to do research...So you should give us ample time, appropriate time to finish regardless research within a day or two, a month. That is something that takes time.

This student dissatisfaction is attributed to Elements of cultural environment, the pressure at IAL, and the assignments for cultural futures, research for innovation. Findings on the design specifications feature of the Development component often overlap with the Inquiry component and indicate interactions with multiple Elements of culture: cultural environment, cultural misconceptions, cultural futures, cultural capital, cultural classifications, cultural knowledge, cultural demographics, and cultural interests.

\section{Mass Distribution Formats.}

This feature of the Development component provides guidance to make an instructional design product more accessible and equitable to mass numbers of people (Young, 2009). In this study, the training program itself is not intended to be distributed en masse, so no data were coded for this feature.

Effective technology: Cultural interaction with the effectiveness of technology choices 
Summary Result: Of the twenty-five elements of culture in the CBM model, even elements of culture were found to interact with design decisions, stakeholder perceptions and project outcomes related to the effectiveness of technology choices: cultural capital, cultural classification, cultural communications, cultural relations, cultural resources, cultural experiences, and cultural futures.

This feature of the Development component is a directive to choose technology that will effectively meet the needs of the target audience and provide efficient entry into the market. In this study, the technology chosen was for a program instead of a product, so matters of efficiency for entry into the market are not considered. All of the technology choices and stakeholders' perceptions of these choices are described above in the Genre section of the Inquiry component. Technology chosen for the face-to-face environment was considered effective by stakeholders; however, students felt more up-to-date technology would have been more effective. Technology initially chosen for distance learning, gotomeeting.com, was not effective in allowing the IAL team to sufficiently view student work; the subsequent technology choice of videoconferencing equipment was found to be effective by all participants but not as desirable as the face-to-face environment for feedback. As described in the findings for the Genre section above, multiple Elements of culture were found to interact with decisions and perceptions of the Effective Technology feature of the Development component: cultural capital, cultural classification, cultural communications, cultural relations, cultural resources, cultural beliefs and values, cultural experiences, cultural ideas, cultural ways, cultural futures and cultural infinities. 
Diversify ICT Format: Cultural interaction with the diversification of technology formats Summary Result: Of the twenty-five elements of culture in the CBM model, eight elements of culture were found to interact with design decisions, stakeholder perceptions and project outcomes related to the diversification of technology formats: cultural capital, cultural classification, cultural communications, cultural relations, cultural resources, cultural experiences, cultural futures, and cultural infinities.

This feature of the Development component is a directive to accommodate multiple learning styles, visual, acoustic and tactile, through diverse ICT formats in a product design. In this study, the ICT format decisions were made for a program instead of a product, so more opportunities for diversification were available. All of the ICT format decisions and stakeholders' perceptions of these choices are described above in the Genre and Framing section of the Inquiry component. ICT formats included: CAVE, PowerPoint, WACOM, example programs, state-of-the-art desktops and laptops, videoconferencing equipment, gotomeeting.com, Skype, telephone, e-mail, and printed materials. As described in the findings for the Genre and Framing sections above, multiple Elements of culture were found to interact with decisions and perceptions of the Diversify ICT Format feature of the Development component: cultural capital, cultural classification, cultural communications, cultural relations, cultural resources, cultural beliefs and values, cultural experiences, cultural ideas, cultural ways, cultural futures and cultural infinities. 
Understand target audience: Cultural interaction with the design team's knowledge of the students

Summary Result: Of the twenty-five elements of culture in the CBM model, thirteen elements of culture were found to interact with design decisions, stakeholder perceptions and project outcomes related to the design team's knowledge of the students: cultural classification, cultural communications, cultural demographics, cultural environment, cultural history, cultural knowledge, cultural language, cultural relations, cultural resources, cultural beliefs and values, cultural experiences, cultural identity, and cultural futures.

This feature of the Development component is a directive to a design team "to gather preliminary research about the audience" and "determine how the design process should proceed given what is known” (Young, p.69, 2009). In this study, rather than designing a product for a particular target audience, the target audience was recruited for having a particular educational background or work experience that qualified them to participate in this program. What the IAL team understood about the target audience was information gathered through recruitment activities:

Director: There were phone interviews and then I interviewed one or two when I was in India. So we had a pretty good feel for what we were getting. And, therefore, we were able to adjust the curriculum accordingly...[The NextGenEd $\mathrm{COO}]$ would call us and then we had a couple of phone interviews with a few of the students. And then he would just go over... other students that weren't there or on the phone. He would just go over their resumes with us and would talk, we would talk through them. And there were certain things that [the Program 
Manager] and [the Primary Instructor] were looking for that some of the applicants didn't have...that would have made it almost impossible for them to be successful. We wanted people to come here that had good programming education and preferably some experience.

Program Manager: We actually had a teleconference with Ashish in India. When they were hiring the people and we went over qualifications-made a list of qualifications about the people needed to start and come in. We actually phone interviewed a number of people. We talked to them and asked them questions and what [the NextGenEd COO] and those people over in India were doing was listening to how we were questioning the students to figure out who-what we were looking for specifically...To give them a list, that works fine, but when you ask questions and people give you answers and then we talk about the person afterwards and then he got a better feeling for who we're interested in.

The Primary Instructor based her understanding of the target audience primarily on the information gleaned in this recruitment process.

Primary Instructor: I asked them who are these people and they say programmers...Okay, what type of education they have. They said... college. How old are they? In their 20s so they just finished their school and some has a few year experience, some has none...So these people that came, they were less than 30 years old...So they are young adults with programming and zero experience in graphics...With the exception of one at most two who had worked in the area involving graphics. So that helped me determine how basic I had to be at the beginning. 
In this excerpt, we see the Primary Instructor restrict her understanding of the target audience to profession, education, age and experience. However, related findings reveal that additional encounters with the culture of the students expand her understanding of the audience. As noted above in the section on Culture-based design specifications earlier in the Development component and expanded on later in the section on the Culturallyinformed Team of the Team component, IAL team members participated in activities and also had some past experience with Indian students and programming students that added to their understanding of the target audience.

In these findings, and the findings of other referenced sections, multiple Elements of culture were found to interact with decisions and perceptions of the Understand Target Audience feature of the Development component: cultural capital, cultural classifications, cultural communications, cultural demographics, cultural relations, cultural resources, cultural experiences, cultural misconceptions, cultural ways and cultural futures.

\section{Explore environmental and individual/group cultures: Cultural interaction with the} design team's encounters with the students' cultures

Summary Result: Of the twenty-five elements of culture in the CBM model, twelve elements of culture were found to interact with design decisions, stakeholder perceptions and project outcomes related to the design team's encounters with the students’ cultures: cultural capital, cultural classification, cultural communications, cultural demographics, cultural environment, cultural knowledge, cultural relations, cultural resources, cultural beliefs and values, cultural misconceptions, cultural ways, and cultural futures. 
This feature of the Development component is a directive to a design team to consider culture from two perspectives: "ways of life” and "people” for a "more holistic interpretation of cultures” (Young, p.69, 2009). Environmental cultures would include societal institutions such as “workplace culture” or "school culture” (Young, p. 69, 2009). Individual or group cultures are defined ethnically with examples like "Native American culture” or "Japanese culture” (Young, p. 69, 2009). In this study, the two organizational cultures under study, NextGenEd and IAL, are considered environmental cultures and the national cultures, US and India, are considered individual or group cultures; findings here represent data related to the IAL team's exploration of the student's individual or group culture and environmental cultures.

As described above in the section on Culturally-informed Team of the Team component, the IAL team had members of the team visit India and planned activities that served purposes of exploring individual or group cultures: slideshow presentation on India, introduction sessions and culture sharing days. In above findings, multiple Elements of culture were explored in the IAL team's visits and activities: cultural aesthetics, cultural artifacts, cultural capital, cultural classification, cultural demographics, cultural environment, cultural language, cultural relations, cultural resources, cultural experiences, cultural interests, cultural ways and cultural infinities. In terms of the environmental culture of the students as NextGenEd employees, all of the students were newly hired for the purposes of the program and had not been enculturated at NextGenEd before arrival. They were mostly strangers to each other when they arrived at IAL, so no prior environmental group culture among the students existed to explore. However, the environmental culture of NextGenEd was a factor in design 
decisions, and the IAL team did explore that culture. The Director and the Primary Instructor both visited the NextGenEd headquarters in India, and all team members. Primary Instructor: There's two parts of NextGen Ed, the first one is in U.S., the other one is in India, so the one in U.S. is good because we can talk eye-to-eye and they are more American. And the one in India, they're on a different agenda, so we gotta understand what agenda that they're into.

The agenda the Primary Instructor refers to were differences in opinion about the design of the training program mostly focused on the pace and quality, as described in above findings of the Framing section in the Inquiry component. Also, as discussed in later findings about financial support, not all members of NextGenEd in India were supportive of the i3Dv project. Cultural infinities, or distance, was seen to interact with the IAL team's ability to explore the NextGenEd culture, and Elements of culture that were explored included: cultural capital, cultural classification, cultural communications, cultural environment, cultural knowledge, cultural relations, cultural resources, cultural ideas, cultural identity and cultural interests.

Quality Design: Cultural interaction with criterion for determining quality of the training program

Summary Result: Of the twenty-five elements of culture in the CBM model, fifteen elements of culture were found to interact with design decisions, stakeholder perceptions and project outcomes related to criterion for determining quality of the training program: cultural classification, cultural communications, cultural environment, cultural knowledge, cultural language, cultural relations, 
cultural resources, cultural beliefs and values, cultural experiences, cultural ideas, cultural identity, cultural interests, cultural misconceptions, cultural ways, and cultural futures.

This feature of the Development is a directive to the design team to create a good product by "focusing on the best interests of the target audience in the design" (Young, p.70, 2009). It is not within the scope of this study to evaluate the quality of the design of this training program. The findings here represent data related only to stakeholders’ perceptions of the quality of the design and some observable outcomes.

The design team's criterion for quality was the outcome: the students would be able to develop 3D applications for CAVE technology. This criterion set up by IAL is related to cultural capital, cultural experiences, cultural knowledge and cultural ideas.

In the observation conducted in India at the NextGenEd CAVE facility, I was able to observe that the students have used the training to produce at least five i3Dv simulations for CAVE technology after returning to India which are regularly demonstrated to potential clients: driving a racecar; riding a rollercoaster, walking in a revolving corridor, interacting in a virtual biology lab, standing in a hallway during an earthquake and touring the Taj Mahal. This observed outcome is related to cultural artifacts, cultural capital, cultural knowledge and cultural resources.

When students spoke of quality, they were concerned with advanced education in 3D technology. Most students felt they received only foundational knowledge in 3D technology.

Student 2: The program in terms of the amount of technicality and the amount of training which was imparted - it lacked in many things. First of all the quality was 
slightly low. Actually I came from an IIT back ground so the quality which was imparted there was way too high when compared to what we got there. It was pretty easy all the things were there. Some things that took one week we could have finished it off in three, four hours. It actually made us think that we can learn the same thing anywhere else within ten times lesser time. So it made us wonder about the program's approach and effectiveness. But well since this type of technology was new and it was only in selected areas where you can get training for this so OK fine.

Student 5: From my friends... in India, they say if you want to learn Open GL, if you get a proper teacher for that, you'll learn it within a month or so. But I remember it took me three months, four months, and still I was struggling with that. So I thought there was something wrong. So when I discussed it with my friends I thought that the quality is not the best, of course, it could have been better.

Student 8: I mentioned that the quality of training we are expecting is not to our standards what we are expecting.

Student 9: My opinion is it could have been much better. The instructors could have been much better with much more knowledge about 3D. It would have been more technical, more comprehensive and...the duration that was there. It could have been two or three months.

These excerpts show where the students’ perceptions are attributed to cultural experiences, cultural knowledge, cultural resources, cultural beliefs and values and cultural ideas. 
The client representative's criterion for quality was that the training program support NextGenEd's goal of producing a staff of employees who could develop 3D applications for CAVE technology for the education market.

Senior Project Manager: The company goals... being able to build immersive 3D applications for commercialization and distribution in the K12 education space. The students have used their training to produce 3D applications for CAVE technology, but as of the date of this writing, over a year since this completion of the training program, none of these applications have been successfully marketed. The senior project managers' perceptions of quality are related to cultural capital and cultural futures. As noted above, the observed outcome of student production is related to cultural artifacts, cultural capital, cultural knowledge and cultural resources.

\section{Authenticate Product.}

This feature of the Development component is a directive to validate an instructional design product as "true to the life of target audiences" (Young, 2009). In this study, the training program is not a product that can be validated as described in this component, so no data were coded for this feature.

\section{Control for Interference.}

This feature of the Development component is a directive to "minimize bias, attitudes and prejudices” and “control for interference by way of humans, machines or the environment” in a product (Young, p. 70, 2009). In this study, the training program is not 
a product that can be released from its original environment, so no data were coded for this feature.

Model the Product or Process.

This feature of the Development component is a directive to create prototypes, sketches or storyboards to provide a visual representation of the product or process followed to create a product (Young, 2009). In this study, no such visual representations were mentioned in interviews, observed or found in artifacts, so no data were coded for this feature.

\section{Cultural Element Interactions with Development}

The above findings highlight through excerpts where multiple cultural elements interact with decision-making, perceptions and outcomes of Development components in the instructional design process. Table 10 provides a visual display of where Elements of culture were coded along with components of Development to reveal frequency and breadth of cultural interactions with these design factors. 
Table 10

Cultural Interaction Matrix: Development

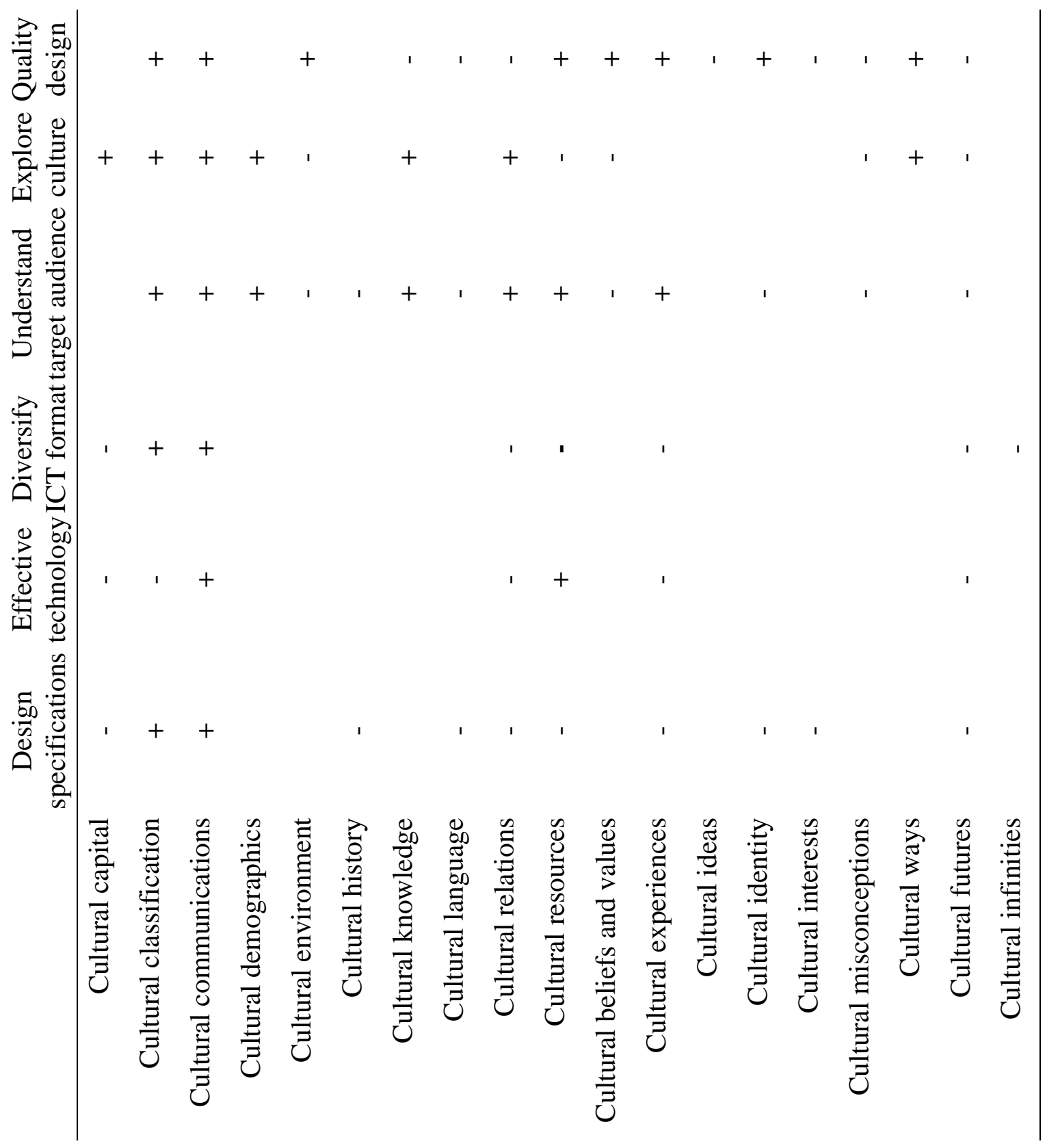

- One overlapping coded reference

+ More than one overlapping coded reference 


\section{Cultural interaction with the composition of the design team}

In the Culture-Based Model (CBM) framework, the Team component is categorized as an area of project management. This component provides guidelines to recruit and support a “culturally sensitive design team” (Young, p. 73, 2009). Under the component of Team, there are three components: 1) cultural expert; 2) enlist educators; and 3) culturally informed team. Table 11 shows the function of each component. In this research, these components are explored as factors in a training program rather than a product, so some aspects do not apply or are slightly modified for this context. The findings below reflect where decisions were made that address or fail to address the directives of the Team component of CBM; where the connection between these decisions and program outcomes are related; what stakeholder perceptions were expressed about these decisions and program outcomes; and where these decisions, stakeholder perceptions and program outcomes interact with or are related to cultural Elements.

Table 11

Team Factors of CBM

Factors Description

Cultural Expert

Enlist Educators

Culturally Informed Team
Insider who acts as a liaison with the target audience

Educators with expertise in the subject matter

An educated creative team with valid interests in the target audience

Quoted from Young (2009) p. 56

Cultural expert: Cultural interaction with the use of cultural experts on the design team 
Summary Result: Of the twenty-five elements of culture in the CBM model, sixteen elements of culture were found to interact with design decisions, stakeholder perceptions and project outcomes related to the use of cultural experts on the design team: cultural capital, cultural classification, cultural communications, cultural demographics, cultural environment, cultural knowledge, cultural language, cultural relations, cultural resources, cultural beliefs and values, cultural experiences, cultural interests, cultural misconceptions, cultural ways, cultural anomalies, and cultural futures.

In the CBM framework, a cultural expert should be a native of the target audience's community and build trust with the target audience in order to serve as a liaison between the design team and the target audience (Young, 2009). In this study, the IAL team did not explicitly set out to hire a cultural expert for their team. However, two members of the training program, who were native to the target audience' community, did take on some of the roles of the cultural expert: to "vibe" with and build trust with the target audience (Young, p. 74, 2009): the Secondary Instructor and the team lead. During early stages of the training program, the IAL Director hired a Secondary Instructor.

Director: The second group started being formulated and I'd talked to [the Primary Instructor] and I said, how are we going to do this?... Can you do both? And she said yeah, I could, I can, but it's going to be hard, it's going to be a challenge, and I said...we know of an Indian professor at [university in the consortium] he's a computer science guy and why don't we see if he'd be interested in working over here...So we talked to [him] and he was very interested in doing that although he was not that well versed in Open GL, that's exactly what 
he would be programming or teaching. So our idea was, well, you sit in the classroom with the first group, absorb as much as you can and if you feel that you're prepared to teach, then we go forward from there with the second group and we'll give you the second group and that's-kind of that's the way we formulated the idea...I thought it would be a very natural match...but there were issues. I thought the fact that he was Indian was just a perfect fit. I felt that he would be ideal-to identify with the students, they with him, and the language wouldn't be an issue... But the fact that he was... a professor, he has his doctorate. As described in the excerpt, this Secondary Instructor was a computer science professor from one of the universities in the US consortium and trained on OpenGL and CAVE technology along with the first group of students in order to prepare to be the instructor for a second group expected to arrive before the end of the training for the first group. This professor was from India and interested in i3Dv technology. He attended classes along with the first group of students and also offered office hours for students. Not all members of the IAL staff believed it was important to have a member of the students’ nationality on the team.

Program Manager: There was an Indian professor on campus who taught computer science but had no idea what this organization was. So, somehow just because some other people got together and decided they would bring on a teacher who was Indian to work with the Indians because that would be so much better. The trouble came down to trying to train him. My opinion is that he wasn't as trainable as the students were. He was already had a $\mathrm{PhD}$. He was a faculty. 
[The Primary Instructor] didn’t want to stand there and tell him he wasn’t doing something right.

The Program Manager felt the Secondary Instructor's lack of experience in 3D domain created difficulties in transitioning him to instructor, and his cultural classification as faculty created problems in training him for the 3D domain.

The Secondary Instructor built rapport with students in both groups and most students found it easier to communicate with him than other members of the IAL team.

Student 1: [He] is native so it was easier to talk to him.

Student 4: He was very helpful in terms of giving his knowledge about how you have performed your work. If you need to improve anything, he was very helpful. Despite the fit in cultural communications, language, relations and ways, however, he was met with mixed reception as instructor of second group because of his lack of experience in the content area.

Director: The fact that [the Secondary Instructor] was observing the first group’s training and then turning around and teaching the second group, the second group perceived that as they were getting a substandard presentation...that [he] wasn’t as qualified as [the Primary Instructor]; therefore, their materials were not being presented as best we could.

Senior Project Manager: [The students] were concerned about [the Secondary Instructor's] understanding of the subject.

To place the students' reaction to the Secondary Instructor in context, it should be noted that most students expressed high expectations for the training program instructors. 
Student 9: After hearing the name of NASA, I thought there would be some highprofile teachers who had written a lot of research papers, and a lot of research background.

One student tied his opinion of the Secondary Instructor specifically to this expectation. Student 7: We expected that some NASA scientist will come and do classes, training, something like that, we thought. We thought that we would be completely submerged with NASA scientists. But actually it was that some institute... Not that much good. Our expectations when they say NASA is too much. But the quality of instruction we got is very inferior.

The students' cultural ideas about NASA led to a cultural misconception about what IAL would be and influenced their perceptions of the cultural expert and the quality of the training program.

Another member of the training program whose role served the purposes of a cultural expert was a member of the first group of students, appointed as a team lead by the client before the students arrived. Originally, two were appointed, but one team lead left within a few months of arriving. The team lead participated in interviewing and recruiting the first group of students.

Team Lead: Almost all of my team members are from top notch colleges of India. I have interviewed them personally, selected and build the team. The team lead communicated student issues with content to the Primary Instructor and was included in design team activities, such as brainstorming the major group projects, throughout the training program. 
Primary Instructor: I met with [the team lead] once a week...He would tell me briefly...what each student was like and how I would approach them...sometimes he would tell me that's too fast and that's too slow and that's too complex. I need to be more detailed in certain area than the other area. I need to spend more time with student in this.

The team lead also served as a liaison to communicate messages from the design team to the students.

Team Lead: [The Primary Instructor] is the point of contact for us to discuss about course quality and content. They always looked at me as a lead for my team, it might be regarding any complaints about the team or behavioral aspects of team or course structure.

However, one student in the first group expressed his feeling that the needs and concerns of the group were not effectively communicated to the design team.

Student 5: There was actually a bit of a problem. It was like we were dealing mostly with [the team leads] who were our managers at that time, and we communicated to them. The thing was we asked them to send our request to the higher management to know that the way they are teaching is not the best in the world and something has to be done... We did communicate that problem to the manager, and they were supposed to take that up with the higher management and up with the instructors...We are facing so many problems. I mean, a simple idea that could be conveyed within a month is taking five months... I did at least tell them regularly I am facing this problem in learning, even to my project managers. Within the group there is also in a sense the quality is not the best. Even when we 
discussed it together we forwarded the idea to manager people [the team leads]. I don't know this is the way it is established in the company, that you need to communicate it to the people above you.

This structure of communication was directed by NextGenEd, but also acknowledged as comfortable by some of the students because of cultural communications norms based on cultural classifications and cultural ways.

The communication structure through the team lead was clear to all members of the first group from the very beginning of the program; however, the second group was not clear about this team lead's role as their supervisor or their liaison to the design team and this created some communication problems for the second group.

Student 8: Because [the team lead] was training in the first batch, so we thought he's our colleague, when then, later on [after two, three months] we learned he's the person we need to talk to if we had any problems.

This excerpt shows an interruption to the structure established with the first group where students had a clear line of communication to the Primary Instructor about training related issues. The second group of students began to directly communicate frustrations or disappointments with the training program to NextGenEd in India.

Student 7: We informed to our management...the management in Atlanta; the management in Mumbai also.

Director: The second group was the group... that we started... to learn were making phone calls back and making allegations against...the teaching quality with [the Secondary Instructor] and what have you and we had no idea that that 
was going on. It really took us by surprise. [The team lead] didn’t know that the students were calling back to India... he was out of the loop.

This direct communication between the students and NextGenEd in India resulted in weekly conference calls between IAL and NextGenEd for India to monitor the training program.

Director: The weekly conference calls... started-we had some routine updates when the first group was here but I think they began in earnest when we started getting negative feedback from the second group.

About three months after the second group began communicating directly with India about their negative perceptions of the training program, all of the students were relocated back to India. At this point, the team lead's role as liaison between the IAL team and the students became integral to transitioning the training program to distance learning.

Director: On virtual training... we could rely on several of members of the first group to kind of augment our teaching team and they're physically in India...So that was something that we leveraged. And we didn't have to do it often but we did do it on occasion. When we would have maybe difficulty contacting one of the students from the second group who returned early we would go to [the team lead] from the first group and he would serve as a liaison... We would be trying to set up the conference call and the video and all that, I believe more often than not [the team lead] was in the room.

Data about the two members of the training program who served roles similar to that prescribed by the CBM framework for Cultural Expert reveal connections between 
multiple Elements of culture and how the cultural experts were received by the target audience and how they functioned as liaisons: cultural capital, cultural communications, cultural demographics, cultural language, cultural relations, cultural resources, cultural experiences, cultural ideas, cultural identity, cultural misconceptions and cultural ways.

Enlist educators: Cultural interaction with the design team members' experience as educators

Summary Result: Of the twenty-five elements of culture in the CBM model, twelve elements of culture were found to interact with design decisions, stakeholder perceptions and project outcomes related to the design team members’ experience as educators: cultural capital, cultural classification, cultural communications, cultural history, cultural language, cultural relations, cultural resources, cultural beliefs and values, cultural experiences, cultural identity, cultural interests, and cultural ways.

The CBM framework prescribes: "Educators with expertise in educating the target audience should be on the team” (Young, p.74, 2009). In this study, educators play a more direct role in interacting with students than intended in the CBM framework where they are expected to consult on the design of a product. In this case study, three members of the design team had formal past experience as educators in the classroom, the primary and Secondary Instructors and the i3Dv programmer. The Program Manager had informal past experience as an educator in training his team of i3Dv programmers at IAL. The Program Manager and Primary Instructor both had informal experience educating a similar target audience (Indian, computer science majors), and the Secondary Instructor 
was himself an Indian programmer whose experience as an educator of this target audience was not discovered in this study.

None of the members of the design team could be characterized as having expertise in educating the target audience. The Primary Instructor and i3Dv programmer had both served as GTAs at the undergraduate level for less than three years. The Primary Instructor had also acted as a peer mentor for 3D visualization in the original IAL training program.

Primary Instructor: When I got [to IAL] I just got my master's degree and then we have a batch of master's students, most of them were Indian, and I was not an expert then so we kind of work along together and at the same time I would have to give them advice...tips and tricks in handling computer in various platforms I was very good at it so I advised them on that thing...yes there were Indian students, but they were not here to be trained under me.

Though the Program Manager led the initial training that started the visualization program at IAL, he did not see himself as an educator.

Program Manager: I'm not an educator, I'm a person who believes that I'm going to tell it to you, get it or don't get it, we're going to keep on going.

However, he explained that he did believe an educator was needed for the team for the NextGenEd training program.

Program Manager: I said...we're going to have to get somebody to teach this course who is actually an educator. Someone who's been through it, understands... we should call [the Primary Instructor]. 
As revealed in above and later findings, several of the design decisions in this training program derive from this cultural experience and cultural history at IAL.

The students’ perceptions of the Primary Instructor as an educator were mixed and most often tied to content rather than her experience as an educator.

Student 3: [The Primary Instructor] had more knowledge of the topic, so she could clear our doubts.

One student expressed his perception of her as inexperienced as an educator.

Student 2: I thought that [the Primary Instructor] had less experience in teaching. This same student, Student 2, expressed satisfaction with her teaching style, but dissatisfaction with her level of expertise on the subject matter. When students did express dissatisfaction with the Primary Instructor's style of teaching, some compared to their past cultural experience and cultural ideas of what teaching should be.

Student 7: In IIT the process is like Hitler's. Yes, like Hitler! Yeah... Process is like Hitler! See, everything is in their hands, right? But while giving the lecture they used to give very quality material... They will give you the exact point, the crux point... That is a good way of teaching.

As described above in the section on Cultural Expert, the second group of students found the Secondary Instructor lacking in subject matter expertise, but a few of the students preferred his instructional style.

Student 5: I found that [the Secondary Instructor] was very good in giving feedback. He used to tell whatever we were doing wrong, whatever we were doing right... So [the Secondary Instructor] used to take a look at all our applications and he used to...See this guy is doing this, this guy is doing that. 
Maybe you could have done it this way, that would have been better. That comparison was helpful. Also he used to point out well what we were doing wrong. He is a Professor in computer science...Of course he is expected to do well.

There was some overlap in the coded references between students' perceptions of the Secondary Instructor as an educator and their perceptions of ease in communicating with him as an Indian.

Student 6: Because [he] is from India... The way he spoke and explanation things. It was easier to understand for us.

The data excerpted here under the Enlist Educators directive in the Team component of the CBM framework shows a dynamic relationship between decisions about this directive, stakeholders' perceptions of the training program and Elements of cultural communications, cultural classifications, cultural experiences, cultural history, cultural relations and cultural language.

\section{Culturally informed team: Cultural interaction with the design team members'} experience with the cultures of the students

Summary Result: Of the twenty-five elements of culture in the CBM model, twelve elements of culture were found to interact with design decisions, stakeholder perceptions and project outcomes related to the design team members' experience with the cultures of the students: cultural aesthetics, cultural capital, cultural classification, cultural communications, cultural environment, 
cultural knowledge, cultural relations, cultural resources, cultural experiences, cultural interests, cultural ways, and cultural futures.

According to the CBM framework, the "culturally informed team” should be trained "in the cultural elements of the target audience, derived from the CBM elements” (Young, p.75, 2009). In this case study, the IAL team participated in planned activities that informed the team about the culture of the target audience. Some activities were intentionally designed for the purpose of familiarizing the team with Indian culture: a slideshow presentation on India to the IAL team, an introduction session with students, and a culture sharing day. Other activities were incidental: the Director and the Primary Instructor each visited India, separately.

The Director of IAL visited India before the training program began and shared a slideshow on his trip with the IAL team.

I3Dv programmer: [The Director] brought back a slide show from when he went to India. That was informative... he just sort of talked about his trip and he went to several different celebrations. I forget what they were called, but he sort of outlined what goes on at the celebrations and the different dances and things like that and they went to several different markets and how the bartering system worked, and it was really cool. And the driving just sort of raised my blood pressure up above 50 points.

When each group of students arrived, the IAL team held an introductory session where all members of the IAL team and all of the students pointed to where they were from on a map and told a bit about themselves. 
Director: So we would go around and have everyone introduce themselves and we had a map of India and a map of the Unites States so they could see where we came from and we could see where in India they were from and they were scattered from all over the country. Both groups were pretty diverse geographically.

Primary Instructor: Cause we wouldn't know what does it mean if you come from the north or south or east or west, but at the beginning of the class, we let them introduce themselves... they'd share about where they were, the type of food, that sort of thing, like we were clueless that they were very different people, clueless.

During the training program, for each group, they had a day where they all wore their native dress.

Director: We had a day where they all wore their-day or two where [the Primary Instructor] wore some native Thai clothing and they came in and they wore their saris... let's-let's get a sense of their nationalism, let us learn from them like they're learning from us and through their experience. And I think that was-I think that was really a good thing to do.

These planned activities reveal the team was informed about the target audience related to Elements of: cultural aesthetics, cultural artifacts, cultural capital, cultural environment, cultural experiences, cultural interests, cultural ways and cultural infinities.

The Director and the Primary Instructor both traveled to India. The Director’s trip, which took place before the training program began, was for the purposes of finalizing the agreement with NextGenEd and to promote the program and its outcomes to potential 
clients. Though the visit was not for the purpose of cultural awareness, the Director learned a lot about the culture from the trip.

Director: They're all from India...so they're all going to be the same. Well that's so wrong. I mean there's a billion people in India, it's a huge country, and they're vastly different...And that's what-I learned that. To assume that just because they're all from India that they'd all be the same, have the same habits, have the same ideas, speak the same languages, even have the same religions, dress the same-no. Their differences are, I think, even magnified more than the cultural differences we see within the United States...like the dress, for instance...I mean the regional dress, I mean you go to LAX, and you go to JFK, or you go to O’Hare, you're going to see people basically wearing the same stuff. But you go to Delhi compared to Mumbai, and it's not going to be the same, it's going to be much different...the other thing about just the Indian culture...that I took out of... the visit was the stark contrast between the people-the rich and the poor. In this excerpt, the Director describes several Elements of culture that he was exposed to on this visit: cultural aesthetics, cultural artifacts, cultural capital, cultural classification, cultural environment, cultural language, cultural experiences, cultural interests and cultural ways.

The purpose of the Primary Instructor's visit was to collaborate with university professors in India for potential revenue generating projects for NextGenEd.

Primary Instructor: So I went to India...It was at the beginning of the second group...I snuck out and walk around and you know I noticed that people don't speak English...they have maids which we don't, so at the company, you know, there will be 
a guy who serves me tea and cookie and bring me sandwiches and he would also serve other people too and even that manager guy, he has his own driver and this driver is like a permanent position because when he doesn't need to drive he stay with the car...I went to that manager's home...his wife cooked everything from scratch including roti, and it was good and it was vegetarian...The wife said she shop every day at the local market...And everything was fresh...I saw different classes of people, because I saw the drivers and I saw the group of taxi driver or auto driver and then there's high lows at the manager level, so I know that the students must have come from different backgrounds, and I didn’t feel appropriate to ask...assuming that I shouldn't treat them any different than anyone....and so that kind of subsided to not really in my thinking, because really, it might be too personal, so if they didn't—it didn’t affect my acting to them.

In this excerpt, the Primary Instructor describes several Elements of culture that she was exposed to on this visit: cultural aesthetics, cultural artifacts, cultural capital, cultural classification, cultural demographics, cultural environment, cultural language, cultural relations, cultural resources, cultural experiences, cultural interests and cultural ways. All of the students interviewed described their perceptions of the design team as welcoming and accommodating for any cultural adjustments.

\section{Cultural Element Interactions with Team}

The above findings highlight, through excerpts, where multiple cultural elements interact with decision-making, perceptions and outcomes of Team components in the instructional design process. Table 12 provides a visual display of where Elements of 
culture were coded along with components of Team to reveal frequency and breadth of cultural interactions with these design factors.

Table 12

Cultural Interaction Matrix: Team

\begin{tabular}{|c|c|c|c|}
\hline & Cultural expert & $\begin{array}{c}\text { Enlist } \\
\text { educators }\end{array}$ & $\begin{array}{l}\text { Culturally informed } \\
\text { team }\end{array}$ \\
\hline Cultural aesthetics & & & + \\
\hline Cultural capital & + & - & - \\
\hline Cultural classification & + & + & + \\
\hline Cultural communications & + & + & - \\
\hline Cultural demographics & - & & \\
\hline Cultural environment & + & & + \\
\hline Cultural history & & + & \\
\hline Cultural knowledge & - & & - \\
\hline Cultural language & + & + & \\
\hline Cultural relations & + & + & - \\
\hline Cultural resources & + & + & + \\
\hline Cultural beliefs and values & + & - & \\
\hline Cultural experiences & + & + & + \\
\hline Cultural identity & & - & \\
\hline Cultural interests & - & - & + \\
\hline Cultural misconceptions & + & & \\
\hline Cultural ways & + & + & + \\
\hline Cultural anomalies & - & & \\
\hline Cultural futures & - & & - \\
\hline
\end{tabular}

- One overlapping coded reference

+ More than one overlapping coded reference 


\section{Cultural interactions with assessing student learning}

In the Culture-Based Model (CBM) framework, the Assessments component is categorized as an area of project management. This component provides design factors to guide assessment of student learning, evaluating the effectiveness of the product and to create culture-specific assessment (Young, 2009). Under the component of Assessments, there are four design factors: 1) multiple evaluation options; 2) assess the assessment; 3) external review and 4) culture-specific assessments. Table 13 shows the function of each design factor. In this research, these factors are explored in a training program that did not prepare formal assessments or design in the product context, so most aspects do not apply. In order to address the Assessments component, the findings below reflect what assessment methods were used in this training program and how some were intended to account for culture; where the connection between these methods and program outcomes are related; what stakeholder perceptions were expressed about these methods and program outcomes; and where these methods, stakeholder perceptions and program outcomes interact with or are related to cultural Elements.

Table 13

Assessment Design Factors of CBM

Factor Description

Multiple Evaluation Options $\quad$ Provide internal and external evaluation opportunities.

Assess the assessment Evaluate the evaluation tools.

External Review Implement other evaluations of the product.

Culture-specific assessments Create specialized evaluations. 
Adapted from Young (2009) p. 76

Multiple Evaluation Options: Cultural Interaction with the variety of methods used to assess student learning

Summary Result: Of the twenty-five elements of culture in the CBM model, ten elements of culture were found to interact with design decisions, stakeholder perceptions and project outcomes related to the variety of methods used to assess student learning: cultural classification, cultural communications, cultural environment, cultural knowledge, cultural language, cultural relations, cultural resources, cultural experiences, cultural interests, and cultural ways.

The IAL team assessed student work through weekly assignments, weekly reports, individual projects and group projects. All products submitted for assessment were application programming, and the criteria for all products was pass or fail, it works or it does not.

Director: We talked a lot about an exam. But actually the applications that were presented to them in the second half of the course was their - that was their exam if you will. [The Program Manager] and company could tell clearly those students that were understanding the material...So there were no formal exams given.

Program Manager: It's pass fail, there is no you kind of... it has to do exactly what I asked them...I wanted them to understand this is real world, there is no C, there is no B, it either works the way I asked for it...Or it doesn't. It’s just you can do it or not...It runs or it doesn't. 
There were no formal scores given to students, but rankings of the students were provided to NextGenEd.

Senior Project Manager: Somewhere into about halfway through the 1st batch program, which is about when the 2nd batch arrived, I started asking [the Primary Instructor] to provide evaluations of the students so that we could identify the skills and capabilities of each of the students.

Director: We did provide NextGenEd for both groups at least once and if not, twice, our feedback as to you know who were the top third, who were the middle third and who were the bottom third of the students and why. And that was submitted to NextGenEd in writing. And through observation and interaction in the classroom and individually [the IAL team] were able to put all their observations together to come up with this composite, snapshot of you know the achievements of the class because not everybody was number one.

Because of the attention to the capabilities of the NextGenEd team, the client's request was coded as cultural futures. In providing rankings of the students to NextGenEd and not the students themselves, the IAL team shows attention to Elements of cultural capital, cultural classifications, cultural communications and cultural ways.

The students were given verbal feedback on their weekly assignments and reports in weekly feedback sessions; later, when the students returned to India they were given feedback through e-mail and videoconferencing.

Director: [The Program Manager] would go around to every workstation and say, "Okay, show me what you've done, tell me what your problems are." ... not only [the Program Manager] but [the i3Dv programmer] and [the Primary Instructor] 
would all three go to each student individually and also require the student to submit in writing the status of their project and any difficulties they would have had encountered...So we got good documentation of where the students thought they were and then we were able to literally go and look over their shoulder and see where they really were and compare the two and work with them to overcome the challenges.

I3Dv programmer: [The Primary Instructor] would assign individual assignments and once those came up due... we would all take a day and walk around the room and see how they're progressing, and I was sort of, I guess, the, I’m not, but I was sort of labeled as the sort of guru who sort of went around and said hey, you might want to change your blending or just sort of eyeball it and see if they were on the right track... offer suggestions, that kind of thing.

Primary Instructor: Every week [we] would walk around and see their program and assign them passing grades. We were there and we talked to them, they talked to us and I take note, you know like a check mark...If they pass, if they didn’t pass... Continue working until they get it...it had to be done before the next, the due date of the next assignment, and if they can't get it done, they just have to move on...And do their best to-to start the new assignment, which sometimes wasn't based on the previous one, which they can start a new program. So they have to learn, you know, to deal with failure.

The students use their cultural language to label one assessor as the guru. The design team relies on cultural experience to form assessment habits. 
Culture Specific Assessments: Cultural interaction with assessments designed with the students' cultures in mind

Summary Result: Of the twenty-five elements of culture in the CBM model, five elements of culture were found to interact with design decisions, stakeholder perceptions and project outcomes related to assessments designed with the students' cultures in mind: cultural classification, cultural communications, cultural language, cultural experiences, and cultural interests.

During feedback sessions, the IAL team used strategies that were related to culture to overcome spoken communication problems.

Program Manager: Well, that's why I always ask for something written. So I can kind of read it and kind of get a gist of what they're going to talk about...And then try to relate it to what they're saying...I'd ask-I'd say...I can't understand what you're saying. Try to explain it differently, or let's get a piece of paper, can you draw it out and talk to me. It's a stress for them and for me both...Yeah, because... the idea is not to embarrass them or anything else...It's just to get the information and to keep moving on. And sometimes one of the other Indian students would help say things clearer.

In this excerpt, the findings show where the Element of cultural language interacts with strategies used in asking for the weekly reports and holding the weekly feedback sessions.

Some students expressed satisfaction with the feedback methods.

Student 2: [No grades]...it was professional training...so there everything whether you're ready or not... whether you learned the concept or not. So if yes, check. If 
not, we need to put more time into this until it gets checked...One time [the Primary Instructor] said you can do this better than this. And it was effective. Student 7: Good way of evaluation. Based on our assignments they used to call us and they used to discuss where we were lacking.

Student 8: It was fine, because you got to know... they are looking at your assignment right there, and they are giving you feedback right there-- so you can also see, yeah, ok, I need to do something here.

Other students did not see these sessions as providing enough feedback about the quality of their work and wanted more feedback in the form of rankings.

Student 1: Actually there wasn't any feedback... there wasn't any feedback. That bothered me a lot because I expected some feedback on what I did. First and foremost how I did, and secondly would be how competitively I did with other people in the group, because there were some people who were really smart and I would definitely like to check my level where am I at after a month of intense training with the class working.

Student 3: Assessments were there...and given remarks. That was not disclosed to us but to our superiors here I think...Yeah, to people who were our superiors here....Not on some scale...it would have been better...It helps...Coming from the same background, It always helps to know exactly how I am standing so that I can improve more in my knowledge... along with the reason why I was given that remark.

Student 4: If a chapter is completed an assignment was given, there was a deadline for it, and we used to submit the assignment before the deadline... If you 
have done a mistake or there could be some improvement, that was informed by the instructor. This was the assessment. There was no overall assessment done. There wasn't any grade associated with each and every student so that at least they could measure among themselves who was better and how the average student can learn to become the best one.

The students' desire for normed evaluations and rankings were found to interact with Elements of cultural classifications, cultural interests and cultural ways.

\section{Cultural Element Interactions with Assessment}

The above findings highlight, through excerpts, where multiple cultural elements interact with decision-making, perceptions and outcomes of Assessment components in the instructional design process. Table 14 provides a visual display of where Elements of culture were coded along with components of Assessment to reveal frequency and breadth of cultural interactions with these design factors. 
Table 14

Cultural Interaction Matrix: Assessment

\begin{tabular}{lcc} 
& Assessment & $\begin{array}{c}\text { Culture-specific } \\
\text { assessment }\end{array}$ \\
\hline Cultural classification & + & - \\
Cultural communications & + & + \\
Cultural environment & - & + \\
Cultural knowledge & - & \\
Cultural language & - & + \\
Cultural relations & + & - \\
Cultural resources & - & \\
Cultural experiences & + & \\
Cultural interests & + & \\
Cultural ways & - & \\
\hline
\end{tabular}

- One overlapping coded reference

+ More than one overlapping coded reference

\section{Cultural interaction with financial support and affordability, involvement of stakeholders, consideration of cultural context and learning goals of the training program}

In the Culture-Based Model (CBM) framework, the Brainstorming component is categorized as an area of project management (Young, 2009). Ten design factors provide guidance during the pre-production period to conceptualize the entire project: 1) financial support; 2) pilot studies/field tests; 3) assess community's response; 4) community representative on team; 5) investigate target audience to authenticate product; 6) reflect and asses learning goals; 7) affordable design; 8) meet needs of target audience; 9) discuss and consider cultural context; and 10) present and consider outcomes. Table 15 
shows the expanded directives of each design factor. In this research, these design factors are explored as factors in a training program rather than a product, so a pre-production period is not clearly identifiable and some directives do not apply or are slightly modified for this context. The findings below relate to activities prior to the start or in the early stages of the training program and reflect where decisions were made that address or fail to address the questions of the Brainstorming component of CBM; where the connection between these decisions and program outcomes are related; what stakeholder perceptions were expressed about these decisions and program outcomes; and where these decisions, stakeholder perceptions and program outcomes interact with or are related to cultural Elements. 
Table 15

Brainstorming Design Factors of CBM

Factor Description

Financial Support

Pilot studies/Field tests of

Product

Assess community's response

Community Representative on

Team

Investigate audience to

authenticate product

Reflect and assess learning goals

Affordable design

Meet needs of target audience

Discuss and consider cultural context

Present and consider outcomes
Obtain comprehensive funding for the project

Engage in assessments throughout the project

Get the public's response to the product

The community representative is a person versed in the cultural nuances of the target audience, and they have been designated as an integral part of the team

Provide the team with an ethnographic portrait of the target audience

Engage in ongoing reflections and assessments of the product

Provide an affordable design ICTs that are financially accessible to the target audience

Determine how the product meets the instructional and/or cultural needs of the target audience

Discuss and consider historical, social, political, economic and educational reasons for implementing the project

Throughout the design process, present and consider outcomes or the user goals

Adapted from Young (2009)

Financial support: Cultural interaction with funding of the training program

Summary Result: Of the twenty-five elements of culture in the CBM model, eighteen elements of culture were found to interact with design decisions, stakeholder perceptions and project outcomes related to the funding of the training program: cultural artifacts, cultural capital, cultural classification, cultural 
communications, cultural environment, cultural knowledge, cultural language, cultural relations, cultural resources, cultural beliefs and values, cultural experiences, cultural ideas, cultural identity, cultural interests, cultural ways, cultural anomalies, cultural futures, and cultural infinities.

This feature of the Brainstorming component is a directive to "obtain comprehensive funding for the project” (Young, p.80, 2009). In this study, findings related to the agreement between NextGenEd and IAL for funding this training program are presented. The funding for this training program was initiated in a memorandum of understanding between NextGenEd and IAL and later formalized in a contract. The specifics of the financial agreement are withheld at the request of NextGenEd. However, general information about the funding was provided by the NextGenEd representative. Senior Project Manager: The project was funded through a direct injection of cash from the Indian parent company. The funding was based on initial budget estimates developed in my business plan as well as calculations of the Indian finance team of how much money would be invested in this effort initially. As new program requirements were discovered such as the need for more computers, laptops and software, additional dollars were applied to the project to fund such needs. The conversation about project finances and justification of expenses were primarily held with India by [the President of US Operations]. I joined these discussions on occasion but often only as a silent participant unless I had to explain the technical nature of a requirement. The total cost expended on the training alone is difficult to address because the cost of the training was blurred by the cost of the 3D initiative at the company. 
The original training program agreement was meant to include development of products for potential clients of NextGenEd. In the last stage of the curriculum, the real-time, real world projects were supposed to be these products for clients. The lines between whose responsibility it was to find these projects became somewhat blurred. While on his visit to India, the Director understood his role to be increasing buy-in for the project by attracting potential investors.

Director: It was a big marketing tour for me, I mean, that was the goal was to get people to sign up to commit to this.

In the Primary Instructor's visit to India, she was asked to meet with university professors about potential projects: to demonstrate how i3Dv could be used for educational purposes in their domains and to collaborate with them on gathering the right data sets to include their project ideas in the students' final projects. She also expressed this feeling about the purpose of the visit:

Primary Instructor: For the professor to try to tell him exactly what we do and what he can get, what they will do to his university project... the main goal, try to make a sale, try to convince them that this is needed.

The meeting referred to in this excerpt was with a professor in India about creating an earthquake simulation, as detailed later in the findings this project went forward and a product was created.

The source of funding for this project also results in doubling the roles of the students: they were both students and employees. Decisions about training often presented a design challenge for IAL in meeting NextGenEd's needs or the student's needs. This factor is detailed in later findings in the "Meet needs of target audience" 
section of the Brainstorming component. In general, funding issues influenced the IAL team's design decisions about equipment and duration of the training program. As presented in the Genre section of the Inquiry component and the Effective Technology and Diversify ICT format sections of the Development component, state-of-the-art equipment was provided by NextGenEd funding throughout the training program. As discussed in the Framing section on Inquiry and Design specifications section of Development components, NextGenEd requested a compressed timeline, and the IAL team continually negotiated for more time according to perceived needs of the target audience. Budget concerns, a desire to reduce expenses of housing and supporting students in the US, influenced the request for a compressed timeline. Findings about the relationship between financial support and the relocation of students to India are presented in the later section Affordable Design.

The source and purpose of the funding for this program, creates an interaction between the company's business goals and the IAL team's training program goals that interact with multiple Elements of culture: cultural capital, cultural classification, cultural communications, cultural relations, cultural resources, cultural experiences, cultural identity, cultural interests, cultural ways and cultural anomalies.

Pilot studies/field tests: Cultural interaction with the design team's revision process after introducing training program to stakeholders

Summary Result: Of the twenty-five elements of culture in the CBM model, thirteen elements of culture were found to interact with design decisions, stakeholder perceptions and project outcomes related to the design team's revision 
process after introducing training program to stakeholders: cultural capital, cultural classification, cultural communications, cultural environment, cultural knowledge, cultural relations, cultural experiences, cultural ideas, cultural interests, cultural misconceptions, cultural ways, cultural futures, and cultural infinities.

This feature of the Brainstorming component prompts the design team to conduct preliminary evaluations so “designs are monitored, manipulated, adjusted or discarded if necessary” (Young, p.80, 2009). In this case, the IAL team did not conduct any formal pilot studies or field tests; however, findings related to revisions to the training program after initial introduction to each group of students are presented. The IAL team engages in revisions to the design of the training program throughout the duration of the contract: 1) to change the pace in balancing the needs of NextGenEd and the students; 2) to adjust content for the second group of primarily engineers rather than computer scientists and 3) to adapt the program for distance learning.

The Primary Instructor describes how the first group acts as a type of pilot study for the materials.

Primary Instructor: The first batch was really a trial and error process, and I went through the up-and-down motion with them; it was interesting. So, as I prepare the material, I have to go back and make changes. Sometime I went forward then backward and then expand and then went forward. So, just have to try to see where they were really and how much or how fast I could teach them, at the same time keep in mind that the time was given to me was so tight.

She also describes needing to revise the materials for the second group. 
Primary Instructor: I did reuse them, and I had to also edit them also since the first batch are different than the second batch...then I have to constantly be changing for the second group to match their needs because the second group students were not programmers. They were engineers.

No students commented on materials as related to their status as engineers or programmers. Findings about design decisions and stakeholder perceptions related to changes in pace and adjustments to the program for distance learning are presented in the Genre and Framing sections of the Inquiry component. These findings were related to the following Elements of culture: cultural capital, cultural classification, cultural communications, cultural environment, cultural knowledge, cultural relations, cultural experiences, cultural ideas, cultural interests, cultural misconceptions, cultural ways, cultural futures and cultural infinities.

Assess community's response: Cultural interaction with the design team's opportunities to get feedback from stakeholders

Summary Result: Of the twenty-five elements of culture in the CBM model, ten elements of culture were found to interact with design decisions, stakeholder perceptions and project outcomes related to the design team's opportunities to get feedback from stakeholders: cultural capital, cultural classification, cultural communications, cultural environment, cultural knowledge, cultural relations, cultural beliefs and values, cultural experiences, cultural misconceptions, and cultural ways. 
This feature of the Brainstorming component is a directive to include stakeholders, including the target audience, in assessment activities during pre-production (Young, 2009). In this study, findings related to assessing the community's response prior to the start or in the early stages of the training program are presented. The IAL team included multiple opportunities to assess the students' responses early in the training program and throughout: encouraging one-on-one and group meetings with students and involving a student team lead as a liaison.

Director: I would go in and you know talk to them and you know just to see if there were problems. Now I did it religiously I would say for about the first six weeks that each group was here. And then I would sit in on the classes, basically for - number one, I wanted to see how things were between the instructor and the students and make sure there were no problems and no issues.

Primary Instructor: When they were working...It is my job to make sure that... they were okay so I had to walk the room, asking them.

Primary Instructor: The first draft of the PowerPoint was coming from my own experience then talking to the leader, and sometime we had the group meeting, then I had the input from the students, and then inputs were used to expand the outline of the PowerPoint I created earlier.

The IAL team's methods for assessing community response derived from IAL cultural experience and related to cultural classification and cultural communications.

The team lead felt that the IAL team was open to student requests and accommodating. 
Team Lead: I always went to [the Primary Instructor] about training structure or doubts or quality of training... she is very approachable and takes appropriate quick action.

Some student responses indicated a feeling that the design team welcomed student feedback and was always responsive to specific requests, but found it difficult to express needs directly to the design team.

Student 5: To [the Primary Instructor] I never mentioned that I am facing ...actually the problem was I couldn't be probably direct with her. Regularly I was communicating with [the team leads] about what the quality is of the training...To [the Primary Instructor] all I could do was, "I am facing this problem, can you give me a solution?”

Students also felt that requests about the training should be group determined.

Student 2: Everything we did for what we went to them we first discussed it among ourselves...We made sure that everyone knows about this...It affected the whole team. So that was a collective decision.

Student 4: [letting the Primary Instructor know that the students wanted to slow down] We did have a discussion with [the Primary Instructor]...All of us together. The client representative felt that NextGenEd's responses to curriculum changes were not sought often enough.

Senior Project Manager: In my recollection, the training team tended not to communicate with me too much about the training itself. Reviewing my emails from them, I received no more than 20 emails related to the content of the curriculum and the topics covered each week. What this meant was that despite 
the conference calls and in-person meetings, most of the decisions made with regard to the training, something I realized only much later in the program, were made by the training team based on their areas of expertise rather than what the companies needs were as far as what the end result needed to be.

Stakeholder perceptions of the methods for assessing community response are related to cultural capital, cultural classification, cultural communications, cultural experiences, cultural knowledge, cultural relations, cultural ways and cultural futures.

Community representative on team: Cultural interactions with the involvement of stakeholders on the design team

This feature of the Brainstorming component directs design teams to include " a person versed in the cultural nuances of the target audience... as an integral part of the team” (Young, p. 81, 2009). In this study, the team lead is considered the community representative on the IAL team. Young explains that "The community representative and the cultural expert can be the same person.” (Young, 2009, p. 74). Findings related to the team lead's role as cultural expert are presented in the Cultural Expert section of the Team component and related to the following Elements of culture: cultural communications, cultural demographics, cultural language, cultural relations, cultural resources, cultural experiences, cultural ideas, cultural identity, cultural misconceptions and cultural ways. 
Investigate target audience to authenticate product: Cultural interaction with the design team's efforts to learn about the students' culture and accommodate discoveries in the design of the training program

Summary Result: Of the twenty-five elements of culture in the CBM model, nine elements of culture were found to interact with design decisions, stakeholder perceptions and project outcomes related to the design team's efforts to learn about the students' culture and accommodate discoveries in the design of the training program: cultural classification, cultural communications, cultural demographics, cultural history, cultural knowledge, cultural relations, cultural resources, cultural experiences, and cultural identity.

This feature of the Brainstorming component provides guidance to create an “ethnographic portrait of the target audience” before production in order to inform culturally authentic choices for the target audience during the design process (Young, p. 83, 2009). In this study, findings related to the IAL team's efforts to investigate the target audience before and in the early stages of the training program and related choices are considered. As discussed in the "Understand Target Audience” and "Explore environmental and individual/group cultures” of the Development component and the Culturally-informed Team section of the Team component, the IAl team participated in activities that allowed the team to investigate the target audience. However, the IAL team's expressed views on design choices resist acknowledgement of any ethnographic information.

Primary Instructor: My first approach was not really to concentrate on their culture but concentrated on the material itself. 
Also, as excerpted above in the Understand Target Audience section of the Development component, the IAL team felt that the training program is intended for an advanced audience of programmers; the audience should be chosen for the program, the program would not be tailored to the audience. As shown in that section, the Primary Instructor lists the extent of her investigation of the target audience to include profession, education, age and experience.

However, findings in the Assessments section and later findings in the Learners section show that the IAL team does make some accommodations to the training program that are attributed to investigations of the culture. Findings on this topic in previous sections and findings here are related to the following elements of Culture: cultural aesthetics, cultural artifacts, cultural capital, cultural classification, cultural demographics, cultural environment, cultural language, cultural relations, cultural resources, cultural experiences, cultural interests, cultural ways, cultural infinities and cultural futures.

Student 3's perception that the training program was not advanced enough, as described above in the Inquiry component, was attributed to the IAL team's lack of investigation of their students' levels.

Student 3: First of all I'd like to know whom I'm teaching...What kind of situation are they expecting, at what pace, at what level? Then only design the course. And you need to know if you are giving a particular thing, a particular subject into your teaching in U.S. Suppose then you need to know in the U.S. It is important because this is not what we're going to get in India...So... you need to report on those topics. 
This student's perception is related to: cultural classification, cultural knowledge, cultural identity and cultural infinities.

Reflect and assess learning goals: Cultural interaction with the design team and stakeholders' characterization of the learning goals of the training program

Summary Result: Of the twenty-five elements of culture in the CBM model, nine elements of culture were found to interact with design decisions, stakeholder perceptions and project outcomes related to the design team and stakeholders’ characterization of the learning goals of the training program: cultural capital, cultural communications, cultural history, cultural knowledge, cultural language, cultural resources, cultural experiences, cultural interests, and cultural futures. This feature of the Brainstorming component reminds designers to stay focused on learning objectives and how they will be met (Young, 2009). In this study, findings related to the learning goals of the training program and to the goals of NextGenEd are considered. Throughout the training program, the IAL team never felt that NextGenEd provided clear direction for the products expected at the end of the training program, and this perceived lack of clarity influenced the Primary Instructor’s decisions about content.

Primary Instructor: That was the question we asked NextGen Ed, too, about what do they actually want. And they were talking about having a marketing department themselves, looking for clients, so originally, at the beginning, we didn't know what they want. So, I would teach the students base this on what we used and work at IAL, but keep in mind also that NextGen Ed is a business corporation, so the need's gonna be different. I also have to incorporate that into 
the teaching that what NextGen Ed might be working on or wanting the student to work on might be something totally different than what we do here.

The Primary Instructor's reflection on the learning goals of the training program in association with the goals of NextGenEd show consideration of IAL's cultural knowledge and cultural experience being balanced with a lack of access to a NextGenEd cultural resource, a marketing department, and cultural identity, cultural interests and cultural futures of NextGenEd as a business corporation.

The client representative believed the learning goals of the training program should support company goals of bringing 3D CAVE technology to education market in India. Senior Project Manager: The learning goals were in large part directed by the training team due to the fact that the company itself did not know much about what needed to be taught in order for students to be able to build the kinds of solutions we expected to build. In other words, we informed the IAL team that we wanted to be able to build a virtual chemistry lab or a solar system application and asked that they build their training program around those needs. As the students entered the "practicals” phase of their training, those training goals were applied to the development of solutions that matched those needs.

The client representative’s quote shows interactions between learning goals and cultural experiences, the IAL team’s lead role, and cultural interests and futures, what NextGenEd intended to build.

In addition to the learning goals on the content topics, OpenGL and CAVE programming proficiency that are detailed in Inquiry component section above, the IAL team set the prototyping process as a learning goal to work towards NextGenEd's goals. 
Program Manager: We started asking them questions and the students were doing that back and forth. How do you ask questions... get anything you can and produce something to give to them, so they'd look at and go, no that's not what I want or I want-that's nice but I need to have this and this and this. So to me it's always a building project...That's how we do all our work...if you ask me to do something for you, I cannot envision what you really want if I don’t first give you something...And you look at it and then go well that's not what I want-I want this...So you get that interactivity going and we do everything I do here like that, systematic, a super prototype...Now that they go well we want this and this and we go add those two things, and then when we hear them talk, you can interpret, well maybe they'll like this, you add a few more things...And we go back and forth and it's a back and forth project to figure it out. [The students] understand the give and take. You explain to me where you're going, I explain to you where I want you to go...They come up with a new idea and we come up with an idea and that's the way it works. It works back and forth and to me, that's where they were gaining most of their experience. Visualization is not hard.

The Program Manager's cultural experience at IAL influences his belief that the prototyping process is an important learning goal in the training program. As noted in the Inquiry component section on OpenGL and CAVE programming proficiency, decisions and perceptions of these learning goals were related to Elements of: cultural capital, cultural resources, cultural knowledge, cultural resources, cultural ideas and cultural futures. 
Affordable design: Cultural interaction with the clients' ability to afford the training program as designed

Summary Result: Of the twenty-five elements of culture in the CBM model, eleven elements of culture were found to interact with design decisions, stakeholder perceptions and project outcomes related to the clients' ability to afford the training program as designed: cultural capital, cultural classification, cultural communications, cultural history, cultural resources, cultural beliefs and values, cultural experiences, cultural identity, cultural ways, cultural futures, and cultural infinities.

This feature of the Brainstorming component provides guidelines for considering whether an instructional product is financially accessible to the target audience. In this study, where the training program is fully financed by the client and no product is created, findings related to the affordability of the design for the client are considered.

As discussed in the above section Financial Support of the Brainstorming component, the stability of the eighteen months of funding to be paid directly to IAL was guaranteed in the contract. However, funding to support and house the students while overseas was not. To continue funding the students' presence in the US required full commitment from decision makers in India. The Director sensed from his visit to India in the initial stages of the training program that not all stakeholders at NextGenEd were fully committed to the project.

Director: Well, board members and/or the owner's inner circle. I mean the people that were working in those offices right next to the owner...so the owner was very interested in [the i3Dv project]. But then these guys would come back 
in and they'd start haggling and I got the impression that...this was not a united team, here, there was some dissension...I sensed that there was some people that just were not buying it at least yet.

Eventually, the funding to house and support students in India was pulled.

Director: Now the second batch... are just about completed with their first half of the training and we get a call from India saying, "Oh, we want to bring those guys back." And our reaction was, "Well, they're not done..." And the answer we got from India was that, "We want 'em back now." And we were just like, "Alright, fine, do you want us to finish the training?" And they said, "Well, yes, we do." So that's when we set out to find different ways to go with the training.

As detailed in the Framing section of the Inquiry component, the IAL team was forced to make the design of the training more affordable by removing the need for expenses of housing and supporting Indian students in the US. Distance learning tools were leveraged in the design of the remainder of the training and influenced design decisions and student's perceptions of the training. As detailed above, this change in funding and the outcomes from this change were found to interact with the following Elements of culture: cultural capital, cultural relations, cultural resources, cultural beliefs and values, cultural ideas, cultural interests, cultural ways and cultural futures.

Student perceptions of the timeline and equipment decisions are provided in the Genre and Framing sections of the Inquiry component. Student perceptions of other funding related issues reveal appreciation for the opportunity and level of support while in the US, and frustration and disappointment at the relocation back to India. 
Student 3: They gave us 10 days lead time to come back. So we had to just pack and come back. We did not have a say in this. We cannot say anything. We had a very long telephonic meeting on this. They said, “Come back here, we'll manage it here.”

Some findings also show that the students' perceptions of the quality of the training are attributed to the relocation.

Student 3: Compared to what we get here in college, I do not think it was rigorous enough. We were cut short in our training three or four months.

The students' perceptions of issues related to the affordability of the design interact with the following Elements of culture: cultural capital, cultural classification, cultural communications, cultural relations, cultural resources, cultural experiences, cultural identity, cultural infinities and cultural futures.

The client representative's perception of the affordability of the design is tied to the value of the investment.

Senior Project Manager: The company does consider that the students who are still with the company to be great assets and continues to leverage their capabilities. However, in retrospect, the program was too expensive and overly ambitious given that we didn't know too much about the technology and application of this technology... to my knowledge, no revenue source has been tapped as a result of this training.

The client representative's perception of funding related issues overlaps with multiple Elements of culture: cultural artifacts, cultural capital, cultural knowledge, cultural resources, cultural ideas, cultural interests and cultural futures. 
Meet needs of target audience: Cultural interaction with efforts of the design team to balance the goals of the client with the needs of the students

Summary Result: Of the twenty-five elements of culture in the CBM model, thirteen elements of culture were found to interact with design decisions, stakeholder perceptions and project outcomes related to efforts of the design team to balance the goals of the client with the needs of the students: cultural capital, cultural classification, cultural communications, cultural demographics, cultural environment, cultural history, cultural knowledge, cultural language, cultural resources, cultural experiences, cultural identity, cultural misconceptions, and cultural ways.

This feature of the Brainstorming component promotes awareness of cultural context "by acknowledging problems and challenges as design issues versus issues of the target audience” (Young, p.85, 2009). In this study, this factor is considered in findings related to efforts of the IAL team to balance the goals of the client, NextGenEd, with the needs of the target audience, the students.

The Framing section of the Inquiry component, the Understand Target Audience section of the Development component, and the Reflect and Assess Learning goals of the Brainstorming component present the relevant excerpts of data about the challenges faced by the IAL team in balancing NextGenEd's needs with the needs of students as the target audience. As shown above, the Primary Instructor felt the students' requests to slow down should override the client's needs. The Program Manager felt the client's needs should be met- he believed that the target audience should be qualified for the program, 
and no adjustments to the training program should be made for different learners. The students felt the Primary Instructor was responsive to communicated needs, but encountered barriers to communicating their needs to her. Students also felt that the curriculum did not meet their needs for advanced training in 3D authoring tools and 3D displays. The client representative felt that the compressed timeline was essential to affordability, and that NextGenEd's needs for the training program were not entirely met because of the singular focus on OpenGL.

As described above, findings show that decisions and perceptions related to efforts to meet the needs of the target audience interacted with the following Elements: cultural capital, cultural classification, cultural communications, cultural demographics, cultural environment, cultural history, cultural knowledge, cultural language, cultural beliefs and values, cultural experiences, cultural identity, cultural interests, cultural misconceptions, cultural ways and cultural futures.

Discuss and consider cultural context: Cultural interaction with the design team's preliminary considerations of the cultural context of the training program and its purpose

Summary Result: Of the twenty-five elements of culture in the CBM model, fifteen elements of culture were found to interact with design decisions, stakeholder perceptions and project outcomes related to the design team's preliminary considerations of the cultural context of the training program and its purpose: cultural artifacts, cultural capital, cultural classification, cultural communications, cultural demographics, cultural environment, cultural history, 
cultural knowledge, cultural language, cultural relations, cultural resources, cultural misconceptions, cultural ways, cultural anomalies, and cultural futures.

This feature of the Brainstorming component is a directive to consider "historical, social, political, economic and educational reasons for implementing this project” (Young, 2009). In this study, this factor represents the IAL team's early considerations of the cultural context of the purpose of the training program and the i3Dv project. In the business plan for the i3Dv project, NextGenEd initiate this project with IAL as a part of a vision for large scale education innovation in India and beyond. As presented in the findings for the Framing section of the Inquiry component, the Program Manager's decision to use OpenGL as the primary content was directly tied to the large scale Indian context, to eliminate licensing issues, and the selection of certain projects were tied to the Indian context: the project to modify a Wii controller to manipulate the CAVE was intended to improve the affordability of CAVE technology in India; the earthquake project was based on the needs of an Indian university and the National Disaster Management Association to prepare for frequent and devastating earthquakes in India; and the structural engineering project as intended to make a an i3Dv educational product available throughout India with the Indira Gandhi National Open University system. As presented in the Framing section of the Inquiry component, findings about decisions and perceptions on these efforts of the IAL team to discuss and consider cultural context were related to: cultural artifacts, cultural capital, cultural demographics, cultural environment, cultural history, cultural knowledge, cultural resources, cultural experiences, cultural 
ideas, cultural interests, cultural anomalies, cultural cultures, cultural futures and cultural nature.

Present and consider outcomes: Cultural interaction with the design team's attention to the learner outcomes and the client's goals of the training program

Summary Result: Of the twenty-five elements of culture in the CBM model, ten elements of culture were found to interact with design decisions, stakeholder perceptions and project outcomes related to the design team's attention to the learner outcomes and the client's goals of the training program: cultural artifacts, cultural capital, cultural classification, cultural communications, cultural history, cultural relations, cultural resources, cultural experiences, cultural interests, and cultural futures.

This feature of the Brainstorming component provides guidance to define learner outcomes or user goals (Young, p. 85, 2009). In this study, attention to this factor considers the IAL team's attention to the learner outcomes and the client's goals of the training program. The client's desired outcome for the training program was to create a Research and Development team capable of producing 3D visualization applications for the CAVE environment to be marketed as an educational product.

Senior Project Manager: The primary goal of this program was to educate NextGenEd personnel in the language, protocols, and methods to build Immersive 3D applications for use in various 3D environments.

The students expressed enthusiasm and high expectations for the intended outcomes of the training program: to introduce an educational innovation to India on a large scale. 
Student 8: The picture was very very big...expectations were very high...we were gonna work on a new technology, and we were gonna make a big difference....and an education company that I knew, in education sector, I was even more inclined to work with, because I have interest in teaching... I had been teaching in past.

The IAL team understood NextGenEd's goals to be served by the learners' outcome as a team that could engage with clients in the prototyping process and produce 13Dv CAVE applications. During the demonstration I attended at NextGenEd headquarters in India, I observed five applications that had been produced in conjunction with potential clients.

Excerpts of data on the decisions and perceptions of choices made towards these outcomes are presented in all sections of the Inquiry component and the Reflect and assess learning goals section of the Brainstorming component. The IAL team's considerations of outcomes were found to relate to: cultural capital, cultural resources, cultural knowledge, cultural resources, cultural ideas and cultural futures.

\section{Cultural Element Interactions with Brainstorming}

The above findings highlight, through excerpts, where multiple cultural elements interact with decision-making, perceptions and outcomes of Brainstorming components in the instructional design process. Table 16 provides a visual display of where Elements of culture were coded along with components of Brainstorming t to reveal frequency and breadth of cultural interactions with these design factors. 
Table 16

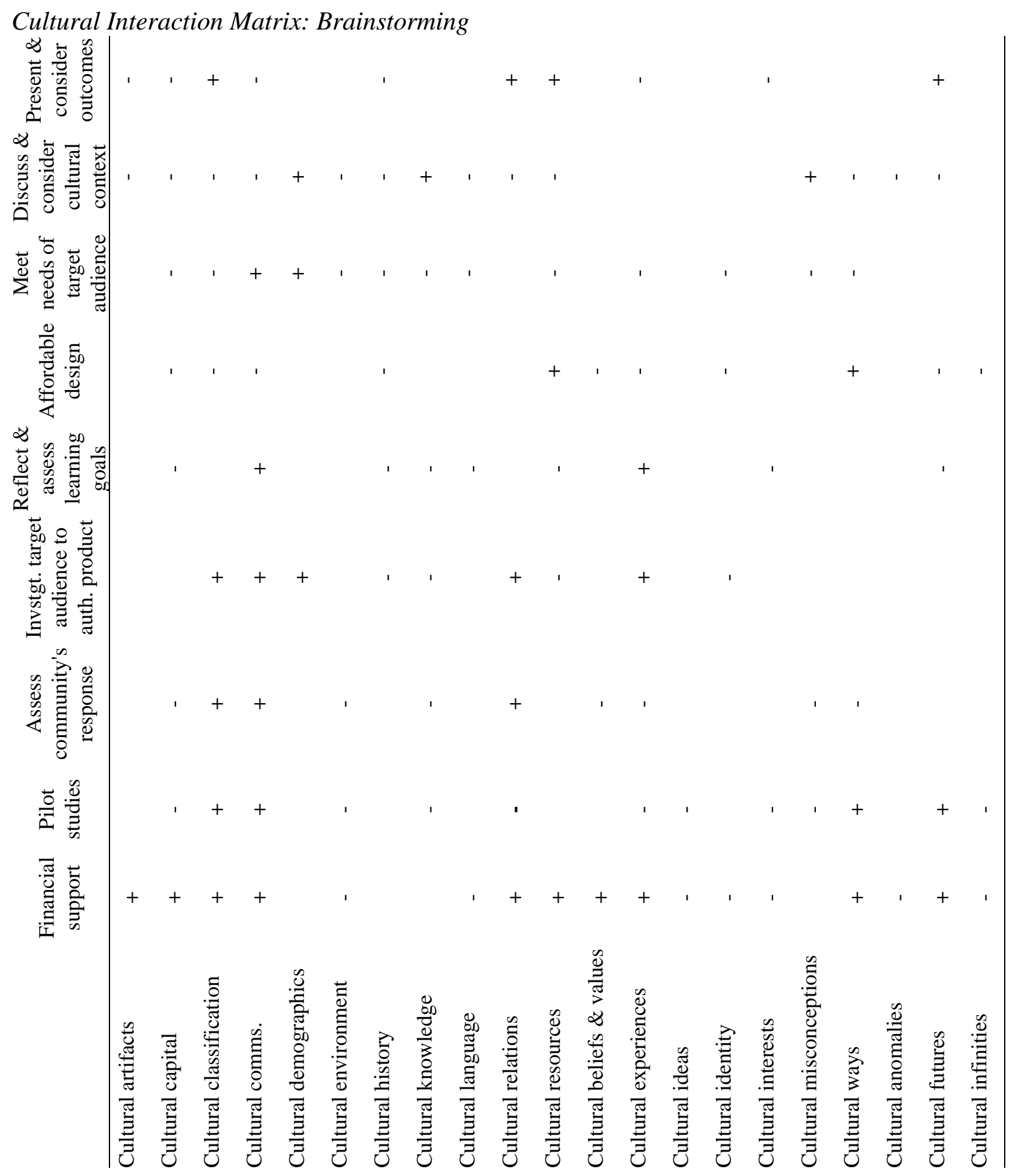

- One overlapping coded reference

+ More than one overlapping coded reference 


\section{Cultural interaction with designing learning environments and opportunities}

In the Culture-Based Model (CBM) framework, the Learners component is categorized as an area of project management. This component provides guidance to "assist in providing a dynamic learning environment that is supportive of the learner's cultural frames of reference and seeks to meet the learning outcomes of the project” (Young, p. 88, 2009). Under the component of Learners, guidelines are offered as design factors to: extend learning beyond design requirements; differentiate learning opportunities; empower and engage learners; instill proactive learning; identify educational objectives; incorporate culture-based instructional strategies; enrich instructional content; adapt instruction to learners; plan for instruction; and enculturate the learner. Table 17 describes these features. In this research, these features are explored as factors in a training program rather than a product, so some features do not apply or are slightly modified for this context. The findings below reflect where decisions were made that address or fail to address the features of the Learners component of CBM; where the connection between these decisions and program outcomes are related; what stakeholder perceptions were expressed about these decisions and program outcomes; and where these decisions, stakeholder perceptions and program outcomes interact with or are related to cultural Elements. 
Table 17

Learners Design Factors of CBM

Factor Description

Extend Learning Provide opportunities for extended learning.

Differentiate opportunities to Provide a variety of learning options.

learn

Empower and engage learners Provide opportunities for empowering learners and engaging instruction.

Teach proactive learning

Help learners to be proactive in improving their own learning

Identify educational objectives

Have an underlying educational and/or learning objective

Culture-specific instructional strategies

Consider instructional strategies that are individual or group specific

Enrich instructional content

Adapt instruction to learner

Plan for instruction

Expand instructional content beyond subject matter Provide adaptable instruction that is not too grade level or age specific

Focus on the short and long term instructional needs of the target audience

Enculturate the learner Use the product to enculturate the learner into the culture

Quoted from Young (2009) p. 89

Extend learning: Cultural interaction with the design team's efforts to offer learning opportunities according to levels of proficiency

Summary Result: Of the twenty-five elements of culture in the CBM model, sixteen elements of culture were found to interact with design decisions, stakeholder perceptions and project outcomes related to the design team's efforts to offer learning opportunities according to levels of proficiency: cultural classification, cultural communications, cultural demographics, cultural environment, cultural history, cultural language, cultural relations, cultural 
resources, cultural beliefs/ values, cultural experiences, cultural ideas, cultural identity, cultural misconceptions, cultural ways, cultural futures, and cultural nature.

This feature of the Learners component offers guidance to "provide proficient learners with complex opportunities that are multi-tiered in difficulty and struggling learners with opportunities to review, reinforce and progress” (Young, p. 90, 2009). In this study, findings related to the IAL team's efforts to offer learning opportunities according to levels of proficiency are presented.

In order to accommodate the students' level of learning proficiency in this training program, the IAL team determined student levels through informal observation, the team lead liaison, and the students’ own self-assessments through weekly reports.

The weekly feedback sessions were used as an opportunity to assess each student's progress in the training program.

Program Manager: We’d go in there, we’d go through everybody’s work. If someone had problems, that's where you address the problems. You know, work on it yourself, if you have a problem then talk to another person, talk to us. They were very reluctant to come and talk to me. They didn’t want to-they didn’t want to use my time up, which I had a hard time, I wanted them to come and ask me questions- because we're glad to help.

These sessions were used as a way around a problem knowing what help the students needed because of the students not approaching the instructors. As also shared in earlier findings, Elements of cultural classification, cultural communications, cultural relations, 
cultural beliefs and values and cultural ways interacted with the students' level of comfort in approaching the instructors.

When the IAL team perceived needs for remediation, the Primary Instructor revised the course to slow down the pace and expanded the material on slides for deeper explanation. As presented in above findings on pace and materials in the Framing section of the Inquiry component, students' perceptions of these revisions were mixed: slowing down and reviewing material helped, but they wished to speed up again after grasping the basic foundations. The students' perceptions were found to be related to the following Elements of culture: cultural classification, cultural knowledge, cultural resources, cultural experiences, cultural identity and cultural ideas.

The IAL team addressed the needs of advanced learners by tailoring projects to ability and interests.

Program Manager: [Decided who to put on projects] basically from the training [the Primary Instructor] had done and what we saw in doing the few projects we had done. So, you know, who was more mathematically inclined, who was more hardware oriented and technically inclined, who was more software inclined. So you kind of get a feel for the group...And certain people do better, so you try to gear activities to the different people for them to excel.

I3Dv programmer: We looked at their backgrounds and what they were interested in and we sort of tailored the projects for them. We saw what their strengths were...one girl had a math background so we put her on a physics-type simulated game...so we tried to incorporate their strengths to their different projects. One 
guy was an engineer and he wanted to do the Wii interface thing, so he got that and he did a great job.

These findings show interactions between the IAL team's decisions to tailor projects according to abilities and interest are based on individual interactions and assessment of individual strengths. No decisions in this section were attributed to or found to be related to Elements of culture.

As presented in above findings on pace and materials in the Inquiry component, students' perceptions of the team's efforts to extend learning did not meet high expectations for advanced level learning. The students’ perceptions were found to be related to the following Elements of culture: cultural classification, cultural knowledge, cultural resources, cultural experiences, cultural identity, cultural ideas and cultural futures.

Differentiate opportunities to learn: Cultural interaction with learning options offered to the students

Summary Result: Of the twenty-five elements of culture in the CBM model, nine elements of culture were found to interact with design decisions, stakeholder perceptions and project outcomes related to learning options offered to the students: cultural classification, cultural communications, cultural environment, cultural history, cultural language, cultural experiences, cultural ways, cultural futures, and cultural nature.

This feature of the Learners component is a directive to provide options for learners (Young, 2009). In this study, findings about learning options offered by the IAL to students in the training program are presented. Several different opportunities to learn in 
this training program were provided: lectures, demonstrations, open-door policy office hours, weekly assignments, weekly feedback sessions, weekly reports, individual projects, group projects and outside client projects. As described in findings of above sections, decisions and capabilities to provide these opportunities were related to the following Elements of culture: cultural capital, cultural communications, cultural history, cultural language, cultural relations, cultural resources, cultural experiences, cultural misconceptions, cultural ways and cultural futures.

The students understood the necessity of the lectures but particularly appreciated opportunities for practical application of the knowledge.

Student 6: Learning is one part, but when you actually start working on those things you get a better understanding of what actually the thing does. So that's why every time you learn something you do some assignment or work related to the same practical aspect it gives always you a better understanding. As presented in above findings in the Framing section of the Inquiry component, the students also wished for more assignments and more diverse datasets for visualization assignments and often found the lectures boring. The students' perceptions of the differentiation of opportunities to learn were found to be related to the following Elements of culture: cultural experiences, cultural ideas, cultural interests, cultural anomalies, cultural cultures, cultural nature and cultural futures. 
Empower and engage learners: Cultural interaction with students' opportunities to learn independently and be creative

Summary Result: Of the twenty-five elements of culture in the CBM model, fifteen elements of culture were found to interact with design decisions, stakeholder perceptions and project outcomes related to students' opportunities to learn independently and be creative: cultural classification, cultural communications, cultural demographics, cultural environment, cultural history, cultural knowledge, cultural language, cultural relations, cultural resources, cultural experiences, cultural identity, cultural ways, cultural anomalies, cultural futures, and cultural nature.

This feature of the Learners component provides guidance for designers to motivate learners with the "alignment of intrinsic stimulus and extrinsic rewards” (Young, p.93, 2009). In this study, findings related to the efforts of the IAL to empower and engage students in the training program are considered. At the end of the first group's training at IAL, several students were asked to take the lead on two potential projects with outside clients.

Program Manager: We wanted them directly interacting with these people on how do you get them data, how do you get things back from them. My main thing was that they understood the social issues and who they should talk to and the language barrier didn’t exist... on a conference call, I had an incredibly hard time understanding... the professors in India and they're used to talking to Indian people...so [the students] were dealing with these professors. 
This excerpt reveals an interaction between the decision to(/?) empower and engage the students to interact directly with clients and Elements of cultural environment, cultural communications and cultural language.

Students did not comment on feelings of empowerment in relation to the design of the training program. One student discussed his feeling of independence in completing assignments.

Student 10: [Assignments were] a good thing. It gave us opportunity to explore independently.

This student did not attribute or relate his perception to an Element of culture.

Students were also encouraged to take creative license in their visualization projects.

Primary Instructor: I taught them how to draw a cube and other objects, but then it was their job to take those simple object into something complicated and create a whole scene on their own, and that would affect how I grade and how I give my personal input back to NextGenEd how the students were doing. This line of work needs a lot of creativity. When they work and when they talk to clients, most clients don't even know what they want. So, in this line of work, they ask themselves sometimes how to create the first program and show that to the client, and the client would be looking at a program and basically give more input to the student without a student really asking, "What do the clients want?"

In this excerpt, the Primary Instructor shows attention to cultural classification, cultural knowledge and cultural futures in her decisions about empowering and engaging learners. 
Summary Result: Of the twenty-five elements of culture in the CBM model, eleven elements of culture were found to interact with design decisions, stakeholder perceptions and project outcomes related to opportunities for student autonomy: cultural classification, cultural communications, cultural history, cultural knowledge, cultural language, cultural relations, cultural resources, cultural experiences, cultural ways, cultural futures, and cultural nature.

This feature of the Learners component provides guidance for designers to helps learners “take responsibility for their own learning” (Young, p.95, 2009). In this study, findings related to the IAL team's efforts to promote student autonomy in the learning process are presented. Throughout the training program, students were both given datasets and required to find their own data for assignments and projects.

Primary Instructor: They had to learn how to get their own data. So we come up with idea...For example, we want to create the solar system...How many planets in the solar or how big or how far apart...And the data of each planet from this period of time to this period of time, they have to get that themselves.

The relocation back to India prompted a significant amount of proactive learning. Student 10: It was totally self-learning when I came here. Of course all of the things I needed were provided by NextGenEd. And subscriptions to online forums. Whatever was needed was provided to me. But most of it was selflearned things. There was no help from [the IAL team] after we came back. The impact of the relocation on the proactive learning aspects of the program are related to: cultural capital and cultural resources. As also shown in related findings that are excerpted in the Framing section of the Inquiry component and in the Empower and 
Engaging learners section, these design decisions, stakeholder perceptions and program outcomes also interact with cultural classification, cultural communications, cultural history, cultural knowledge, cultural language, cultural relations, cultural experiences, cultural ways, cultural futures, and cultural nature.

Identify educational objectives: Cultural interaction with the design team's identification and presentation of learning objectives

Summary Result: Of the twenty-five elements of culture in the CBM model, eight elements of culture were found to interact with design decisions, stakeholder perceptions and project outcomes related to the design team’s identification and presentation of learning objectives: cultural classification, cultural communications, cultural environment, cultural history, cultural knowledge, cultural experiences, cultural interests, and cultural futures.

This feature of the Learners component is a directive to have an "outcomes-based view of learning and the learner” and to share educational objectives with the learners (Young, p. 95, 2009). In this study, findings related to the IAL team's identification and presentation of learning objectives are presented. All of the OpenGL and CAVE application learning objectives were presented in the syllabus in the form of topics; the objectives do not follow best practices for including observable outcomes.

Most assignments for the first group were given verbally in face-to-face sessions with the Primary Instructor and the Program Manager and learning objectives were not expressed. The students were expected to ask questions for more information on projects as part of the prototype philosophy of discovering client's needs. 
Primary Instructor: [The Program Manager] was the one who told them what to do. And they were complaining about they didn't get enough input from [the Program Manager]. I just have to tell them that [the Program Manager] was your client, you just have to be the one who be more forward to the client and ask them. Because if they don't know what the client wants, they can't do the job, and they can't guess what the client wants either.

Program Manager: I was trying to get them to interact with me. Ask questions, get answers. I ask you to do something, it's like-if I said I need you to make me a ball...Okay, you should really come back, you know, to say is that a sphere? Is that a football? Is it red, is it rubber, is it leather? There's a lot of questions you need to ask. Same thing on the programs. We ask them to do something, uh, do you want it mouse driven, do you want to drive it from the keyboard... what types of questions should you ask to make a successful project.

The learning objective of client interaction and learning to ask questions was not explicitly communicated to students.

Program Manager: We weren't telling them this but we were basically making them do it anyway...It's more hidden so that they learned it not knowing they were learning it...I found out years ago that if I-when I gave programming tasks out, if I came in and told you the entire project, you'd be overwhelmed and impossible to do...I come in and give a person, I need this one little piece...And then they do that in an hour. And I say okay now I need you to do this and this... It's the same type thing, you're trying to not scare them and say you have to deal 
with clients and do all this, but you can tell who can do it and who can’t just by talking.

The Program Manager attributes this decision not to be clear about this objective to his cultural experience at IAL.

Most students did not explicitly comment on whether educational objectives were desired or missed, but one student commented on this style of presenting assignments.

Student 10: [The Program Manager gave] assignments which were not very straightforward and he wanted us to discover that by doing the assignment. While we were presenting it to him, he wanted us to know what our experience was doing that assignment.

This students’ perception was not found to interact with cultural Elements.

Culture-specific instructional strategies: Cultural interaction with the design team's attention to the organizational or national of the students in choosing instructional strategies

Summary Result: Of the twenty-five elements of culture in the CBM model, six elements of culture were found to interact with design decisions, stakeholder perceptions and project outcomes related to the design team's attention to the organizational or national culture of the students in choosing instructional strategies: cultural classification, cultural communications, cultural environment, cultural language, cultural experiences, and cultural ways.

This feature of the Learners component provides guidance for specialization of design for the target audience's educational needs (Young, 2009). In this study, findings related to 
the IAL team's efforts or failures to use instructional strategies tailored to the organizational and national culture of the students. As presented in above findings, strategies derived from the IAL's cultural experience and directed towards creating a visualization programming culture at NextGenEd included a prototyping style of presenting assignments. As presented in above findings on Culture-specific assessments, the Program Manager's past cultural experience at IAL led him to form a cultural misconception that Indian students needed very clear deadlines and no chance for extensions. The IAL team also required weekly reports and participated in weekly feedback sessions to overcome barriers to communication related to cultural classification, cultural communications, cultural language, cultural relations, cultural beliefs and values and cultural ways.

Enrich instructional content: Cultural interaction with the design team's efforts to offer content that considered the students' lives holistically

Summary Result: Of the twenty-five elements of culture in the CBM model, seven elements of culture were found to interact with design decisions, stakeholder perceptions and project outcomes related to the design team's efforts to offer content that considered the students' lives holistically: cultural classification, cultural communications, cultural knowledge, cultural language, cultural experiences, cultural ideas, and cultural futures.

This feature of the Learners component is a directive to "consider all aspects of the learners' lives in the design process” (Young, p. 96, 2009). In this study, findings related to the IAL team's efforts to offer content that considered the students' lives holistically 
are presented. Including the prototyping philosophy in this training program took into account the students' roles as employees of NextGenEd who would need to interact with clients.

Program Manager: All of them are Internet savvy, all of them could go find stuff...that wasn’t a problem. The problems come into when you-how do you interact with customers which is more-it's not really that technical skill, it's a personality skill. How do you talk to somebody nice, try... to get information from them...that takes a lot of work.

One student felt this aspect of the training program made it worthwhile to go to the US for the training program.

Student 5: If in the future we have to meet with clients who are abroad then it is very much important. I have often seen that people over here have difficulty in communicating their ideas with foreign clients maybe because, mostly because the accent problem and another thing is the jargons that they use is different, the lingo that they use is different. That is another reason. Once you go there you get an idea of how the culture is. So it is very much important. People then get to learn all of those phrases... all those things. That's the way ... unless you go there you can't do it. I think the interaction was important when that happened.

This students’ perception relates to Elements of cultural communications, cultural language and cultural futures.

As described in above findings in the Inquiry component, student were willing and eager to learn any and all additional content and felt there was too little additional content. The students' perceptions of enrichment of instructional content were found to 
be related to the following Elements of culture: cultural experiences, cultural ideas, cultural interests, cultural anomalies, cultural cultures, cultural nature and cultural futures.

Adapt instruction to learner: Cultural interaction with addressing students' multiple levels of learning ability

Summary Result: Of the twenty-five elements of culture in the CBM model, thirteen elements of culture were found to interact with design decisions, stakeholder perceptions and project outcomes related to addressing students' multiple levels of learning ability: cultural classification, cultural communications, cultural demographics, cultural environment, cultural history, cultural language, cultural relations, cultural experiences, cultural ideas, cultural identity, cultural misconceptions, cultural anomalies, and cultural futures. This feature of the Learners component provides guidance for designers to make learning “contingent upon the learner's ability” (Young, p. 96, 2009). In this study, findings related to the IAL team's efforts or failures to address the students' multiple levels of learning ability are presented. Because this was a training program and not a product, the IAL had several opportunities to adapt their instruction to the learners: revisions to pace, expanded materials, feedback sessions and projects based on interests and abilities. Overlapping with the findings in Extend Learning, findings here show that the IAL team's efforts to adapt instruction to learners are often based on individual interactions and assessment of individual strengths. No decisions in this section were attributed to or found to be related to Elements of culture. As presented in above findings on pace and 
materials in the Inquiry component, students' perceptions of the team's efforts to adapt instruction did not meet high expectations for advanced level learning. The students’ perceptions were found to be related to the following Elements of culture: cultural classification, cultural knowledge, cultural resources, cultural experiences, cultural identity, cultural ideas and cultural futures.

Plan for long term and short term needs for instruction: Cultural interaction with the design teams' efforts to address long-term and short-term learning needs of the students Summary Result: Of the twenty-five elements of culture in the CBM model, nine elements of culture were found to interact with design decisions, stakeholder perceptions and project outcomes related to the design teams' efforts to address long-term and short-term learning needs of the students: cultural classification, cultural communications, cultural history, cultural knowledge, cultural language, cultural relations, cultural resources, cultural experiences, and cultural futures. This feature of the Learners component prompts designers to consider the long-term and short-term “ramifications of the instructional aspects of the design” (Young, p.96, 2009). In this study, findings related to long-term and short-term planning of the IAL team are presented. By including the following instructional strategies in the design of the training program, the IAL showed attention to long-term needs of the students: working in teams related to working at NextGenEd; pass or fail criteria related to real world stakes; and verbal instructions related to real world client interactions. The students' short-term needs were accommodated in securing state-of-the-art equipment and adapting the IAL facility for the training program. These decisions interacted with the following Elements of 
culture: cultural classification, cultural communications, cultural environment, cultural resources, cultural experiences, cultural relations, cultural interests, cultural ways and cultural futures.

Observable outcomes of the program show accommodation of long term needs: the students have self-taught significantly beyond training program; developed projects with outside clients; and still use materials from training program as aids. The students perceived themselves as having received a strong foundation for self-teaching when they arrived back in India. These outcomes and perceptions are related to the following Elements of culture: cultural artifacts, cultural knowledge, cultural resources and cultural interests.

Enculturate the learner: Cultural interaction with the design teams' efforts to orient the students

Summary Result: Of the twenty-five elements of culture in the CBM model, nine elements of culture were found to interact with design decisions, stakeholder perceptions and project outcomes related to the design teams' efforts to orient the students: cultural communications, cultural demographics, cultural history, cultural knowledge, cultural language, cultural resources, cultural experiences, cultural misconceptions, and cultural ways.

This feature of the Learners component provides guidance for product designers in acknowledging influences of a dominant culture in the design and helping integrate learners from other cultures by "bridging connections between the learner, content and 
technology” (Young, p.97, 2009). In this study, where design decisions are made for a training program rather than a product, those efforts made by stakeholders to orient the students at IAL are considered. When the first group of students arrived in the US, NextGenEd hired a professional to conduct a brief cultural orientation session at their US headquarters. The NextGenEd US Senior Project Manager then personally escorted the students to their residences near the NASA space center and took them to the local stores, including a local Indian district where Indian goods and restaurants were available. The second group of students did not participate in an orientation session in Atlanta; they were escorted to their residences near the NASA space center by a NextGenEd administrative assistant. NextGenEd's attempts to enculturate the students are related to Elements of cultural aesthetics, cultural artifacts, cultural environment and cultural experiences.

The students were also welcomed at IAL with an introduction session.

Director: When each group came, the first thing we did was have them introduce themselves to their Indian counterparts, I mean these were all strangers until they got here or to the airport and found out they were all coming to the NASA space center location, so none of them, maybe one or two had known each other previously or worked with one another previously, but very few, so they were all strangers to one another and of course they were strangers to us, so we would go around and have everyone introduce themselves and we had a map of India and a map of the United States so they could see where we came from and we could see where in India they were from and they were scattered from all over the country. This activity shows attention to Elements of cultural demographics and cultural identity. 
The students expressed only satisfaction with their cultural experiences in the US and several stated that being with fellow Indian students near an Indian district made almost no cultural adjustment necessary.

Student 3: [Any cultural adjustments?] Not really. Because we were a big group there. We lived in the same housing complex you can say.

Student 7: Because we were Indian people only, right? So that's why we didn't face any problem.

These students reveal a connection to their cultural identity and level of comfort with others like them. However, as noted in the excerpt for Cultural Relations in the Elements section (Appendix L), one student experienced difficulty adjusting to his Indian roommate because he was vegetarian and his roommate was not.

The IAL team also attempted to bridge connections to the learning environment by inviting in the Secondary Instructor as described in the section on the Team component. This decision and students’ perceptions of this effort towards enculturation were related to cultural classification, cultural communication, cultural language, cultural ideas and cultural misconceptions.

\section{Cultural Element Interactions with Learners}

The above findings highlight, through excerpts, where multiple cultural elements interact with decision-making, perceptions and outcomes of Learners components in the instructional design process. Table 18 provides a visual display of where Elements of 
culture were coded along with components of Learners to reveal frequency and breadth of cultural interactions with these design factors. 
Table 18

Cultural Interaction Matrix: Learners

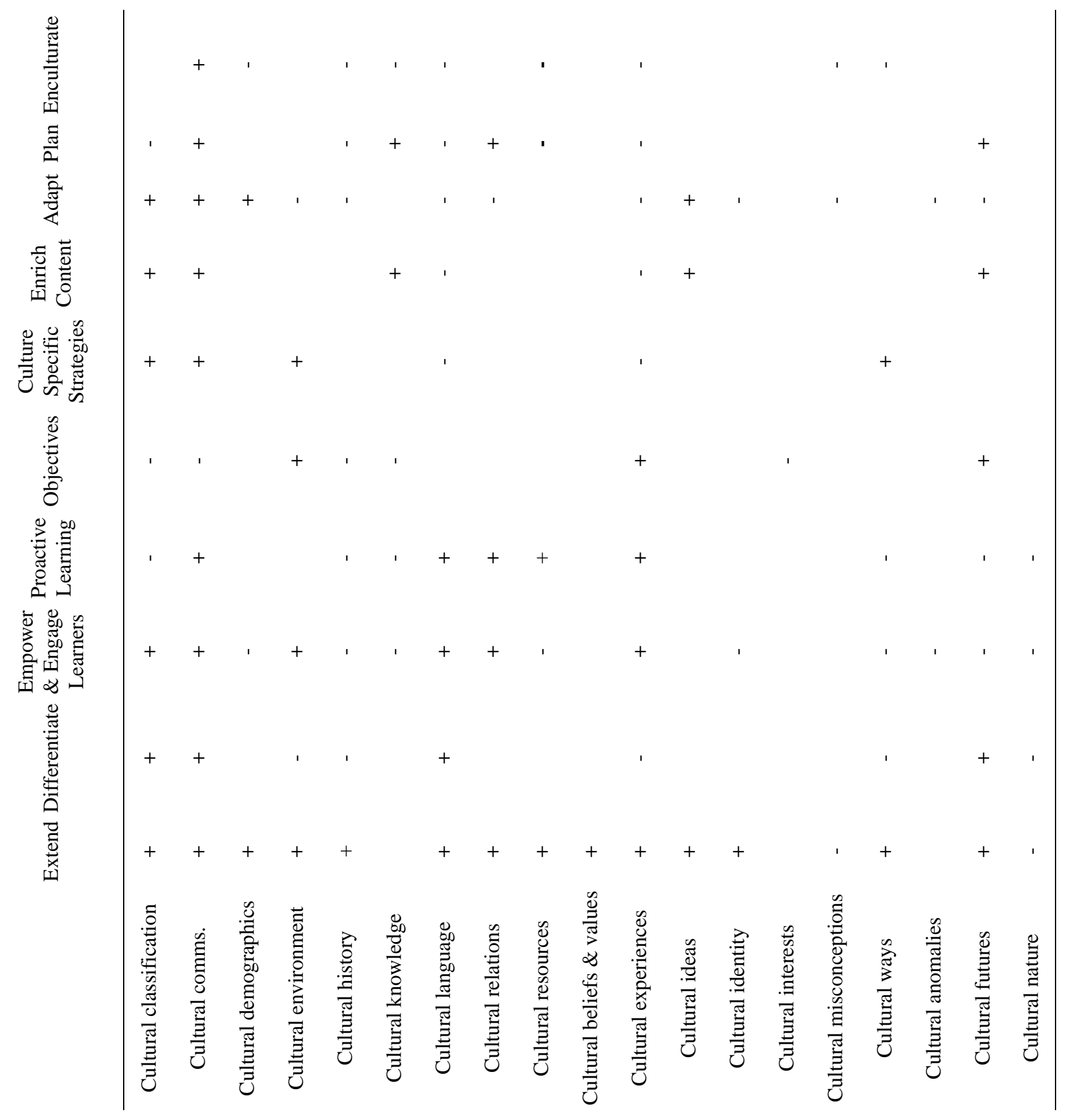

- One overlapping coded reference

+ More than one overlapping coded reference 


\section{$\underline{\text { Conclusion }}$}

Cultural interaction with multiple components of the instructional design process is evident in this case. Young's CBM framework, modified to act as a research lens rather than a model for design, highlights the cultural dynamics at every stage of the design process; Young's Elements of culture applied to multiple cultures in this case study rather than only the target audience, reveal cultural dynamics in the decisions and perceptions of all stakeholders. The findings indicate that multiple Elements of culture are at work throughout the project in the: 1) goals and funding decisions of the client, NextGenEd; 2) goals and design decisions of the design team, IAL; 3) perceptions of the training program of all stakeholders; and 4) the observable outcomes of the training program. In the next chapter, I present holistic findings gleaned from the aggregate of the detailed findings. 


\section{CHAPTER 6: AGGREGATE FINDINGS}

\section{$\underline{\text { Introduction }}$}

This chapter presents findings that emerged from a holistic consideration of the detailed findings presented in the previous chapter. Aggregate findings about cultural interactions with the design decisions, stakeholder perceptions and program outcomes of this instructional design process reveal: 1) limited participant acknowledgement of interaction between decisions, perceptions and outcomes with culture; and 2) the systemic presence of cultural interactions in the instructional design process.

\section{Limited participant acknowledgement of interaction between decisions, perceptions and outcomes with culture}

Summary Result: When asked specifically about culture, participants either deny or acknowledge only limited interaction of culture with decisions, perceptions and program outcomes.

In the interview process, participants were asked specifically about how culture influenced decisions, perceptions and program outcomes. Questions either overtly included the term "culture" or phrases that described the cultures defined in this study. For example, participants were asked about the adjustments they made during the training program related to encountering and engaging with people and places outside of their organization or country of origin. The findings in this section present participant responses about their awareness of adjustments related to culture to reveal convergence and/or divergence with findings from Chapter 5 about cultural interactions. 
When asked broadly about the interaction of the students' culture and the design process, the Primary Instructor, on more than one occasion, stated that culture did not matter, only the content.

Primary Instructor: "The culture thing, is just a sideline that, you know, happening along the way, but is not part of my decision in doing my course.” However, the detailed findings of this study as presented in Chapter 5 reveal multiple elements of culture interacting with the Primary Instructor's decisions across several IDTABLET components: in particular, the influence of her cultural experiences on technology and content choices and the design of learning environments and opportunities.

As shown in Chapter 5, the Program Manager acknowledges the influence of culture on his design decisions to the extent of expecting Indian students to be technologically savvy and using methods to overcome language/communication barriers and enforce strict deadlines.

Program Manager: It's the only thing we did because I expected them to be, you know, high end I mean that's the reason why we wanted high end people, you know, people with a degree or masters who were fluent in English...self-starters, ... trainable, understand what they're doing. If they're not meeting that...don't even send them. Don't send them to another country where they have all their other issues. They should walk in, they're ready to go. And they were. When this statement is compared to the detailed findings in Chapter 5, the Program Manager's statement reveals limited acknowledgement of the interaction between culture 
and design decisions in this training program. It also reveals his resistance to a situation where adjustments to the design would need to be made according to culture.

There is no place in the data where a student consciously acknowledges a cultural influence on their perceptions of the learning environment. When students were asked about challenges with cultural adjustments, they stated there were none because they felt surrounded by their own cultural group while in the US.

Student 3: [Any cultural adjustments?] Not really. Because we were a big group there.

Student 7: Because we were Indian people only, right? So that's why we didn't face any problem.

However, as shown in the detailed findings in Chapter 5, students often cite their past experiences in India or their Indian cultural identity to provide context for their expectations or disappointments with the IAL training program. Some students attribute their dissatisfaction to their cultural experiences at Indian universities; one student attributes his disappointment to his cultural identity and cultural desires as an Indian, presuming that Indians seek "more and more” intellectual challenge.

These findings reveal limited participant acknowledgement of interaction between decisions, perceptions and outcomes with culture as defined by this study.

\section{Systemic presence of cultural interactions in the instructional design process}

Summary Result: Cultural interactions have a systemic presence in the instructional design process in this case. 
The findings reveal cultural interactions across the instructional design process in this case, including culture-related power dynamics and patterns of communication and bidirectional cultural exchanges between the participants.

The findings reveal systemic cultural interactions with the roles of the instructors and students and the hegemonic relationships between them. Aggregate results reveal that two elements of culture interact most broadly and frequently across components of the instructional design process as defined by the ID-TABLET framework: cultural classification and cultural communications. Table 19 shows the breadth and frequency of interactions between the ID-TABLET components and cultural classification and cultural communications elements in this case. 
Table 19

ID-TABLET Interactions with Cultural Classification and Cultural Communications

\begin{tabular}{|c|c|c|c|}
\hline \multicolumn{2}{|c|}{ ID-TABLET Component } & \multirow{2}{*}{$\frac{\text { Cultural classification }}{-}$} & \multirow{2}{*}{$\begin{array}{c}\text { Cultural communications } \\
+\end{array}$} \\
\hline Inquiry & Genre & & \\
\hline & Framing & + & + \\
\hline & Omission & - & + \\
\hline & Backgrounding & & + \\
\hline & Foregrounding & & + \\
\hline & Visual Representations & + & + \\
\hline \multirow[t]{6}{*}{ Development } & Design specifications & + & + \\
\hline & Effective technology & - & + \\
\hline & Diversify ICT format & + & + \\
\hline & Understand target audience & + & + \\
\hline & Explore culture & + & + \\
\hline & Quality design & + & + \\
\hline \multirow[t]{3}{*}{ Team } & Cultural expert & + & + \\
\hline & Enlist educators & + & + \\
\hline & Culturally informed team & + & - \\
\hline \multirow[t]{2}{*}{ Assessment } & Multiple evaluation options & + & + \\
\hline & Culture-specific assessments & - & + \\
\hline \multirow[t]{10}{*}{ Brainstorming } & Financial support & + & + \\
\hline & Present and consider outcomes & + & - \\
\hline & Pilot studies & + & - \\
\hline & Assess community’s response & + & + \\
\hline & Community representative on team & + & + \\
\hline & Investigate target audience & + & + \\
\hline & Reflect and assess learning goals & & + \\
\hline & Affordable design & + & + \\
\hline & Meet needs of target audience & + & + \\
\hline & $\begin{array}{l}\text { Discuss and consider cultural } \\
\text { context }\end{array}$ & - & - \\
\hline \multirow[t]{10}{*}{ Learners } & Extend Learning & + & + \\
\hline & Enculturate the learner & & + \\
\hline & Differentiate opportunities to learn. & + & + \\
\hline & Empower and engage learners & + & + \\
\hline & Teach proactive learning & - & + \\
\hline & Identify educational objectives & - & - \\
\hline & $\begin{array}{l}\text { Culture-specific instructional } \\
\text { strategies }\end{array}$ & + & + \\
\hline & Enrich instructional content & + & + \\
\hline & Adapt instruction to learner & + & + \\
\hline & Plan for instruction & - & + \\
\hline
\end{tabular}

- One overlapping coded reference

+ More than one overlapping coded reference 
Excerpted findings in Chapter 5 show that elements of cultural communications and cultural classification can interact as catalysts and/or barriers to design decisions, stakeholder perceptions or project outcomes.

The findings also reveal systemic cultural interactions in the bi-directional flow of cultural knowledge and resources and the impact of this flow on design decisions, stakeholder perceptions and project outcomes. The training agreement between IAL and NextGenEd included the completion of marketable i3Dv products as part of the training program. This goal resulted in members of the IAL team serving multiple roles as instructional designers-by-assignment, instructors, marketing and salespeople, project managers and product designers. The summary results in Chapter 5 for cultural interactions with the IAL team's efforts to explore and accommodate the culture of their target audience reveals that cultural classification, cultural communications, cultural demographics, cultural history, cultural knowledge, cultural relations, cultural resources, cultural experiences, and cultural identity interacted with the design team's decisions, stakeholder perceptions and project outcomes. In the aggregate findings for this case, three components of instructional design share these same nine cultural interactions: investigating the target audience, understanding the target audience and content. These findings show overlap of cultural interactions between the IAL team's experiences encountering the target audience and content decisions.

The Director of IAL visited India to promote the NextGenEd i3Dv initiative.

Director: It was a big marketing tour for me, I mean, that was the goal... to get people to sign up to commit to this. 
The Primary Instructor of IAL visited India to consult with potential clients on projects for the students to complete, serving both a sales and marketing role as well as a project manager and instructional design role.

Primary Instructor: The main goal [of the trip to India] try to make a sale, try to convince them that this is needed.

As shown in the detailed findings for Chapter 5, these personal visits to India by two of the design team members allowed them to understand the target audience, explore environmental and individual/group cultures, and form a more culturally-informed team.

Also, the projects that IAL designed for students based on this collaboration with potential clients in India involved students in direct interaction with these clients in India, creating teams of all Indian natives for introducing the i3Dv technology into India, including collaboration with IGNOU, India’s open university system.

Student 10: We collaborated in India here in Mumbai with a professor on this project...a 3D simulation of an earthquake which is completely realistic.

During my observation at the Mumbai site, I experienced this completed simulation which, according to interview data and artifact analysis, had attracted the most attention from potential clients in India.

Furthermore, many of the students stated that the CAVE technology was the only reason the training program needed to be located in the US:

Student 2: For this training... CAVE and the crystallized glasses... Anything else we could have got anywhere.

Student 3: The leading technology was the CAVE, but now we have a better system I think. 
The CAVE represented the primary reason for the training program, and it was a cultural resource that was not available in India at the time. However, as a result of this training collaboration between IAL and NextGenEd, there is now a CAVE in India that is more updated and powerful than the IAL's model. This CAVE is the first and only fully immersive, stereoscopic three-dimensional visualization environment in India.

\section{Conclusion}

This chapter highlighted holistic findings about cultural interactions with the design decisions, stakeholder perceptions and program outcomes of the training program. These holistic findings offer insight into what stakeholders do or do not consciously attribute to culture and cultural interactions with the systemic outcomes of the instructional design process. In the next section, I will discuss the significance of the detailed and holistic findings, how they relate to the literature and their implications for: research on culture in the instructional design process; designers in similar situations; and the use of Young's CBM model as a research lens. 


\section{CHAPTER 7: DISCUSSION}

\section{$\underline{\text { Introduction }}$}

This study was designed to explore the complexity of cultural dynamics in a case of instructional design in a cross-border, cross-sector context. Young's (2009) CBM framework, modified to act as a research lens rather than a model for design, highlights the cultural dynamics at every stage of the design process. Young's Elements of culture, as applied to the cultures of the design team and the client in this case study rather than only the target audience, reveal cultural dynamics in the decisions and perceptions of all stakeholders. The findings indicate that at least twenty-three distinguishable elements of culture interact with every component of the design process in the: 1) goals and funding decisions of the client, NextGenEd; 2) goals and design decisions of the design team, IAL; 3) perceptions of the training program of all stakeholders; and 4) the observable outcomes of the training program. The findings also offer insight into what stakeholders do or do not consciously attribute to culture. This chapter will discuss what these findings mean in the context of instructional design models, practice and research.

\section{Guiding Questions}

How does culture interact with the instructional design process, as defined by Young's Culture-Based Model (CBM) framework, in this case of a cross-sector, cross-border training program?

a) What design team decisions, stakeholder perceptions, and program outcomes relate to ID-TABLET components of the CBM framework? 
b) With which CBM Elements of culture do design team decisions, stakeholder perceptions and program outcomes interact?

\section{$\underline{\text { Culture in the Instructional Design Process }}$}

The list of cultural Elements in Young's (2009) CBM provides the most comprehensive taxonomy of culture available in current instructional design models. Other models either: 1) rely on dimensional definitions of culture that require designers to broadly characterize groups of learners according to polarized constructs by national, regional or tribal boundaries; or 2) use vague references to culture to capture group tendencies. The findings in this study show that a comprehensive taxonomy of culture provides a powerful lens to explore the more complex and subtle intricacies of cultural dynamics in the instructional design process. These findings provide empirical evidence that "cultural contextuality is a variable of consequence” and lend further support to the premise of Henderson’s Multiple Cultural Model that instructional design paradigms are influenced by “a) world view; b) values, ideologies, culture, class, and gender; and c) commitment to a particular design paradigm" (Henderson, p. 86, 1996). Furthermore, the findings of this study would support adding multiple elements of culture to the list of influences on instructional design paradigms.

\section{$\underline{\text { Cultural Experiences and Design Decisions }}$}

The findings of this case reveal the persistent and repeated influence of the cultural experiences of the design team in their design decisions, but it is not evident whether this design team ever questioned the applicability of their past cultural experience to design 
decisions for this training program. The Program Manager created the i3dv program and trained two of the design team members of the training program; he describes his instructional strategy as grounding the learning experience in practical application. The Primary Instructor of this team was trained by the Program Manager and cited past experiences from his training program in her decision-making process for the design of the training program for NextGenEd. The cultural experiences of the design team members at IAL are found to interact frequently with content, technology, assessment, and feedback decisions. For example, the content decision to focus on OpenGL was tied to the IAL's competency in and past experience with OpenGL; the technological applications at IAL were primarily topographical because their data were derived from responses to a cultural anomaly (a local natural catastrophe), the local cultural environment and the cultural resources of IAL. Findings in this study about the complex interaction between the cultural experience of the design team and their design decisions offer empirical support for those who call into question how instructional designers are falsely positioned as objective analysts in the ADDIE model and its progeny, such as Thomas, Mitchell \& Joseph (2002) and Wilson (2005).

\section{$\underline{\text { Cultural Interaction with Technology and Content Choices }}$}

Findings from this study also reveal complex interaction of multiple elements of culture with content and technology decisions as well as the stakeholders' perceptions of these decisions. For example, the IAL team's decision to use OpenGL was grounded in their competency and in the perceived need of NextGenEd to avoid licensing issues in distributing its future i3dv applications in India. The findings show that the students and 
the client were dissatisfied with the singular focus on OpenGL and that their dissatisfaction is attributed to multiple elements of culture. Two primary complaints emerged: 1) the students felt they could have learned OpenGL faster and more in-depth in India (cultural resource and cultural knowledge), and 2) OpenGL was too basic for the project development plans of NextGenEd (cultural futures). Yet, the IAL team investigated the target audience through interviews before their arrival to determine that the majority of the students did not have a background in OpenGL, and the curriculum description provided to NextGenEd before the program began detailed extensive and exclusive attention to OpenGL as the graphics programming language. Furthermore, once the students arrived, the students collectively asked the Primary Instructor to slow down the instruction of the OpenGL material and she obliged. Then most of the students interviewed complained that the pace was too slow.

This paradoxical problem highlights the need for more flexible understandings of the design process in a cross-sector and cross-border training for innovation context. Our models should emphasize how culture impacts how instructional designers are able to listen to the target audience. The design team's decision making process for choosing OpenGL reflects traditional tenets of instructional design in targeting the needs of the client and understanding the target audience; they even adjusted the pace of presenting the OpenGL content in response to feedback from the learners. However, they were not able to garner a holistic understanding of the stakeholders' needs and meet their client's and learner's needs and expectation. The findings show that students were inhibited in communicating directly with the design team because of cultural beliefs and values about 
the status of teachers in India and cultural communication patterns at NextGenEd based on cultural classifications.

The findings also show that NextGenEd relied on IAL to customize the curriculum for their desired outcome of building a team of i3Dv programmers like the one at IAL. However, like the CAVE equipment at IAL, OpenGL as the primary programming language for i3dv may have also started to be out of date since the formation of IAL ten years prior. In this case, as in many cases, the subject-matter experts serve the role of instructional designers in order to impart their knowledge and expertise (Keppell, 2001, Merrill, 2007). This case reveals how the cultural experience and cultural knowledge of the IAL subject-matter experts significantly influenced content decisions. The problematic outcome of these decisions suggest that even expertise must be continuously questioned and updated in order to keep up with the fast-paced changes of technological innovation. Traditional ISD models do not provide guidance for navigating such complex interaction of cultural elements with a design team’s ability to ascertain and accommodate the changing needs of a target audience from across borders and across sectors in training for innovation environments. As the field of instructional design continues to open up to considerations of culture, it is important that we include strategies in ISD models for building dialogic relationships and including a variety of perspectives in solving instructional design problems.

\section{$\underline{\text { Cultural Interactions with Project Management }}$}

The Development component of the ID-TABLET of Young's CBM includes the project management factors of instructional design and they relate to team dynamics; it offers mandates and guidance on design specifications, ICT choices, target audience 
concerns and product creation. Findings from this case study show an ad-hoc approach to design specifications by the design team and the client. This ad-hoc method is attributed to the nature of research and development projects by the client. The Program Manager attributes his ad-hoc approach to his past experience of "free-form" training, a reflection of his status as a designer-by-assignment. The design team indicates that most of the design specifications were drawn from the Program Manager’s prior experience training the IAL team. Thus, the IAL team's cultural experience and cultural knowledge is shown to also interact significantly with development activities of the design process.

The importance of funding and affordability for diversification of ICTs is emphasized in these findings and supported by several studies on ICT integration in different cultural contexts (Chitiyo \& Harmon, 2009; Kim \& Santiago, 2005; Lim, 2007; Marchessou, 2001; Merrill, 2001; Soulier, 1999; Zhang, 2007). However, most of these studies consider the challenges of ICT integration in underfunded initiatives. In this case study, we are able to take a close look at a situation not often encountered in the literature on ICTs in emerging economies: a private company from an emerging economy providing much-needed funding for a consortium in the US non-profit sector. In this case, stakeholders expressed satisfaction with the ICT equipment, but dissatisfaction with choices related to distribution of materials, time spent on certain technologies and quality of feedback through distance learning methods. Decisions and perceptions on the diversification of ICT were found to interact with elements of: cultural capital, cultural classification, cultural communications, cultural relations, cultural resources, cultural beliefs and values, cultural experiences, cultural ideas, cultural ways, cultural futures and cultural infinities. These findings of complex cultural interactions provide new insight on 
the diversification of ICT under conditions of optimal funding rather than the deficit conditions found in most studies in an emerging country context.

Optimal funding in this case also enabled the stakeholders to recruit highly advanced students for the training program; most were graduates from top universities in India with highly competitive standards. More than one member of the design team referred to the students as “cherry-picked.” However, in describing their understanding of the target audience for the training program, the design team members characterized the students as beginners in the specific content knowledge of graphics programming and developed materials to provide basic building blocks of the programming language. The findings show student dissatisfaction with the amount of time spent on basics and feelings that the program was not challenging enough. There is a discrepancy in the design team's understanding of the learning needs of the target audience and the target audience’s self-concept and expectations. The design team's analysis of the target audience's content knowledge does not provide enough information for them to meet the more holistic learning needs of these advanced students. This study provides insight into a complexity not addressed in most ISD models: the interaction of cultural identity and cultural experiences with the target audience's needs.

\section{$\underline{\text { Using a Cultural Expert }}$}

The design team’s decisions to invite an Indian professor to serve as the secondary instructor and to have a student team lead serve as a liaison were directly tied to elements of cultural communications, cultural language and cultural relations. The students' perceptions of the secondary instructor show they built rapport with him that 
some attributed to his being an Indian. However, the findings also show that his lack of content expertise in the training program was viewed negatively and caused a group of students to complain about the program to executives in India. Here, the design team's attempt to address cultural issues by inviting a member of the students' national culture onto the team backfired when he was not also a subject-matter-expert. This finding highlights the potential of the cultural expert's role as more than just cultural representation and suggests the need for further research on the use of cultural experts in cross-sector, cross-border educational collaborations.

The findings also show that the use of a cultural expert/community representative, a student who was designated as a team lead and liaison to the design team, mediated some of the communication barriers between the design team and the students; however, some students expressed frustration that this team lead did not always communicate their needs. Also, the second group of students did not understand the team lead's role as a liaison and set up direct contact with executives in India to lodge complaints about the program. When this training program transitioned to a distance learning program, the team lead's role as liaison became even more important. These findings reveal significant complexities in choosing and defining the roles of cultural experts or community representatives in the instructional design process.

\section{$\underline{\text { Cultural Interactions with Perspectives on the Role of Educators }}$}

The roles of the IAL design team members reflect their attitudes about being educators in this training program. The Program Manager eschews the label of educator, a role he seems to view as less connected with the real-world. The Program Manager's 
decisions about the curriculum, assigning projects and providing feedback are tied to his cultural experience of training his own team where learning occurred through simulating or actually participating in real-world projects. He also positions himself as a stand-in client in his interactions with the students. However, he does believe an educator should be recruited for the OpenGL training part of the program in order to accommodate the large number of students. The educators enlisted are the Primary Instructor, who expresses an affinity for teaching, and the Secondary Instructor, whose views on being an educator are not part of the data in the study. The Primary Instructor adopts a traditional lecture style in the classroom with updated tools, her three-pronged approach to the presentation of materials through PowerPoint, the WACOM pad and application demonstrations in order to show static and dynamic dimensions of the content. She also interacts with the students inside and outside of the classroom about their work and gets feedback on their progress, making adjustments to pace and materials based on their needs.

The findings reveal that student expectations for educators are attributed to their cultural experiences with educators in India; they expected design team members to have several publications and/or patents, and they find the design team at IAL to be friendlier and less demanding than their professors in India. This dynamic is a factor in forming the students' opinions that this program was not challenging enough. Their perceptions of the educators in this design team are also connected to their inflated expectations for a NASA training program. The students describe a shared cultural idea of NASA as the pinnacle of cutting edge technology and knowledge. They express disappointment at finding that the design team is part of a NASA consortium rather than actual NASA scientists. This 
finding is peculiar to this study, yet many prestigious institutions across the globe are seeking to leverage their brands for educational collaborations across borders and across sectors. This finding highlights the important influence a brand may wield on students’ perceptions of their learning experience.

\section{$\underline{\text { Cultural Interactions with Instructor and Student Roles }}$}

Findings from this study also offer some insight into shifting roles in intercultural collaborative teams for training and development across sectors. Studies on cross-sector learning have attempted to characterize differences in learning practices between forprofit and non-profit sectors (Birdi, Patterson \& Wood, 2007; Wang, Yang and McLean, 2007) and amount and type of career activities in different sectors (Van der Heijden, 2006); however, not many studies have focused on cross-sector team collaborations for training. The findings from this study show that multiple elements of organizational culture interact with a chain of events that leads to building a more culturally-informed design team. For example, the for-profit client in this case considers this a research and development initiative and recruits the design team to participate in promoting the i3Dv technology in India; the non-profit consortium design team finds its training role expanded and becomes involved in marketing activities on behalf of the client in order to secure funding and to find real-world projects for the curriculum. Some of these marketing activities exposed members of the design team to the target audience's culture and resulted in real-world projects that were grounded in the students' home culture. Two members of this design team were exposed in person to the student's national culture and expressed important cultural revelations about the students as a result. These findings 
prompt consideration of how ISD models address the blurring of boundaries and roles across sectors in global instructional design collaborations.

The findings of this study reveal that the students' perceptions of the training program and their ability to communicate with the design team about their learning needs were impacted by team-building decisions. Traditional ISD models do not account for team-building, nor do they provide a structure for navigating the complex interactions of cultural communications, cultural language and cultural relations involved in teambuilding.

\section{Cultural Interactions with Assessment}

The findings show that the IAL design team's assessments differentiated and that written reports were used to overcome cultural language barriers. Following from the Program Manager's real world application philosophy for the training program, no declarative knowledge is assessed in this training program. All assessments were all project-based, testing procedural knowledge and problem-solving ability. The only criteria were for their computer applications to work. Feedback was provided one-on-one in open class sessions and through personal meetings with the instructors. This approach to assessment and feedback was hindered in the distance-learning environment because of fewer opportunities for informal formative assessment through personal interaction, a finding consistent with most research on distance learning (Oosterhof, Conrad \& Ely, 2008). The students' perceptions of the assessment and feedback methods were mixed. Those who responded positively to this style attributed their preference to the professional environment and the opportunity for individual feedback. Those who desired 
feedback in the form of grades or rankings cited past cultural experience and cultural ways in India, an educational environment deeply tied to competitive performance. The design team did not intend to offer evaluations in the form of rankings until they were requested by the client; the rankings were then provided but not shared with the students. The students were aware that they had been ranked and not informed of their rankings and this caused some frustration.

The design team's approach to assessment and feedback were connected to patterns of cultural relations and cultural communications built through IAL's cultural experience of training through managing and building a team of practitioners in a research and development environment. Their approach was also tied to cultural capital and cultural futures in the goals of NextGenEd for developing products ready for the market during the training program. Researchers and practitioners paying attention to the connection between development trends, ICTs and education in emerging economies express both enthusiasm and caution for such projects as the one in this case study where a private company seeks to introduce a high-level technological innovation into a new market (Lieberman, 2003; Marchessou, 1999; Visser, 2007). Lieberman (2003) considers this type of initiative widespread and inevitable and advocates for a "pro-active and culturally-sensitive approach to technology introduction.” Here, the systemic significance of instructional design decisions in the cross-border, cross-sector training for innovation context is particularly clear. The projects designed for real-world assessment involved students in direct interaction with clients in India, creating teams of all Indian natives for introducing the i3Dv technology into India, including collaboration with IGNOU, India's open university system. Updating traditional ISD models should include prompts for 
designers to consider the systemic implications of assessment and feedback decisions in a globalized knowledge economy.

\section{Cultural Interactions with Funding}

This training program was financed by a private education software company in India. These findings introduce a new perspective on cultural capital and cultural resources into the conversation about ICTs in emerging economies. Shifting economic patterns in India have changed the deficit narrative to one of growth and opportunity, and this shift is evident in this case study where funding flows from India to the US as part of a project for India to introduce a US cultural resource into its educational market. As a result of this funding structure, the Director of IAL visited India to secure financing and promote the i3dv project for NextGenEd and the Primary Instructor visited India to collaborate with potential NextGenEd clients for i3dv applications. Personal visits to India by two of the design team members allowed them to understand the target audience, explore environmental and individual/group cultures, form a more culturally-informed team, and secure and maintain financial support. Luschei, Padmo and Spector (2009) emphasize the importance of on-site visits to the success of their long-term cross-border project. Findings in the training and development literature also support the value of global relocation for cross-cultural exposure (Kho, 2001; Sofo, 2007).

\section{$\underline{\text { Cultural Interactions with Balancing the Needs of Stakeholders }}$}

The findings of this case also reveal challenges in balancing the goals of the client, the learners and the instructional design team and highlight the complex interaction of cultural elements with this balancing act. In the design team's efforts to 
respond to feedback from students about the pace of the program, they had to break with the client's request for an expedited schedule. They even had to negotiate different expectations of the US-based and India-based members of NextGenEd. In the end, the NextGenEd recalled the students back to India before the training program was completed, partly due to the expense of housing the students in the US. This abrupt change created difficulties for the design team in successfully carrying out the training as intended and negatively influenced the students' perceptions of the training program. However, it also introduced new opportunities for the IAL team to explore their training capabilities in distance learning, an option they plan to pursue in future projects, and also forced the transition of the students into independent roles in managing their final projects with potential clients and grounded these projects in India. This design team had to maintain an agile and flexible approach to instructional design in order to balance the needs of stakeholders across borders and across sectors in this project and decisions, perceptions and outcomes interacted with: cultural capital, cultural classification, cultural communications, cultural relations, cultural resources, cultural knowledge, cultural experiences, cultural identity, cultural interests, cultural ways, cultural futures and cultural anomalies. Traditional ISD models acknowledge and address the complexity of balancing the needs of stakeholders but do not take cultural dynamics into account.

\section{Cultural Interactions with the Design of Learning Environments \& Opportunities}

Young (2009) advises designers on accommodating “the learner's cultural frames of reference” in the Learners component of the ID-TABLET framework. By including real-world projects as part of the curriculum, this design team's methods were found to 
answer concerns of the Learners component of the ID-TABLET framework to extend learning, differentiate opportunities to learn, empower and engage learners, teach proactive learning, enrich instructional content and plan for instruction. As discussed above, the design team's decision to ground the students' learning in real-world, Indiabased projects allowed the students to work independently with potential Indian clients to introduce the i3dv technology innovation into India. This approach addresses both learner-centered concerns and concerns about culturally-sensitive technology introduction and emphasizes how from a systemic view, every component of the instructional design process, from steps taken to products generated, should acknowledge and engage cultural context. In this case, the findings show a clear connection between the learner-centered instructional design decisions and the method for introducing the innovation into an emerging country context.

The findings in this case also provide some specific insight into the complex interaction between cultural experiences, cultural ideas, and cultural beliefs and values and this group of learners' perceptions of their learning experience. For example, when students expressed negative opinions of the training program, they compared the training program to their cultural experiences of education in India or cultural ideas of what a training program at NASA would be like. Also, some students attributed their reluctance to express dissatisfaction to their instructor to an Indian cultural belief and value about the status of teachers. Other students attributed their desire for more advanced levels of training to their Indian cultural background and their IIT educational background.

Yet, the primary attention to culture in the instructional design context has been on customization of content according to reductive characterizations of learners or a 
narrow focus on cultural communications, cultural language and cultural resources. The findings of this study show that these elements of culture are pervasive and impactful in content decisions; however, this research design also allowed for discovery of several additional elements of the culture of all stakeholders that interact frequently and significantly with all learner-centered decisions. Rogers, Graham and Mayes (2007) found that instructional designers designing for other cultures place less emphasis on context and experiences of learners and focus more on content. The findings of this study suggest a need for models that prompt designers to consider culture beyond language and communications.

\section{Limitations of this Case Study}

Results of this case study are "limited to describing phenomenon rather than predicting future behavior” (Merriam, 1998, p.41). Some of the descriptions are limited by the data available: participant sampling represents only one client perspective of the NextGenEd i3Dv management team; observation data is limited to demonstrations and tours and does not include observation of training activities; and artifact analysis is limited by the extent of “authenticity and accuracy” of the documents (Merriam, 1998). Finally, using Young's (2009) CBM as an a priori theoretical framework and taxonomy may have limited the discovery of emergent themes by providing convenient categories for “data selection” instead of “generation” (Glass \& Strauss, qtd. in Merriam, 1998). Efforts to mediate these limitations are described in Chapter 3 on Methodology.

This case study is limited in generalizability by the special circumstances of this training program. The findings may be useful for user or reader generalizibility (Walker, 1984 cited in Merriam, 1998) where readers may decide what provides useful guidance 
for their own needs. The circumstances and findings of this case are carefully categorized and described throughout in order to aid the reader in cross-referencing. However, the anonymity of this case limits some of the information available for cross-referencing this case (Yin, 2003).

With these limitations in mind, the next section considers the findings along with relevant literature in order to offer suggestions and considerations for researchers and practitioners who find this case useful for their needs.

\section{$\underline{\text { Implications for Researchers and Practitioners }}$}

Close attention to the dynamics in this case offer additional empirical support and further insight to answer the calls for attention to culture that have often been made in case studies offering general descriptions of international projects and concluding with a list of challenges or lessons learned about the process of design in the cross-cultural, cross-border or cross-sector context (Hergert, 2003; Luschei, Padmo \& Spector, 2009; Soulier, 1999). These authors recognize how impactful culture was in their design experience and highlight communications and resources as important cultural considerations. The findings in this case provide specific attention to these dynamics at every stage of the design process and more in-depth consideration of additional cultural elements at work. For example, the findings here on the framing of content, including visual representations, show aspects of cultural communications and language also interact with the design team's and the target audience's cultural aesthetics, cultural artifacts, cultural environment, cultural history, cultural interests, cultural anomalies, cultural cultures, and cultural nature. Further research on content choices and visual 
representations might use a more comprehensive approach to the study of cultural communications and language by considering these additional elements of culture and how they impact instructional design. By exploring the influence of cultural elements on the target audience's needs as well as the design team's perspective in decision making, we may discover additional areas for improving our current design models and practices.

Researchers and practitioners only interested in issues of cultural communications and cultural language in a similar context may consult findings here on the influence of roles in hierarchical structures, the use of cultural experts and interactions with: cultural capital, cultural classifications, cultural experiences, cultural identity and cultural ways. Findings in this case highlight cultural dynamics related to collaboration and communication in teams and distance learning settings to augment that provided in the instructional design and technology literature and prompt further inquiry (Burniske, 2003; Ku \& Lohr, 2003; Paulus, et al., 2005; Shih \& Cifuentes, 2003). These findings also indicate a connection between cultural classification and cultural communications. Prior instructional design research has only explored such dynamics by applying Hofstede’s dimensions of low and high power distance (Paulus et al., 2005; Ku and Lohr, 2003). The findings in this case offer a multi-perspective description of the dynamics of cultural communication and cultural classifications to prompt inquiry beyond reductive characterizations of groups of learners.

Researchers and practitioners concerned with broader issues of education in a globalized context may also consult findings here related to the bi-directional flows of cultural capital, cultural resources and cultural knowledge across borders and across sectors in this case. These findings reveal that the client and the students share a general 
sense of enthusiasm for the introduction of high-level technology that is the focus of the training program. These findings support the findings of Ezer (2006) that attitudes towards ICT and ICT in education in India show optimism for ICTs and openness to Western models of success. The findings of this case offer an in-depth look at how the students' perceptions of the content and quality of the training program interact with cultural experiences, cultural ideas, cultural identity, cultural knowledge, cultural resources and cultural futures. For example, the students felt the training in the US was only necessary for the one cultural resource available in the US and not available in India, the CAVE; once the CAVE was available in India, the private company brought the students back to India. Also, the students’ cultural ideas of a training program promoted as part of NASA were noted as part of their eventual disappointment with the quality of the training program. This shared sense of high-expectations interacted with their reactions to the learning environment, technology, instructors, content and achievement. These findings offer prompts for inquiry in the instructional design discipline into the complex interaction of power politics, market forces and knowledge flows across cultures and across sectors.

\section{Implications for Young's model}

This study is limited to post-hoc investigation of activities by instructionaldesigners-by-assignment in a unique case. The use of Young's (2009) CBM model as a lens for examination of attention to cultural factors in the instructional design process in this case is not intended to serve as a form of evaluation or validation of the model. However, the findings of this case suggest that this team of instructional-designers-byassignment engaged in many of the activities suggested by Young's model; this study, 
therefore, does offer one case towards building empirical support to claim that Young's prescriptive model includes components that are descriptive of basic instructional design activities in an intercultural context. These findings also support Young's claim that culture and design have a semiotic relationship. According to Richey’s (2005) suggestions for model validation, case studies offer acceptable evidence for component investigation. Future attempts at evaluation or validation of Young’s CBM framework might draw on findings from this case to augment additional findings.

The complexity of cultural interactions revealed in this study supports the need for more research using Young's model to explore beyond characterizations of learners according to reductive cultural constructs. Hofstede’s oft-used cultural dimensions have been called reductionist because of their cultural determinism (Nicholson \& Sahay, 2001). Whereas, using Young's model for cultural Elements as a taxonomy in this study provided a framework for: 1) description and exploration of culture rather than measurement; 2) application to multiple levels of culture as units of study; 3) presentation of participant perspectives individually and contextually rather than as representations of entire groups of people; 4) collection and description of rich, contextualized data; and 5) identification of twenty-three elements of culture for a more comprehensive description and analysis of this case. The findings of this case study offer a catalog of empirical descriptions of Young's CBM elements that could be used to inform the application of these codes for data analysis of other research projects. Future research applying Young's CBM framework as a research lens or the cultural Elements as a taxonomy for describing multiple cultures in an instructional design context may offer richer descriptions and 
exploration of cultural dynamics rather than reductive characterization of learners or organizational learning.

The use of Young's CBM framework as a research lens in this case study reveals some limitations in how Young proposes that Elements of culture be applied. Young acknowledges consideration of the teaching/learning philosophy of design teams and instructors in preliminary discussions in the book and notes the importance of awareness of bias in discussion of several components of the framework, but the model introduces cultural elements only as a way to understand the societal and cultural contexts of the learners, not other stakeholders like the design team or clients. The way the cultural elements are applied in this research as a lens on cultural dynamics in the program and as a way to explore the cultures of all stakeholders offers the opportunity to move away from reductive characterization of learners and towards working with culture in a more dynamic way. A practitioner using Young's model could apply cultural elements for attention to culture in dialogic elements of design such as instructor-student interaction, feedback and revision and examine the culture of instructors/design teams, not just learners. Tessmer and Richey (1997) acknowledge a content culture to characterize teacher's instructional beliefs, but Young's model applied to designers and instructors may offer a more comprehensive tool for exploring instructional beliefs.

\section{$\underline{\text { Conclusion }}$}

In introducing the problem that is the context for this study, I describe the challenge of applying Western-biased instructional design models to global instructional design projects and consider whether current ISD models, based on the fundamental 
model of ADDIE, are flexible, yet descriptive enough to provide cultural guidance for designers-by-assignment in environments of cross-sector, cross-border training for innovation. Findings from this study reveal that multiple elements of culture interact with multiple components of the instructional design process in complex ways that are not reflected in or addressed by traditional ISD models.

By empirically illuminating the pervasive presence of cultural interactions across the instructional design process, this study offers strong support for the impact of culture to be recognized more fully in the institutionalized texts of the field. If we ground our discipline in the understanding of systemic processes, we cannot ignore a prevalent and impactful variable in that system. The basic definitions and models of our discipline that are offered in textbooks, studied in classrooms and optimized in internet searches will inform the work of instructional design practitioners who are involved in learning collaborations across the globe.

This study joins other empirical efforts and analytical calls to value culture as a construct of importance in our field. It demonstrates the powerful capabilities of using a comprehensive descriptive model as a lens for exploring cultural dynamics in the instructional design process. Young's model and the findings of this study make the construct of culture more accessible as a variable for in-depth research. The potentially generative nature of the findings here points to rich ground to move the conversation about culture in instructional design and technology beyond stereotyping learners and towards recognizing the complex interaction between the cultures of all stakeholders and the implications for all steps in the design process. 


\section{REFERENCES}

Albrechtsen, K., Mariger, H. \& Parker, C. (2001). Distance Education and the Impact of Technology in Europe and Japan. Educational Technology Research \& Development, 49(3), 107-114.

Armstrong, AM (2004). Instructional Design in the Real World: A View from the Trenches. Hershey, PA: IRM Press.

Arya, K., Margaryan, A. \& Collis, B. (2003). Culturally sensitive problem solving activities for multi-national corporations. TechTrends, 47(6), 40-49.

Aydin, C.H. \& McIsaac, M.S. (2004). The Impact of Instructional Technology in Turkey. Educational Technology Research \& Development, 52(1), 105-112.

Barta, J., Jetté, C. \& Wiseman, D. (2003) Dancing Numbers: Cultural, Cognitive, and Technical Instructional Perspectives on the Development of Native American Mathematical and Scientific Pedagogy. Educational Technology Research \& Development, 51(2), 88-96.

Bentley, J.P.H., Tinney, M.V. \& Chia, B.H. (2004) Intercultural Internet-Based Learning: Know Your Audience and What It Values. Educational Technology Research \& Development, 53(2), 117-127.

Bhabha, H. (1994). The Location of Culture. New York: Routledge.

Bhawuk, D.P.S. \& Brislin, R.W. (2000). Cross-cultural training: A review. Applied Psychology: An International Review, 49(1), 162-91.

Birdi, K.S., Patterson, M.G. \& Wood, S.J. (2007). Learning to perform? A comparison of learning practices and organizational performance in profit- and non-profit- 
making sectors in the UK. International Journal of Training \& Development, 11(4). 265-281.

Branch, R.M. \& Deissler, C.H. (2008). In Januszewski, A., \& Molenda, M. (Eds.), Educational technology: A definition with commentary. New York: Lawrence Erlbaum Associates.

Bradshaw, A.C., Keller, C.O. \& Chen C. (2003). Reflecting on ethics, ethical codes, and relevance in an international instructional technology community. Tech Trends, 47(6) 12-18.

Britz, J.J., Lorc, P.J., Coetzee, I.E.M., \& Bestere, B.C. (2006). Africa as a knowledge society: A reality check. The International Information \& Library Review, 38, 2540.

Burniske, R.W. (2003). East Africa Meets West Africa: Fostering an Online Community of Inquiry for Educators in Ghana and Uganda. Educational Technology Research \& Development, 51(4), 106-113.

Carter, L. (2004). Thinking differently about cultural diversity: Using a postcolonial theory to (re)read science education. Science Education, 88(6), 819---836.

Chitiyo, R. \& Harmon, S.W. (2009). An analysis of the integration of instructional technology in pre-service teacher education in Zimbabwe. Educational Technology Research \& Development, 57, 807-830.

Collis, B. (1999). Designing for differences: Cultural issues in the design of WWWbased course-support sites. British Journal of Educational Technology, 30(3), 201-216. 
Creswell, J.W. (2003). Research Design: Qualitative, Quantitative, and Mixed Methods Approaches. Thousand Oaks, CA: Sage.

Dahlman, C. \& Utz, A. (2005). India and the knowledge economy: Leveraging strengths and opportunities. Washington, D.C.: The World Bank.

Damarin, S.K. (1998). Technology and multicultural education: The question of convergence. Theory into Practice, 37(1), 11-19.

Daniel, J.S. (1996). Mega Universities and Knowledge Media. Technology Strategies for Higher Education. London: Kogan Page.

Davidson-Shivers, G.V. \& Rasmussen, K.L. (2007). Competencies for Instructional Design and Technology Professionals. In R.A. Reiser \& J.V. Dempsey (Eds.) Trends and Issues in Instructional Design and Technology 2nd ed. (pp. 271-286). New Jersey: Pearson.

Debry, D.P. (2002). Analysis of Emerging Practices in Globalizing Instructional Materials. Educational Technology Research \& Development, 50(4), 73-82.

Derrida, J. (1974) Of Grammatology. Trans. Gayatri Chakravorty Spivak. Baltimore: Johns Hopkins.

Devos, C., Dumay, X., Bonami, M., Bates, R. and Holton, E. (2007). The Learning Transfer System Inventory (LTSI) translated into French: internal structure and predictive validity. International Journal of Training \& Development, (11)3, 181199.

Dick, W. (1996) The Dick and Carey model: Will it survive the decade? Educational Technology Research \& Development, 44(3), 55-63. 
Dodig-Crnkovic, G. \& Horniak, V. (2006). Togetherness and respect: Ethical concerns of privacy in global web societies. AI \& Society, 20, 372-383.

Eastmond, J.N., Martiz, G., Gutierrez, R. \& Shanley, K. (2010). Conducting a cultural audit: A case study in service learning for the Dominican Republic. TechTrends, 54(2), 16-18.

Edmundson, A. L. (2007) Globalized e-learning cultural challenges. Hershey, PA: Information Science Publishing.

Ezer, J. (2006). Gandhi's third assassination: Information and communications technology education in India. Information Technology for Development, (12)3, 201-212.

Gunawardena, C.N., Jayatilleke, G. \& Lekamge, G.D. (1996). Learning style of the open university students of Sri Lanka. Educational Technology Research and Development, 44(1), 115-120.

Gunawardena, C. N., \& LaPointe, D. (2008). Social and cultural diversity in distance education. In T. Evans, M. Haughey, \& D. Murphy (Eds.), International handbook of distance education (pp. 51-70). Bingley, UK: Emerald.

Gustafson, K. \& Branch, R.M. (1997). Revisioning models of instructional development. Educational Technology Research and Development, 45(1), 73-89.

Heemskerk, I., Brink, A., Volman, M. \& ten Dam, G. (2005). Inclusiveness and ICT education: a focus on gender, ethnicity and social class. Journal of Computer Assisted Learning, 21, 1-16. 
Henderson, L. (1996) Instructional design of interactive multimedia: A cultural critique. Educational Technology Research \& Development, 44(4). 85-104.

Hergert, T. (2003) Consultant's dilemmas: Trust, ethics, and effective practice across cultures. TechTrends, 47(6), 26-33.

Hofstede, G. (1984). National cultures and corporate cultures. In L.A. Samovar \& R.E. Porter (Eds.), Communication Between Cultures. Belmont, CA: Wadsworth.

Keppel, M. (2001). Optimizing instructional designer-Subject-Matter-Expert communication in the design and development of multimedia projects. Journal of Interactive Learning Research, 12(2), 209-27.

Kim, C. \& Santiago, R. (2005) Construction of E-learning Environments in Korea. Educational Technology Research \& Development, 53(4), 108-114.

Kho, E.C. (2001). An evaluation study of the effectiveness of a U.S.-based global leadership development program. Dissertation Abstracts International, 62(03), 1120. (UMI No. 3009228)

Kinuthia, W. (2007). African Education Perspectives on Culture and E-learning Convergence. In A. Edmundson (Ed.) Globalized e-learning cultural challenges (pp. 60-72). Hershey, PA: Information Science Publishing.

Kinuthia, W. \& Marshall, S. (Eds.). (2010). Cases'n'Places: Global Cases in Educational Technology. Charlotte, NC: Information Age Publishing.

Kroeber, A.L., \& Kluckhohn, C. (1952). Culture: A critical review of concepts and definitions. Harvard University Peabody Museum of American Archeology and Ethnology Papers 47.

Ku, H. Y., \& Lohr, L. L. (2003). A case study of Chinese students' attitudes toward their 
first online learning experience. Educational Technology Research and Development, 51(3), 95-102.

Ku, H., Pan, C.,Tsai, M., Tao, Y. \& Cornell, R.A. (2004) The impact of instructional technology interventions on Asian pedagogy. Educational Technology Research \& Development, 52(1), 88-92.

Lieberman, A.E. (2003). Taking ownership: Strengthening indigenous cultures and languages through the use of ICTs. Retrieved February 11, 2008 from Learnlink website:

$<$ http://learnlink.aed.org/Publications/Concept_Papers/taking_ownership.pdf $>$

Lim, C.P. (2007) Effective integration of ICT in Singapore schools: pedagogical and policy implications. Educational Technology Research \& Development, 55, 83116.

Lincoln, Y., \& Guba, E. (1985). Naturalistic inquiry. New York: Sage.

Loewer, A. (2003). Preserving, restoring, integrating: Educational practices of the Yanomamo, Ojibway, and Aborigines in contemporary society. Educational Technology Research \& Development, 51(2), 83-87.

Luschei, T.F., Padmo, D. \& Spector, J.M. (2009). The Open University of Indonesia and Florida State University: Communication, collaboration, and the important work of training teachers. TechTrends, 53(1), 20-22.

Marchessou, F. (1999). From instructional technology (IT) to open and distance learning: A brief overview of educational technology in Western Europe. Educational Technology Research \& Development, 47(1), 113-123. 
Marchessou, F. (2001). Some ethical concerns in ed-tech consultancies across borders. Educational Technology Research \& Development, 48(4), 110-114.

McLoughlin, C. (1999). Culturally responsive technology use: developing an on-line community of learners. British Journal of Educational Technology, 30(3), 231243.

Merriam, S.B. (1998). Qualitative Research and Case Study Applications in Education. San Francisco, CA: Jossey-Bass.

Merrill, M.D. (2001) Distance Education in South Africa. Educational Technology Research \& Development, 49(3), 123-125.

Merrill, D.M. (2007) The proper study of instructional design. In R.A. Reiser \& J.V. Dempsey (Eds.) Trends and Issues in Instructional Design and Technology 2nd ed. New Jersey: Pearson.

Morey, A.I. (2004). Globalization and the emergence of for-profit higher education. Higher Education, 48, 131-50.

Nicholson, B \& Sahay, S. (2001) Some political and cultural issues in the globalization of software development: case experience from Britain and India. Information and Organization, 11, 25-43.

Nicholson, B \& Sahay, S. (2004). Embedded knowledge and offshore software development. Information and Organization, 14, 329-365.

Oosterhof, A., Conrad, R. \& Ely, D.P. (2008) Assessing Learners Online. New Jersey: Pearson. 
Paulus, T. M., Bichelmeyer, B., Malopinsky, M.P. \& Rastogi, P. (2005). Power distance and group dynamics of an international project team: a case. Teaching in Higher Education, 10(1), 43-55.

Perkins, R. A. (Nov/Dec 2008). Challenges and questions concerning "CulturallySensitive Design.” TechTrends, 52(6), 19-21.

Perkins, R.A., Gwayi, S.M., Zozie, P.A. \& Lockee, B.B. (2005). Distance education in Malawi. Educational Technology Research \& Development, 53(4), 101-108.

Petrina, S. (2004). The politics of curriculum and instructional design/theory/form: Critical problems, projects, units and modules. Interchange 35(1), 81-126.

Powell, G. C. (1993). Incorporating learner cultural diversity into instructional systems design: An investigation of faculty awareness and teaching practices. Unpublished doctoral dissertation, The University of Georgia, Athens.

Powell, G. (1997). On being a culturally sensitive instructional designer and educator. Educational Technology, 37(2), 6-14.

Reiser, R.A. (2007). What field did you say you were in? Defining and naming our field. In R.A. Reiser \& J.V. Dempsey (Eds.) Trends and Issues in Instructional Design and Technology 2nd ed. (pp. 2-9). New Jersey: Pearson.

Reiser, R.A. \& Dempsey, J.V. Trends and Issues in Instructional Design and Technology 2nd ed. New Jersey: Pearson.

Richey, R.C. (2005). Validating instructional design and development models. In J. M. Spector \& D.A. Wiley (Eds.) Innovations in instructional technology: Essays in honor of M. David Merrill (pp. 171-185). Mahwah, NJ: Lawrence Erlbaum Associates, Publishers. 
Richey, R.C. (2009). Foreword. In P.A. Young, Instructional design frameworks and intercultural models (pp. ix-xi). Hershey, PA: IGI Global/Information Science Publishing.

Richey, R.C., Morrison, G.R. \& Foxon, M. (2007). Instructional Design in Business and Industry. In R.A. Reiser \& J.V. Dempsey (Eds.) Trends and Issues in Instructional Design and Technology 2nd ed. (pp. 174-184). New Jersey: Pearson.

Rogers, P. C., Graham, C. R., \& Mayes, C. T. (2007). Cultural competence and instructional design: Exploration research into the delivery of online instruction cross-culturally. Educational Technology Research \& Development, 55(2), 197217.

Schram, T.H. (2006). Conceptualizing and Proposing Qualitative Research. Upper Saddle River, NJ: Pearson Education, Inc.

Schumpeter, J.A. (1936). The Theory of Economic Development: An Inquiry into Profits, Capital Credit, Interest and the Business Cycle. Cambridge: Harvard University Press.

Seufert, S. (2001). Cultural perspectives. In H.H. Alderberger, B. Collis, \& J.M. Pawlowski (Eds.) Handbook of Information Technologies for Education and Training. Berlin et. al: Springer.

Shih, Y.D. \& Cifuentes, L. (2003) Taiwanese intercultural phenomena and issues in a United States-Taiwan telecommunications partnership. Educational Technology, Research \& Development, 51(3), 82-102.

Sofo, F. (2007). Transfer of training: a case-study of outsourced training for staff from Bhutan. International Journal of Training \& Development, (11)2. 103-120. 
Soulier, J.S. (1999). Using technology to improve the quality of labor development in Thailand. Educational Technology, Research \& Development, 47(2), 124-128.

Stake, R. E. (1995). The art of case study research. Thousand Oaks, CA: Sage Publications.

Subramony, D.P. (2004) Instructional technologists' inattention to issues of cultural diversity among learners. Educational Technology, 44(4), 19-24.

Tessmer, M. \& R.C. Richey (1997). The role of context in learning and instructional design. Educational Technology, Research \& Development, 45(2), 85-115.

Thomas, M., Mitchell, M. \& Joseph, R. (2002). The third dimension of ADDIE: A cultural embrace. TechTrends, 46(2), 40-45.

Tirri, K. \& Campbell, J.R. (2010). Current trends and dilemmas in cross-cultural research. In D.K. Sharpes (Ed.), Handbook on International Studies in Education. Charlotte, NC: Information Age Publishing, Inc.

van der Heijden, B.I. (2006). Age differences in career activities among higher- level employees in the Netherlands: a comparison between profit sector and non-profit sector staff. International Journal of Training \& Development, (10)2, 98-120. van der Wende, M. (2002). The role of higher education in the global e-learning market. Center for Studies in Higher Education Research and occasional paper series. Available: <http://www.utwente.nl/cheps >

Visscher-Voerman, I. \& Gustafson, K.L. (2004). Paradigms in the theory and practice of education and training design. Educational Technology Research and Development, 52(2), 69-89. 
Visser, J. (2007). Learning in a global society. In M. G. Moore (Ed.), Handbook of Distance Education (Second Edition ed.). Mahwah, NJ: Lawrence Erlbaum Associates.

Visser, J. \& Berg, D. (1999). Learning without frontiers: Building integrated responses to diverse learning needs. Educational Technology Research and Development, 47(3), 102-114.

Visser, L., Plomp, T., Amirault, R.J., \& Kuiper, W. (2002). Motivating students at a distance: The case of an international audience. Educational Technology Research and Development, 50(2), 94-110.

Visser, J. \& Suzuki, K. (2007). Designing for the World at Large: A Tale of Two Settings. In R.A. Reiser \& J.V. Dempsey (Eds.) Trends and Issues in Instructional Design and Technology 2nd ed. (pp. 235-244). New Jersey: Pearson.

Vrasidas, C., Zembylas, M. \& Glass, G.V. (2009). ICT for Development: Challenges and Possibilities. In C. Vrasidas, M. Zembylas \& G.V. Glass (Eds.) ICT for Education, Development \& Social Justice (pp. 3-16). Charlotte, NC: Information Age Publishing, Inc.

Wang, C. M. \& Reeves, TC (2007). The Meaning of Culture in Online Education: Implications for teaching, learning, and design. In A. Edmundson (Ed.) Globalized e-learning cultural challenges (pp. 2-17). Hershey, PA: Information Science

Wang, X., Yang, B, \& McLean, G.N. (2007). Influence of demographic factors and ownership type upon organizational learning culture in Chinese enterprises. International Journal of Training \& Development, (11)3. 154-165. 
Wild, M., \& Henderson, L. (1997). Contextualizing learning in the World Wide Web: Accounting for the impact of culture. Education and Information Technologies, 2, 179-192.

Willis, J. (2005). Culture, context, and the diffusion of technology in education. International Journal of Technology in Teaching and Learning, 1(1), 9-18.

Wilson, B.G. (2005) Broadening our foundation for instructional design: Four pillars of practice. Educational Technology 45(2), 10-15.

Yin, R.K. (2003). Case Study Research: Design and Methods. Thousand Oaks, CA: Sage.

Young, P.A. (2008). Integrating culture in the design of ICTs. British Journal of Educational Technology, 39 (1), 6-17.

Young, P.A. (2009). Instructional design frameworks and intercultural models. Hershey, PA: IGI Global/Information Science Publishing.

Zagoumennov, I. (2010) International cooperation for educational innovations in Belarus. In D.K. Sharpes (Ed.), Handbook on International Studies in Education. Charlotte, NC: Information Age Publishing, Inc.

Zhang, J. (2010). Technology-supported learning innovation in cultural contexts. Educational Technology Research and Development, 58, 229-243. 


\section{APPENDIXES}

APPENDIX A

\section{Questionnaire $^{1}$ for Student Team Lead}

\section{Communications}

What do you remember about how each member of the IAL team communicated with you as the team lead? Primary Instructor? Program Manager? Supporting Instructor? Director?

Did you make any adjustments to your communication style because of cultural differences with the training team?

Who did you go to with questions or concerns about the training? Why did you choose this person/these persons?

What do you remember about communicating with your fellow team members about the training? Did you have any communication problems?

Please describe your experience as team lead- challenges and benefits.

\section{Overview}

Are you glad you participated in the training?

Do you think it was worthwhile for the training to be in the US?

\footnotetext{
${ }^{1}$ Modified to maintain anonymity of participants
} 


\section{APPENDIX B \\ Questions from Questionnaire ${ }^{2}$ for NextGenEd US Project Manager}

Please describe your role and experiences as part of the i3Dv training program.

\section{Communications}

What do you remember about how each member of the IAL team communicated with you as the project manager? Primary Instructor? Program Manager? Supporting Instructor? Director? What do you remember about how training participants communicated with you as the project manager? What do you remember about how NextGenEd leadership from Atlanta and India communicated with you as the project manager? Who did you go to with questions or concerns about the training? Why did you choose this person/these persons? Overall, did you encounter any communication problems?

\section{Affordability}

How was this project supported financially? Has the company seen a return on investment in the program? Were any financial problems related to this training program encountered? Does the company consider the training program to have been a good value for the investment?

\section{Project Management}

What were the project management requirements for this program? Were project management challenges encountered because of the disparate locations involved? If so, what were they?

\section{Goals}

What were the goals of this training program? Learning goals? Company goals? How well did the training team help the company reach its goals for the training program? What training components, if any, exceeded expectations? What training components, if any, did not meet expectations?

Please address any items of interest that have occurred to you while writing about this training program.

\footnotetext{
${ }^{2}$ Modified to maintain anonymity of participants
} 


\section{APPENDIX C}

\section{Designers-by-Assignment Team First Interview Protocol}

- Schedule interview with consenting participants over the phone or at a location convenient to the participant.

- Begin interview by asking participant to describe his/her experiences as part of a cross-sector, cross-border instructional design team.

o Do not interrupt participant's narrative except to clarify or show interest for a minimum of 10 minutes.

- Follow up with questions about his/her experience with process in designing instruction. Cover the following aspects of process in CBM model (ID-TABLET):

o Inquiry

o Development

o Team

o Assessments

o Brainstorming

0 Learners

o Elements

o Training

- Ask participant to consider what, if any, other phases of the process the team participated in.

- Ask participant to describe what activities, if any, seemed new or surprising.

- Allow a minimum of 10 minutes at the end of the interview for the participant to explore any items of interest that had occurred to him/her during the interview.

- After transcribing the interview, provide a copy of transcription to be commented on by the participant. 


\section{APPENDIX D}

\section{Designers-by-Assignment Team Second Interview Protocol}

- Schedule interview with consenting participants over the phone or at a location convenient to the participant.

- Begin interview by clarifying any issues from first interview.

- Ask participant follow-up questions from first interview related to CBM model's 70 design factors of ID-TABLET.

- Probe for more description and information on responses related to CBM elements of anthropology, psychology or science of culture.

- Allow a minimum of 10 minutes at the end of the interview for the participant to explore any items of interest that had occurred to him/her during the interview.

- After transcribing the interview, provide a copy of transcription to be commented on by the participant. 


\section{APPENDIX E}

\section{Training Participant's Interview Protocol}

- Schedule interview with consenting participants over the phone or at a location convenient to the participant.

- Begin interview by asking participant to describe his/her experiences as part of a cross-sector, cross-border training program.

o Do not interrupt participant's narrative except to clarify or show interest for a minimum of 10 minutes.

- Ask questions about his/her perceptions of the following components of the training program:

o Communications

o Content

o Materials

o Presentation and distribution of materials

o Use of ICT

o Learner preferences

- Ask participant to describe what training components, if any, were particularly helpful.

- Ask participant to describe what training components, if any, were particularly frustrating.

- $\quad$ Probe for more description and information on responses related to CBM elements of anthropology, psychology or science of culture.

- Allow a minimum of 10 minutes at the end of the interview for the participant to explore any items of interest that had occurred to him/her during the interview.

- After transcribing the interview, provide a copy of transcription to be commented on by the participant. 
Site:

\section{APPENDIX F \\ Observation Protocol}

Date:

Activity:

Participants:

Use the following chart to note environmental factors related to the ID_TABLET Components of Young's (2009) Culture Based Model.

\section{Inquiry}

Genre

Framing

Omission

Backgrounding

Foregrounding

Visual Representations
Describe ICTs used in training.

Describe content presented to target audience.

Describe omissions. What has not been considered?

Describe content that is placed in the background.

What content is emphasized?

Describe visual representations. Who is portrayed in these visual representations? What is portrayed in these visual representations? Where are these visual representations placed? Do any visual representations seem inappropriate?

\section{Development}

Describe distribution formats.

Describe diversification of ICT format.

\section{Learners}

Describe differentiated opportunities to learn

Describe environmental affordances to empower or engage learner.

Describe environmental affordances for proactive learning. 


\section{APPENDIX G}

\section{Coding for ID-TABLET Components}

\section{Code}

\section{Inquiry}

I1 Genre

I1a What ICTs are being used and why?

I1b Which ICTs are more effective given the content?

I1c Is the project affordable to the target audience, given the ICTs used?

I1d How have ICTs influenced the design of the product?

\section{I2 Framing}

I2a Who is the target audience?

I2b How is the content presented to the target audience?

I2c What is the content presented?

I2d Is the content appropriate for the target audience and why?

I2e Where, within the products design, is the content most appropriate?

I2f Why is this content appropriate?

I3 Omission

I3a What has been intentionally omitted and why?

I3b What has been unintentionally omitted and why?

I3c What has not been considered?

I3d Will these omissions be detrimental to the project and why?

I4 Backgrounding

I4a What has been backgrounded?

I4b Is the backgrounding intentional or unintentional and why?

I4c Will this backgrounding be detrimental to the project?

I5 Foregrounding

I5a What is emphasized and why?

I5b Is this what should be emphasized?

I5c How does this emphasis influence the overall design?

I6 Visual Representations

I6a How do the visual representations frame the product?

I6b How do visual representations assist in the instructional process?

I6c Who is portrayed in these visual representations?

I6d What is portrayed in these visual representations?

I6e What purpose do the visual representations serve?

I6f Are inappropriate visual representations in the design?

I6g Where are these visual representations placed in the product?

I6h Why were these visual representations selected? 


\section{Development}

D1 Consider technical, aesthetic, content, culture-based, and target audience design specifications.

D2 Mass distribution formats.

D3 Effective technology.

D4 Diversify ICT format.

D5 Understand target audience.

D6 Explore environmental and individual/group cultures.

D7 Quality design.

D8 Authenticate product.

D9 Control for interference.

D10 Model the product or process.

\section{Team}

T1 Cultural expert.

T2 Enlist educators.

T3 Culturally informed team.

\section{Assessments}

A1 Multiple evaluation options.

A2 Assess the assessment.

A3 External review.

A4 Culture-specific assessments.

\section{Brainstorming}

B1 Financial support.

B2 Pilot studies/field tests of product.

B3 Assess community's response.

B4 Community representative on team.

B5 Investigate target audience to authenticate product.

B6 Reflect and assess learning goals.

B7 Affordable design.

B8 Meet needs of target audience.

B9 Discuss and consider cultural context.

B10 Present and consider outcomes.

\section{Learners}

L1 Extend learning.

L2 Differentiate opportunities to learn.

L3 Empower and engage learners. 


\begin{tabular}{ll}
\hline L4 & Teach proactive learning. \\
L5 & Identify educational objectives. \\
L6 & Culture-specific instructional strategies. \\
L7 & Enrich instructional content. \\
L8 & Adapt instruction to learner. \\
L9 & Plan for instruction. \\
L10 & Enculturate the learner.
\end{tabular}

\section{Elements}

\section{Anthropology of culture}

E1 Cultural aesthetics: that which is considered beautiful.

E2 Cultural artifacts: products that exist or remain.

E3 Cultural capital: economics and material wealth.

E4 Cultural classification: divisions in a culture or society.

E5 Cultural communications: the exchange or transmission of information.

E6 Cultural demographics: characteristics of a population.

E7 Cultural environment: physical or social conditions in which a human being, other species or entity lives and develops.

E8 Cultural history: narrative representation of historical events.

E9 Cultural knowledge: what is known and what one comes to know.

E10 Cultural language: language form, content, use and meaning.

E11 Cultural physiology: physiological characteristics of a human being, other species or entity.

E12 Cultural relations: the relationship of one being to another being.

E13 Cultural resources: use and cultivation of resources.

\section{Psychology of culture}

E14 Cultural beliefs and values: shared truths and shared ideas.

E15 Cultural experiences: interpretation of the world from inside and out.

E16 Cultural ideas: the use and meaning of ideas and perceptions.

E17 Cultural identity: distinguishing qualities of a human being, other species or entity.

E18 Cultural interests: deeply personal desires, wants, wishes.

E19 Cultural misconceptions: untruths, myths, stereotypes.

E20 Cultural ways: behaviors, norms, feelings.

Science of culture

E21 Cultural anomalies: happenings that promote, initiate, or force cultural change.

E22 Cultural cultures: the scientific identification of cultures, worlds, ecosystems.

E23 Cultural futures: that which is to come.

E24 Cultural infinities: those things without limits: time, space, distance.

E25 Cultural nature: intrinsic characteristics of a human being, other species or 
entity.

\section{Training}

Tr1 Product training.

Tr2 Culture-based training.

Note. Taken from Young (2009) pages 41-45. 


\section{APPENDIX H}

\section{Code Book for ID-TABLET Components ${ }^{3}$}

\section{Label: Inquiry}

Definition "monitors development, automates the internal flow of the design process, and functions as internal sensors" (Young, 2009, p. 55)

Description Flag this theme when you notice discussion or evidence of the presence or influence of codes I1-I6 in the data.

\section{Label: Development}

Definition "provides the management structure for problem solving" related to design specifications, distribution formats, efficiency, accessibility, versatility, quality and authentication (Young, 2009, p. 65-66)

Description Flag this theme when you notice discussion or evidence of the presence or influence of codes D1-D10 in the data.

\section{Label: Team}

Definition "focuses on the recruitment of a culturally sensitive design team" (Young, 2009, p. 73)

Description Flag this theme when you notice discussion or evidence of the presence or influence of codes T1-3 in the data.

\section{Label: Assessments}

Definition "design factors for implementing” methods for evaluation (Young, 2009, p.

76)

Description Flag this theme when you notice discussion or evidence of the presence or influence of codes A1-4 in the data.

\section{Label Brainstorming}

Definition preproduction efforts to "align the project with its design team, assess the financial status of the project from conception and beyond its completion, discuss the overall design, implement preliminary assessments and determine learning outcomes” (Young, 2009, p. 80)

Description Flag this theme when you notice discussion or evidence of the presence or influence of codes B1-10 in the data.

\section{Label: Learners}

Definition "design factors that assist in providing a dynamic learning environment that is supportive of the learner's cultural frames of reference and seeks to meet the learning outcomes of the project” (Young, 2009, p. 88)

Description Flag this theme when you notice discussion or evidence of the presence or influence of codes L1-10 in the data.

\footnotetext{
${ }^{3}$ Cross-referenced with Appendix 7 detailing the ID-TABLET Components
} 


\section{Label: Elements}

Definition Tangibles and intangible identifiers that are "intended to be comprehensive in providing the fundamental total of which all culture is composed" (Young, 2009, p. 100) Description Flag this theme when you notice discussion or evidence of the presence or influence of codes E1-25 in the data. 


\section{APPENDIX I}

\section{IRB Approval}

INSTITUTIONAL REVIEW BOARD

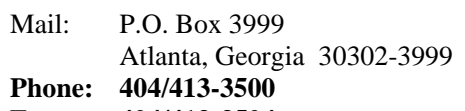

In Person: Alumni Hall

30 Courtland St, Suite 217

March 30, 2009

Principal Investigator: Wang, Xiaoxue

Student PI: Roxanne Russell

Protocol Department: Middle Sec Educ \& Instruc Tech

Protocol Title: Cross-sector, Cross-border Training for Innovation

Submission Type: Protocol H09346

Review Type: Expedited Review

Approval Date: March 30, 2009

Expiration Date: March 29, 2010

The Georgia State University Institutional Review Board (IRB) reviewed and approved the above referenced study and enclosed Informed Consent Document(s) in accordance with the Department of Health and Human Services. The approval period is listed above.

Federal regulations require researchers to follow specific procedures in a timely manner. For the protection of all concerned, the IRB calls your attention to the following obligations that you have as Principal Investigator of this study.

1. When the study is completed, a Study Closure Report must be submitted to the IRB.

2. For any research that is conducted beyond the one-year approval period, you must submit a Renewal Application 30 days prior to the approval period expiration. As a courtesy, an email reminder is sent to the Principal Investigator approximately two months prior to the expiration of the study. However, failure to receive an email reminder does not negate your responsibility to submit a Renewal Application. In addition, failure to return 
the Renewal Application by its due date must result in an automatic termination of this study. Reinstatement can only be granted following resubmission of the study to the IRB.

3. Any adverse event or problem occurring as a result of participation in this study must be reported immediately to the IRB using the Adverse Event Form.

4. Principal investigators are responsible for ensuring that informed consent is obtained and that no human subject will be involved in the research prior to obtaining informed consent. Ensure that each person giving consent is provided with a copy of the Informed Consent Form (ICF). The ICF used must be the one reviewed and approved by the IRB; the approval dates of the IRB review are stamped on each page of the ICF. Copy and use the stamped ICF for the coming year. Maintain a single copy of the approved ICF in your files for this study. However, a waiver to obtain informed consent may be granted by the IRB as outlined in 45CFR46.116(d).

All of the above referenced forms are available online at https://irbwise.gsu.edu. Please do not hesitate to contact Susan Vogtner in the Office of Research Integrity (404-4133500 ) if you have any questions or concerns.

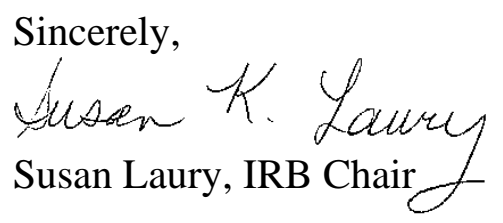

Federal Wide Assurance Number: 00000129 


\title{
APPENDIX J
}

\section{IRB Continuing Review}

\author{
INSTITUTIONAL REVIEW BOARD \\ Mail: $\quad$ P.O. Box 3999 \\ Atlanta, Georgia 30302-3999 \\ Phone: 404/413-3500 \\ Fax: 404/413-3504 \\ In Person: Alumni Hall \\ 30 Courtland St, Suite 217
}

March 10, 2010

Principal Investigator: Wang, Xiaoxue

Protocol Department: Middle Sec Educ \& Instruc Tech

Protocol Title: Cross-sector, Cross-border Training for Innovation

Submission Type: Continuing Review \#1 for H09346

Review Type: Expedited Review

Approval Date: March 30, 2010

Expiration Date: March 29, 2011

The Georgia State University Institutional Review Board (IRB) reviewed and approved the above referenced study and enclosed Informed Consent Document(s) in accordance with the Department of Health and Human Services. The approval period is listed above.

Federal regulations require researchers to follow specific procedures in a timely manner. For the protection of all concerned, the IRB calls your attention to the following obligations that you have as Principal Investigator of this study.

1. When the study is completed, a Study Closure Report must be submitted to the IRB.

2. For any research that is conducted beyond the one-year approval period, you must submit a Renewal Application 30 days prior to the approval period expiration. As a courtesy, an email reminder is sent to the Principal Investigator approximately two months prior to the expiration of the study. However, failure to receive an email reminder does not negate your responsibility to submit a Renewal Application. In addition, failure to return the Renewal Application by its due date must result in an automatic 
termination of this study. Reinstatement can only be granted following resubmission of the study to the IRB.

3. Any adverse event or problem occurring as a result of participation in this study must be reported immediately to the IRB using the Adverse Event Form.

4. Principal investigators are responsible for ensuring that informed consent is obtained and that no human subject will be involved in the research prior to obtaining informed consent. Ensure that each person signing the written informed consent form (ICF) is given a copy of the ICF. The ICF used must be the one reviewed and approved by the IRB; the approval dates of the IRB review are stamped on each page of the ICF. Copy and use the stamped ICF for the coming year. Maintain a single copy of the approved ICF in your files for this study.

All of the above referenced forms are available online at https://irbwise.gsu.edu. Please do not hesitate to contact Susan Vogtner in the Office of Research Integrity (404-4133513) if you have any questions or concerns.

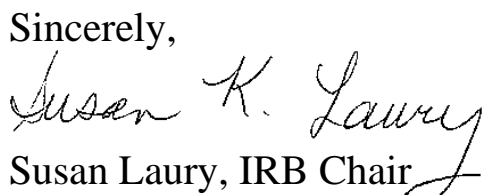

\section{Federal Wide Assurance Number: 00000129}




\section{APPENDIX K}

\section{IRB Amendment}

INSTITUTIONAL REVIEW BOARD

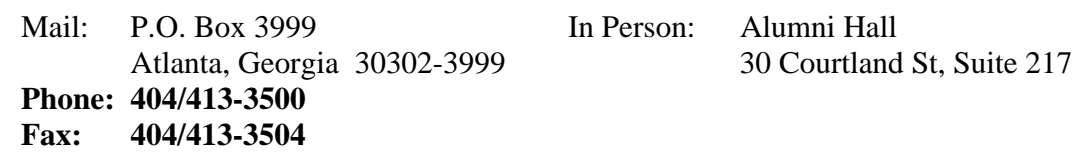

June 29, 2010

Principal Investigator: Kinuthia, Wanjira L

Protocol Department: Middle Sec Educ \& Instruc Tech

Protocol Title: Cross-sector, Cross-border Training for Innovation

Submission Type: Amendment \#1 for H09346

Review Type: Expedited Review

Approval Date: March 30, 2010

Expiration Date: March 29, 2011

The Georgia State University Institutional Review Board reviewed and approved your amendment to your above referenced Protocol.

This approval period is listed above and must be renewed at least 30 days before the expiration date if research is to continue beyond that time frame. Renewal proposals may be resubmitted in abbreviated form.

Any adverse reactions or problems resulting from this investigation must be reported immediately to the University Institutional Review Board.

For more information visit our website at www.gsu.edu/irb.

Sincerely,

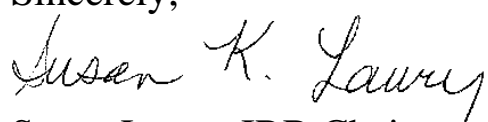

Susan Laury, IRB Chair

Federal Wide Assurance Number: 00000129 


\section{APPENDIX L}

\section{Reference Findings for Taxonomy of Elements of Culture}

To clarify how each Element of culture was coded in the findings, I define each Element of culture in the CBM framework, provide a description of how each Element was interpreted in the context of the case, and offer one example from the data where the Element appears to be at work

\section{Cultural aesthetics}

The Element, cultural aesthetics, prompts a designer to be aware of "that which is considered beautiful” in a culture (Young, p.104, 2009). Young constrains the definition to include only art and beauty in the visual or auditory sense (visual artifacts or music), but matters of preference and taste also involve the other senses: cultures may form aesthetics of flavor, smell and touch. In this research, the code for cultural aesthetics was applied anytime a shared preference or expectation related to the five senses appeared in the data. For example, during the observation at the US site, the Primary Instructor's crinkled in distaste in recalling and describing the smell of the lounge area at lunchtime when the students were at IAL:

Primary Instructor: They ended up cook[ing] their own food to come to work because you know they can't find food that they eat at any place unless they cook for themselves. So you smell Indian food a lot in their area. But they, you know, warm their food in the microwave-Indian food have a lot of spices- Oowee. When it's heated and the aroma just... 
The Primary Instructor's reaction to the smell of the food of the students' culture reveals her different cultural aesthetic from the students. Because Young’s CBM framework is product-oriented, there is no consideration of learning environments. However, in adapting this model to this program-based instructional design case where the physical learning environment was considered, this excerpt shows where cultural aesthetics interacts with the Primary Instructor's perceptions of a space in the learning environment.

\section{Cultural artifacts}

A cultural artifact is an item produced by a member of a culture or found in a cultural environment that might be examined to provide information about that culture (Young, 2009). Young uses Fleming's (1974) schema to classify what information an artifact can provide about a culture: "history, design, materials, construction and function” (p. 107, 2009). In this research, the code for cultural artifacts was applied to data involving an item known to be produced in the context of one or more of the cultures defined as part of this study. For example, IAL produced certificates of completion for the students when they finished the program. They intended to distribute these certificates to the students in a ceremony at the end of the training program, but were prevented from doing so by NextGenEd who said they wanted to present the certificates to the students themselves.

Director: NextGenEd India made a big deal... that they wanted a certificate of completion. We made one up, that was fine, and we were going to have...this big gala event at which time the students that had graduated would all be presented with their... certificates. Suddenly, that became don't give those to the students, send them back to the company, we'll take care of giving them out... We want to 
have the certificates here and we are going to present them to the students in a grand opening of the new visualization center at some point in the future.

These certificates were part of the outcomes for this training program and would be considered a cultural artifact specific to the IAL and NextGenEd cultures and shared between them.

\section{Cultural capital}

The Element, cultural capital, represents factors related to the economics and material wealth of a culture (Young, 2009). In defining cultural capital and forming guiding questions, Young (2009) focuses on economic categories of production, distribution and consumption of goods and services. In this research, cultural capital is identified in the data where market forces, such as products and employment, and wealth are at work. For example, in brainstorming real-time, real world group projects for the students, the IAL team decided to assign one group to modify the Wii remote as a controller for the CAVE display:

Program Manager: Every place in India is not going to buy a $\$ 15,000.00$ tracking system when I have a \$100.00 tracking system from a game machine when all it is, is the remote and the infrared...you don't even... need the actual computer. So what we're doing is using existing technology, if you don’t create anything new, so I'm using your Wii remote that you sold me and I'm raising your bar, there's nothing you can do to say that we've infringed on your patent or anything. Where if you build a new device, then you have patent issues. And like right now, you know the PlayStation and Xbox are building wireless systems and there is a lot of legal issues and all that but we're trying to use an existing technology that would 
be available to any of you- And it would be cheap. So you could build a 3D system that's not stereo on a-on a flat screen and then let the Wii remote sit there and actually control the amount of data. But it's one of those things we could do if the market is big enough. If the market's not big enough, you're just wasting time.

This group project decision is related to cultural capital because it was based on the goals of NextGenEd for the potential Indian market.

\section{Cultural classification}

Cultural classification refers to "the divisions" in a culture, usually related to power or prestige (Young, p. 120, 2009). Young describes two types of cultural classification: stratification and social groups. In this research, aspects of cultural classifications are noted when data is related to shared categorizations of individuals or groups based on: 1) roles according to an organizational hierarchy; 2) status or prestige; 3) age; 4) sex; 5) region of origin; 6) merit rankings; and 7) social groups. For example, the Program Manager describes his sense of the students' status based on their educational background:

Program Manager: I remember that the people that went to the certain...people when they spoke about certain schools they were more held in honor than other schools. There seemed to be almost a tier system of where you went to school... made a big difference and I'm not...and see I'm an anti, I don't believe in any of that. If you graduated college, it means you can learn. And now you're going to work... I didn't know anything about the schools they went to but I could hear it in their voices....More pride, like, I graduated here. 
This excerpt reveals the Program Manager's attitude towards a perceived form of cultural classification among the Indian students.

\section{Cultural communications}

The Element, cultural communications, considers "the exchange[s] or transmission of information” in a culture (Young, p. 126, 2009). Young's definition and description include forms of verbal, non-verbal, written and semiotic communication in a culture (2009). In this research, aspects of cultural communications are found in the data when individuals or groups convey messages according to shared norms, systems or requirements of a culture. When asked how he communicated problems with the training program to the IAL team, Student 9 responded:

Student 9: We did not communicate directly to the IAL team. We communicated it to our company. And we did not directly communicate it. We asked [the team lead] to communicate it. So I don't know how it was communicated. This excerpt describes a system of communication between the students and IAL, the students and NextGenEd, and the students and their team lead; the accuracy of this description is supported by most participants.

\section{Cultural demographics}

Cultural demographics refer to mostly quantitative information used to describe the characteristics of a population according to geographic area (Young, 2009). Young includes the following characteristics in describing demographic data: age, assets, birth, death, density, disease, educational achievement, ethnicity, family, growth, housing, incarceration, income, language, marital status, migration, mobility, occupation, race, sex, and size. In this research, data were coded for cultural demographics when 
awareness of or consideration of demographic data was evident. For example, the Primary Instructor describes learning more about her students from her visit to India during the training program:

Primary Instructor: I noticed that people don’t speak English. I thought Indian people spoke English because English was the official language. I learned that only people that have money are allowed to send their kids to school and it had to be certain school that would teach them English. So that gave me a sense of how lucky my students were that they spoke three languages. Their local area language, their local, country-level language, and then English, so they must be pretty smart to handle three languages as a common thing.

The Primary Instructor reveals a misconception about the Indian culture because of demographic data about the official language and shows how more information about the language influenced her understanding of her target audience. Note: There are actually at least thirty-five languages with official status in different regions of India; however, English is the only language with official status statewide.

\section{Cultural environment}

The Element, cultural environment, refers to the "physical or social conditions in which a human being, other species or entity lives and develops” (Young, p. 160, 2009). Young divides this broadly into three categories with underlying subcategories: 1) the natural world, climate, air, landforms, water, plants, and populations; 2) the natural and humanmade world, environmental conditions like pollution or global warming; and 3) the human-made world, structures, technology and social. In this research, cultural environment is identified when aspects of the above categories are evident in the data. 
For example, the Program Manager described a welcome activity where the IAL team and the students used a map to show where they were from:

Program Manager: They stood up and showed where they were from and spoke slightly about it. They were more diversified. I expected everybody to be, you know, basically, the same...but you know...there’s no scale for me of how big India is... just to see that they're all from different parts and some of its arid and deserts and mountains. I haven’t been there, you don’t really know what to expect.

This excerpt shows how the introductory activity made the Program Manager more aware of the diversity of his students' cultural environment.

\section{Cultural history}

Cultural history gives information about the shared past of a culture (Young, 2009). Young describes cultural history as working to "preserve the past, tell the stories of human beings, record information, and chronicle a legacy” (Young, p. 175, 2009). In this research, cultural history refers to data relating to the national or organizational histories of the US, India, IAL or NextGenEd. The following excerpt is the Program Manager's narrative on the beginnings of IAL:

Program Manager: I got tired just doing Navy work and came over here with, actually the Director here was one of my sponsors when I was with the navy and so he opened the place. He saw me in a parking lot walking across, going 'do you want to open a vis center?' I was like, 'Sure, what does that mean?' 'We're going to build a building' and whatnot. So I thought I was walking into a group of people here. When I got here the first day, you know, and walked in, I was like 
'Where’s the viz center?' He goes, 'You're it!' I think I had 12 students to start with, graduate students from [one of the universities in the consortium]. [The i3Dv programmer] and [the Primary Instructor] were part of the original group. What we did was I started a training program and for the first year we were here we actually went through training and trained everybody. I did everything. It was just me, I'd been doing it and no one else knew what I was even talking about. They had books they were reading. I said that's great, but the examples in the book always work, and that's wonderful, but we're going to do real world stuff... We worked a lot in, uh, like a group environment to where we sit in front of a screen and we give applications out to groups of two people-Get about six things going and then each person would sit there. When they had trouble, well we'd bring every-let's get the whole group together and we'd sit there, what's the problem? They'd, you know, don't be embarrassed, we want to see what [are] the common errors, what is something hard and new we're going to learn, and by doing that, at the end of a year, I had 12 people who could do the work. I picked the four best and hired them.

This excerpt detailing the cultural history provides insight into the IAL culture, the Program Manager's educational philosophy and the IAL team's visualization education experience in the past training program.

\section{Cultural knowledge}

Cultural knowledge refers to what is known in a culture (Young, 2009). Young describes cultural knowledge as acquired, learned, translated, transferred, taught, recorded, documented, preserved, created, accessed, used and applied (Young, p. 215, 2009). In 
this research, the code for cultural knowledge was applied when references were made to shared knowledge in one of the cultures being studied. For example, the Program Manager believed the students in the program would be prepared for the program because of India's reputation for technological knowledge:

Program Manager: I expected the students to be good because there’s so much technology over there already...Call centers, any tech group...it’s well known. People I worked with that, you know, they use technology centers on the other side of the world to work 24 hours a day...I was surprised how many technology people there were in India. There was-I believe where NextGen Ed is over there, there were just like 10,000 programmers in that area...that's an amazing amount of people.

The Program Manager held a belief about cultural knowledge, the technological knowledge in India, which influenced his perceptions of the students' readiness for the training program.

\section{Cultural language}

The Element, cultural language, is defined as the "system to communicate the spoken sounds of humans," including form, content, use and meaning (Young, 2009). In this research, cultural language is identified when the data relates to systems to communicate within or across the national and organizational cultures. For example, most participants commented on difficulties understanding the accents of individuals from other countries or regions. The Indian students described problems with the Primary Instructor's Thai accent and the Program Manager’s Southern United States’ accent. 
Student 4: [The Program Manager] his being a South[ern] American, his accent was a bit...it was like listen and then re-phrase it in your mind and then understand it.

The IAL team also described cultural language problems understanding some of the Indian accents and acknowledged awareness that the students might have struggled with the Primary Instructor's accent; whereas, none of the IAL team expressed awareness that the Program Manager’s accent was also a challenge for the students.

\section{Cultural physiology}

Cultural physiology is the physical "characteristics of a human being, other species or entity” (Young, p. 221, 2009). For Young, this element comes into play when target audience members need to be classified according to physical terms. In this research, this element was not identified in the data.

\section{Cultural relations}

The Element, cultural relations, refers to relations between and across cultures, groups and other species (Young, 2009). Young specifically distinguishes dominant groups in a particular society as a factor of enough consequence to assign this section twice as many questions as society/culture and species (p.224, 2009). In this research, cultural relations are identified when matters of how one culture or group relates to another culture, group or species are evident in the data. For example, the students in this program were housed together; some were vegetarian and some were non-vegetarian:

Student 8: I asked my roommate- I'm not comfortable, so I want to stay with my friend, you move or I move, it's up to you. My roommate was a non-vegetarian guy and I am totally vegetarian. 
The choice of being vegetarian or non-vegetarian is a matter of cultural relations, between humans and other species. This difference in belief about how humans relate to other species created some discomfort for this student while in the training program that was never accommodated.

\section{Cultural resources}

The Element, cultural resources, refers to the use and cultivation of resources in a culture (Young, p.225, 2009). Young restricts the definition of cultural resources to natural resources or non-human-made resources. In this research, I include human-made resources such as particular types of technology. I made this decision because this case study is contextualized in the system of emerging economies seeking technological innovation in a globalized knowledge economy. The data revealed that differences in technological resources between the cultures were relevant to decisions about and perceptions of the training program, and no other Element sufficiently captured the appropriate meaning. For example, many of the students stated that the CAVE technology was the only reason the training program needed to be located in the US:

Student 2: For this training... CAVE and the crystallized glasses... Anything else we could have got anywhere.

Student 3: The leading technology was the CAVE, but now we have a better system I think.

The CAVE represented the primary reason for the training program, and it was a cultural resource that was not available in India at the time. As a result of this training collaboration between IAL and NextGenEd, there is now a CAVE in India that is more updated and powerful than the IAL's model. 


\section{Cultural beliefs and values}

Cultural beliefs and values are shared concepts of reality and ideals (Young, 2009). Young notes that these "ideologies inform thinking, acting and understanding” (Young, p. 234, 2009). In this research cultural beliefs and values are identified when data is related to a culture's shared opinions. For example, in India teachers are revered:

Student 7: We feel like teacher is like a god to us. First is mother, next to father, next to teacher.

In this excerpt, Student 7 reveals an Indian cultural belief and value about the status of teachers that is found to be relevant to interactions in the training program as shown in later findings.

\section{Cultural experiences}

The Element, cultural experiences, refers to how experience in a culture shapes an individual's worldview (Young, p. 236, 2009). Young suggests gathering narratives to know what "people say about their experiences" and observing to see "what people do in their everyday lives and their interpretations of these actions” (p. 236, 2009). In this research, cultural experiences were coded when the data was related to shared cultural experiences that shaped decisions about or perceptions of the training program. For example, when asked about differences in her experience in India and US:

Student 4: The Indian education system and the US education... there are differences... we had the normal classroom pattern... you have a blackboard, you have an instructor assigned, who will teach you, give you assignments, get it verified, give you practice assessment, theoretical assessment and you were given grades based on that. 
Student 4 expresses a perception of what is normal based on cultural experience.

\section{Cultural ideas}

The Element, cultural ideas, refers to "shared patterns of thinking, or schemas” (Young, p. 238, 2009). Young also gives attention to how ideas are generated and whose ideas are valued and accepted in a culture. In this research, cultural ideas were identified when the data related to shared perceptions. For example, the students in this training program shared an idea what the training program would be like because it was associated with NASA:

Student 3: In India, when we were going to NASA we thought the main thing, the NASA is a big thing. We are getting to learn something beyond what is taught here.

As revealed in later findings, this cultural idea about NASA interacts significantly with the students' perceptions of the training program.

\section{Cultural identity}

The Element, cultural identity, refers to “distinguishing qualities of a human being, other species or entity" (Young, p. 239, 2009). Young describes some of the ways that groups maintain a cultural identity, such as language, clothing, and cuisine. In this research, data were coded for cultural identity when members of the group specifically described themselves as a group member. For example, when asked about cultural adjustments to the community in the US, Student 7 refers to their student community as Indian people:

Student 7: Because we were Indian people only, right? So that's why we didn't face any problem. 


\section{Cultural interests}

The Element, cultural interests, represents “deeply personal desires, wants, and wishes” that may be shaped by exposure to cultures (Young, p. 241, 2009). In this research, data were coded for cultural interests when shared desires and wishes were evident. For example, all of the students expressed a wish that their performance during the training program had been clearly ranked:

Student 3: Coming from the same background, it always helps to know exactly how I am standing so that I can improve more in my knowledge. As shown in later findings, the students' interest in ranking feedback interacts with their perceptions of the quality of the training.

\section{Cultural misconceptions}

Cultural misconceptions are held by and about a culture; they are "untruths, myths or stereotypes” (Young, p. 242, 2009). Young describes the origin of cultural misconceptions and ways that a culture engages in such. In this research, cultural misconceptions were identified when lies, myths or stereotypes about a culture were evident. For example, when describing the Primary Instructor, one student held a negative opinion of Thai education based on unsubstantiated hearsay:

Student 4: I have heard that people in [Southeast Asia], the education background of that country, is not that difficult.

Student 4 related this cultural misconception to her experiences with the Primary Instructor in the training program. 


\section{Cultural ways}

The Element, cultural ways, refers to "ways of doing” (Young, p.244, 2009). In this research, the code for cultural ways was applied when shared behaviors, norms, habits, activities and feelings/emotions were evident (Young, 2009). For example, one student described a habit he picked up from US culture:

Student 2: One thing I learned from the U.S. and I sort of incorporate it into my daily life - even unknowingly I do sort of. It's just a basic thing but it makes a huge impression. I first saw [the Program Manager] do it. When he was ahead of me he opened the door and kept it open for me. That is a practice in the U.S. but not in India. Here people are very fast moving and everything. Pace is very fast, life is fast. And you can't wait. But now it has come into my habit to do that. I don't care if that person does it for me, I will do it for them.

This excerpt shows an observed element of cultural ways that this student included in his learning experience during the training program.

\section{Cultural anomalies}

A cultural anomaly is an irregular force of nature or humanity that "promotes, initiates, or forces cultural change” (Young, p. 255, 2009). In this research, cultural anomalies are noted for natural catastrophes, economic upheavals and terrorist activity. A natural disaster, or cultural anomaly, occurred in the region where IAL was located:

Primary Instructor: Now after [a natural catastrophe]...FEMA, went into the area and did some buildings, trees with high-water marks. They measured the height of where each mark is and made it available for free, so we asked [a university] professor to make a surface of the high water marks and then we overlaid that 
onto this program with the same lat/long, of course, so that we can see the effect of [the natural catastrophe].

As a result, many of the datasets IAL had available for the content of the training program and for students' assignments were topographical data.

\section{Cultural cultures}

The Element, cultural cultures, refers to "the scientific identification of cultures, worlds [and] ecosystems” (Young, p. 261, 2009). This element is classified by physical sciences, biological sciences and ecology. Data related to cultural cultures were not identified in this study.

\section{Cultural futures}

Cultural futures are related to plans, intentions and projections for later possibilities (Young, 2009). In this research, references in the data to thinking or working towards a future in a culture were coded as cultural futures. NextGenEd's desire to bring this technology to India is grounded in a company vision for education in India expressed in the business plan for the i3Dv project:

Artifact/NextGenEd Business Plan: NextGenEd seeks to revolutionize education delivery. Leveraging its position as a leader in education software, NextGenEd will push the boundaries of how students are taught complex concepts.

This visionary decision to pursue CAVE technology as the primary driver of the business plan reflects the influence of cultural futures on the training program.

\section{Cultural infinities}

The Element, cultural infinities, refers to "those things without limits: time, space, distance, dimension, speed and numbers” (Young, p. 279, 2009). In this research, time 
and distance were the primary aspects of cultural infinities noted in the data. For example, the time difference was a challenge when the training program switched to distance learning that was noted by several participants.

Program Manager: It was late at night there. They're tired.

Differences in time between the US and India, a cultural infinity, influenced aspects of the training program as shown in the Inquiry section on Genre.

\section{Cultural nature}

Cultural nature is the "intrinsic characteristics of a human being, other species or entity," (Young, p. 291, 2009). In this research, data related to cultural nature were identified in the data sets used for visualization assignments and in choices made for real-time, real world projects. For example, according to data in artifact analysis, several of the datasets chosen for the assignments are topographical and include data from the surrounding ecosystem. 